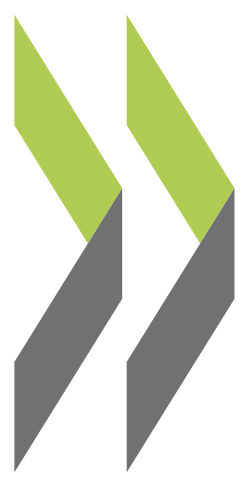

OECD Labour Market and Social Policy Occasional Papers No. 49

Age of Withdrawal from the Labour Force in OECD

\title{
Peter Scherer
}

\section{Countries}


Organisation de Coopération et de Développement Economiques

Organisation for Economic Co-operation and Development

11-Jan-2002

DIRECTORATE FOR EDUCATION, EMPLOYMENT, LABOUR AND SOCIAL AFFAIRS

English/French EMPLOYMENT, LABOUR AND SOCIAL AFFAIRS COMMITTEE

LABOUR MARKET AND SOCIAL POLICY - OCCASIONAL PAPERS NO. 49

AGE OF WITHDRAWAL FROM THE LABOUR FORCE IN OECD COUNTRIES

Peter Scherer

JT00119341

Document complet disponible sur OLIS dans son format d'origine

Complete document available on OLIS in its original format 


\title{
DIRECTORATE FOR EDUCATION, EMPLOYMENT, LABOUR AND SOCIAL AFFAIRS
}

\section{OCCASIONAL PAPERS}

This series is designed to make available to a wider readership selected labour market and social policy studies prepared for use within the OECD. Authorship is usually collective, but principal writers are named. The papers are generally available only in their original language -- English or French -- with a summary in the other.

Comment on the series is welcome, and should be sent to the Directorate for Education, Employment, Labour and Social Affairs, 2, rue André-Pascal, 75775 PARIS CEDEX 16, France. Additional, limited copies are available on request.

The opinions expressed and arguments employed here are the responsibility of the author(s) and do not necessarily reflect those of the OECD

\section{Applications for permission to reproduce or translate all or part of this material should be made to:}

\author{
Head of Publications Service \\ OECD \\ 2, rue André-Pascal \\ 75775 Paris, CEDEX 16 \\ France
}

\section{Copyright OECD 2001}




\section{ACKNOWLEDGEMENTS}

I am indebted to Bernard Casey and Georges Lemaître for constructive and challenging comments, to Véronique de Fontenay and Maxime Ladaique for invaluable statistical assistance and to Isabelle Vallard for her patience in preparing successive drafts. It will also be seen from the paper that I am deeply indebted to the pioneering work of Denis Latulippe. I am also grateful for his helpful comments on an earlier draft. None of them are responsible, however, for the methods proposed here or the conclusions which are drawn from them. 


\section{SUMMARY}

The age of withdrawal from the labour force is an issue of great policy importance. As populations age, an accurate understanding of trends and cross-country differences has become important. However, the age of withdrawal from the labour force cannot be measured directly using cross-sectional data only. Direct observation of net withdrawal rates are needed. This paper presents estimates of these rates derived from comparisons of activity rates at five year periods. A method is proposed (in the Annex) for using data on the stock of people employed at age 65 and above to derive estimates of the net rate of withdrawal at ages 65 and above. The results indicate that net age of withdrawal for men and for women is similar in most countries, and that both show strong cyclical fluctuations.

\section{RESUME}

L'âge de retrait de la population active est une question d'une grande importance politique. Alors que la population vieillit, une juste compréhension des tendances et des différences internationales est devenue importante. Toutefois, on ne peut pas mesurer directement l'âge de retrait de la population active en utilisant uniquement des données en coupe. Des observations directes des taux nets de retrait sont nécessaires. Ce document présente des estimations de ces taux, dérivées des comparaisons des taux d'activité par périodes de cinq ans. Une méthode est proposée (en Annexe) pour utiliser les données concernant les personnes employées à l'âge de 65 et plus afin d'arriver à des estimations sur les taux nets de retrait à l'âge de 65 ans et plus. Les résultats montrent que l'âge net de retrait est similaire pour les hommes et les femmes dans la plupart des pays. De fortes fluctuations cycliques sont en outre enregistrées à la fois pour les hommes et pour les femmes. 
TABLE OF CONTENTS

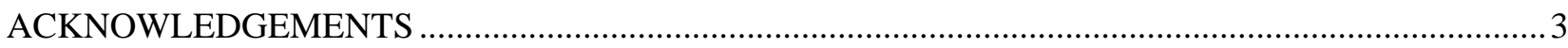

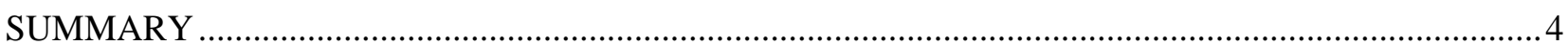

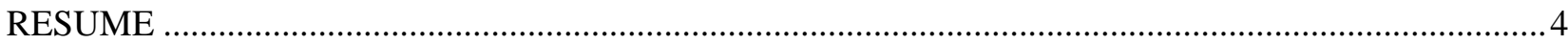

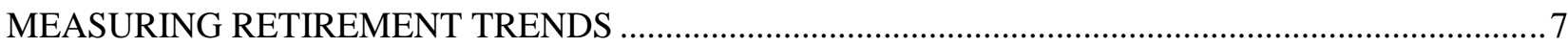

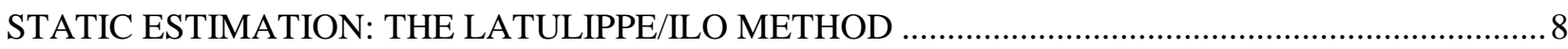

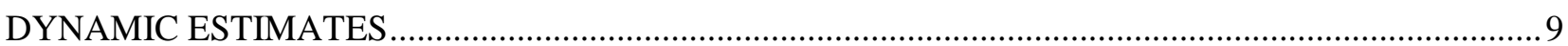

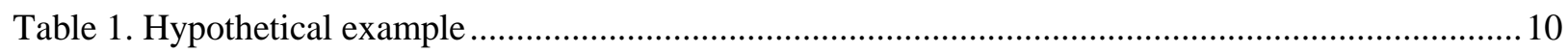

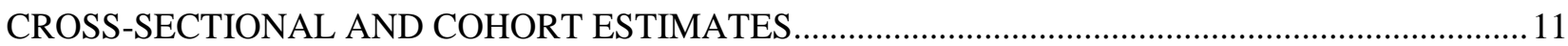

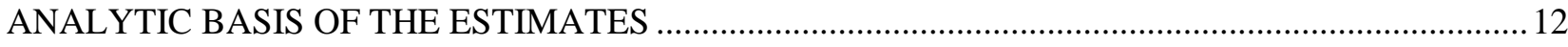

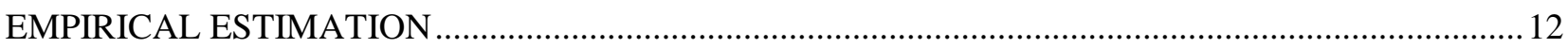

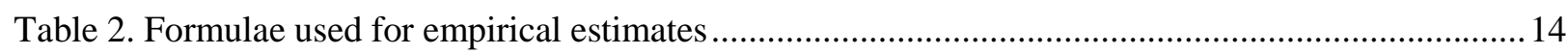

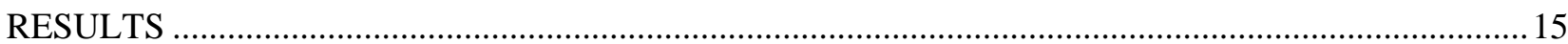

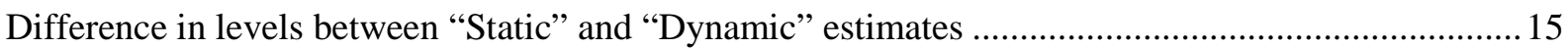

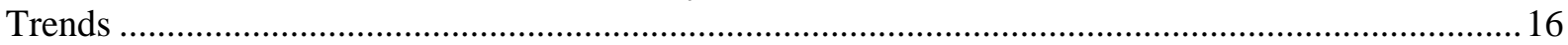

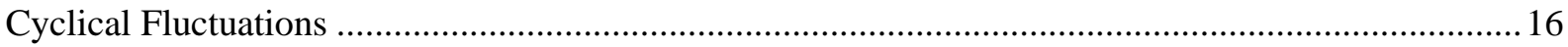

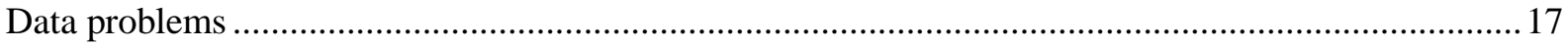

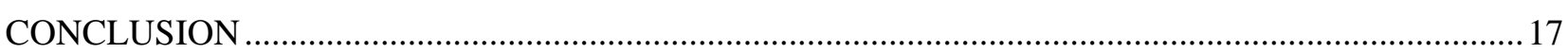

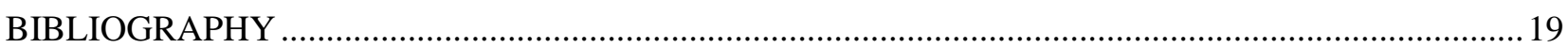

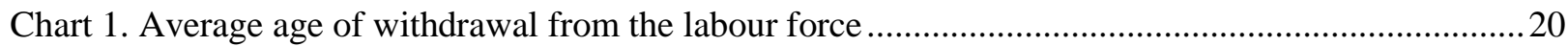

USA A

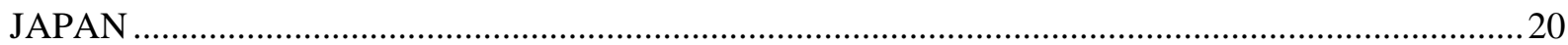

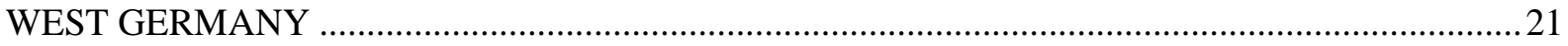

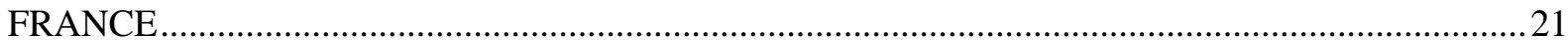

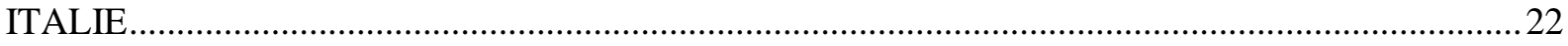

UNITED KINGDOM

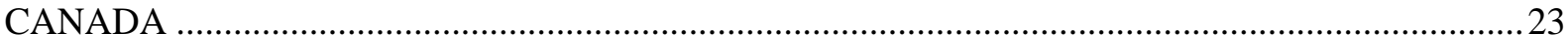

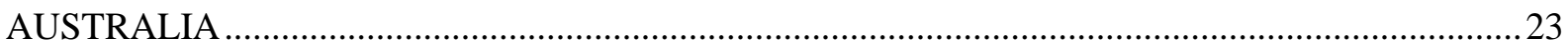

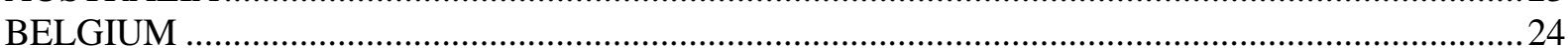

DANEMARK

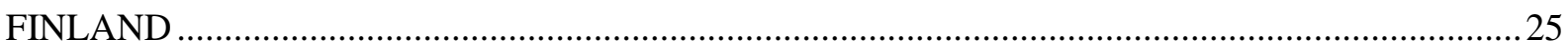

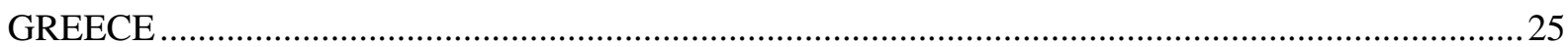




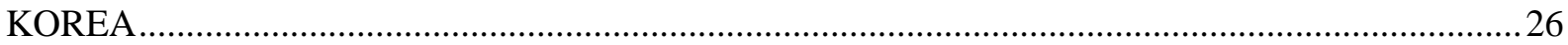

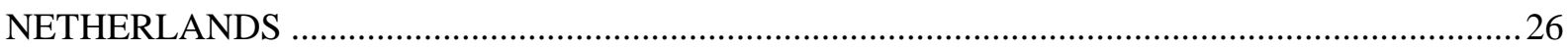

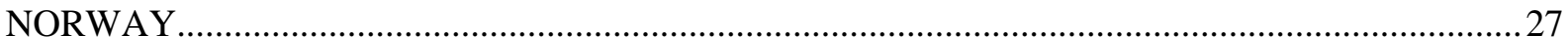

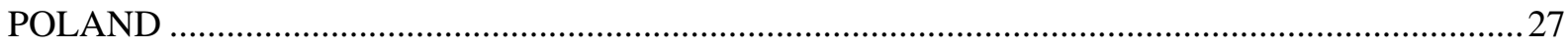

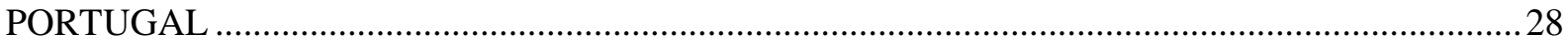

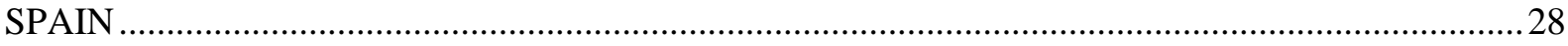

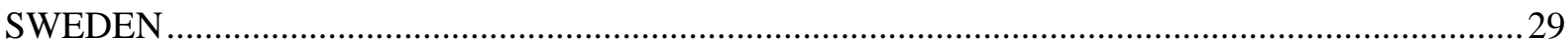

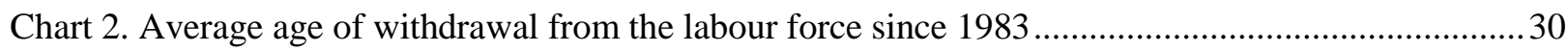

Table 3. Estimates of average age of withdrawal from the labour force ..........................................31

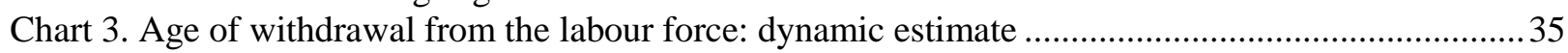

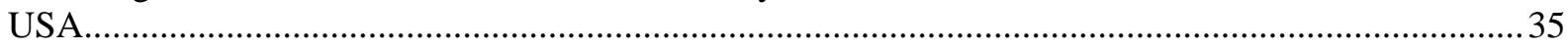

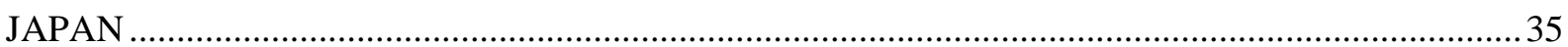

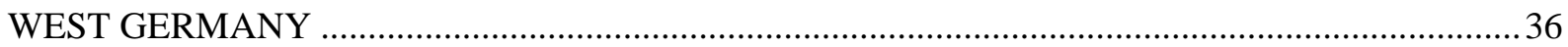

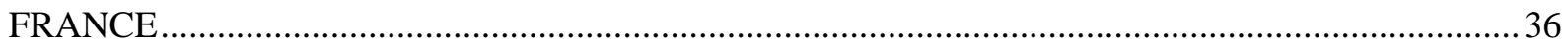

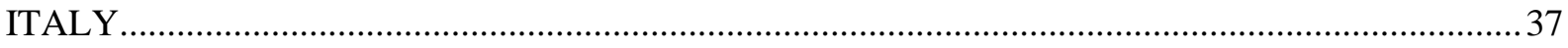

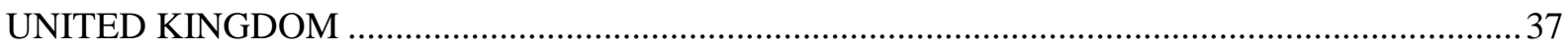

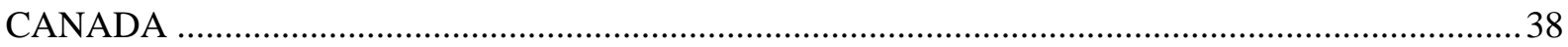

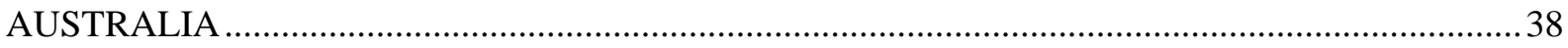

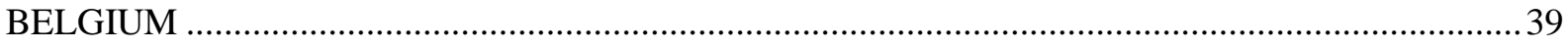

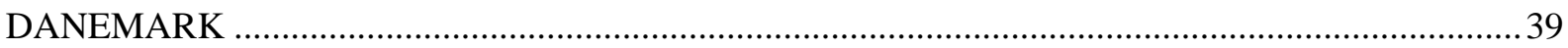

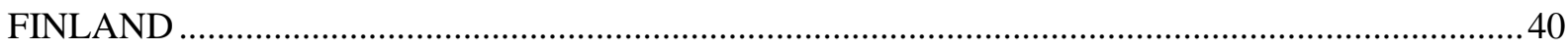

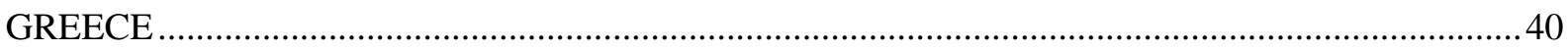

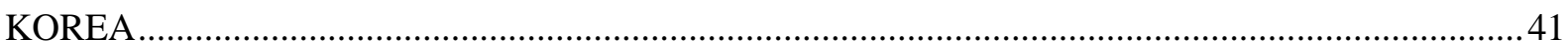

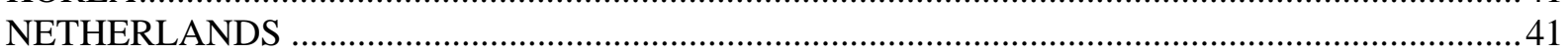

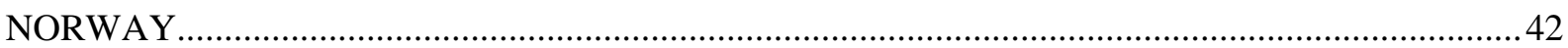

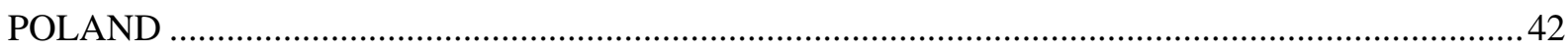

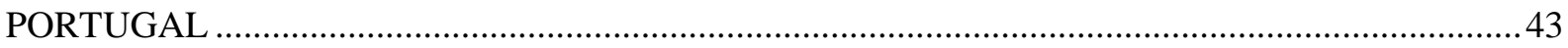

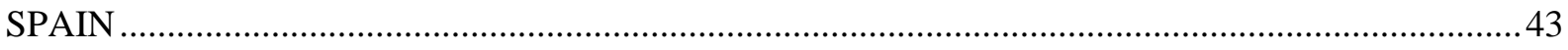

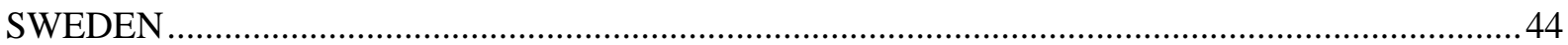

Table 4. Distribution of age of withdrawal from the labour force (Dynamic estimates)........................45

ANNEX A ESTIMATING AVERAGE AGE OF WITHDRAWAL WITH CENSORED DATA...........49

Table A1. Comparison of Direct and Censored Estimates of Expected Age of Withdrawal, adjusted for censored "Direct" data .......................................................................................................53

Chart A1: Comparison showing effect truncation of participation at age 70 instead of age $80 \ldots \ldots \ldots \ldots . . .54$

Chart A2 (a): Actual and Estimated Average Staying Rates over five year period, men, ages 60-64 to 75-79, USA.

Chart A2 (b): Actual and Estimated Average Staying Rates over five year period, women, ages 60-64 to 75-79, USA .................................................................................................................56

Chart A3 (a): Actual and Estimated Average Staying Rates over five year period, men, ages 60-64 to 7579, France ........................................................................................................5

Chart A3 (b): Actual and Estimated Average Staying Rates over five year period, women, ages 60-64 to

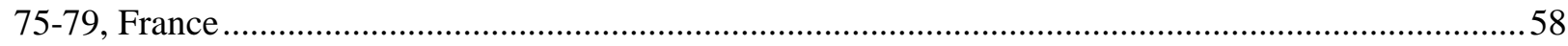


DEELSA/ELSA/WD(2001)2

\section{MEASURING RETIREMENT TRENDS}

1. Discussions of retirement trends in OECD countries have been dominated by the trend to earlier retirement. This trend is difficult to measure directly, as "retirement" differs in its meaning from country to country, and also between types of pension arrangements within each country. For this reason, most international studies have used movement out of the labour force, as measured by labour force survey data, as a proxy for "retirement". Those above a specified age (usually 45) are defined are regarded as "retired" if they are not in the labour force at the time of the survey. Net movement into retirement is then the change in time in the proportion of the population above 45 who are neither working nor classified as unemployed.

2. Clearly, this definition is only loosely related to the common meaning of "retirement". Retirement is generally associated with cessation of work from a "main" job and receipt of a pension, rather than labour force status as such A person can cease to work (or to actively look for work) not because he or she has "retired" in this sense, but because no opportunities for work are thought to be available: that is withdrawal from the labour force can be hidden unemployment. Common usage is particularly ambiguous in the case of people who have been intermittently in the labour force, and so feel they never had a "job": particularly those whose spouse was employed in a "main" job.

3. Conversely, people who have "retired" from their main job can well start a new career or find new employment to supplement their pension, while still feeling they have "retired" from their main career. Furthermore, the ILO definition of employment (one hour or more a week in employment for pay or profit) will include in the labour force pensioners engaged in part-time work who regard themselves (or are regarded by others) as retired.

4. However, for purposes of international comparisons - or even national comparisons over time as pension rules change and pension schemes mature, or between groups with different pension entitlements it is difficult to arrive at a definition which does correspond more closely these common usages of the term, while being measurable with available data. While it is possible to define retirement more satisfactorily in national surveys of the retirement process ${ }^{1}$, none of these definitions has been adopted as an international standard. Data using any one of them are not available for other countries ${ }^{2}$.

5. For these reasons, "net withdrawal from the labour force" is probably the only definition of "retirement" which is operationally useable for international comparison at present. Using this definition, a secular increase in the proportion of the population who are retired can be observed in most OECD countries.

1 For example, the Australian Bureau of Statistics' Retirement and Retirement Intentions Survey defines retired people as "those aged 45 years and over who have ceased full-time work and who do not intend to work or to look for work on a full-time basis in the future". However, for other analyses by the same Bureau, early retirement is examined "mainly in terms of men aged 55-64 years who are not in the full-time labour force". It will be seen that these definitions ignore part-time work, even if it is of a permanent nature, and the latter definition excludes women entirely. See ABS, 1994: 126

2 Gendell (1998) has published estimates based on rates of withdrawal from the labour force for four OECD countries. He (and a co-author) have published similar times series over the years for the United States, and he has compared this with the age of first receipt of old age social security. In the United States, the two series do on the whole move in parallel. (Gendell, 2001) 


\section{STATIC ESTIMATION: THE LATULIPPE/ILO METHOD}

6. In order to summarise this trend, the ILO has published a proposal for calculating the average age of movement into retirement. (Latulippe, 1996). This proposes that the average age of movement into retirement be calculated by comparing the proportions in each five-year age group who remain in the labour force. For example, the proportion of the population who retire between the ages 45-49 and the ages 50-54 is estimated from the difference between participation rate of those aged 45-49 and that of those aged 50-54.

7. Using this method, the average age of retirement can be calculated for any year using labour force data classified by age. Latulippe's paper uses ILO estimates of the age distribution of the labour force from 1950 onwards to show retirement rates for a number of OECD countries at 10 year intervals. Estimates of retirement ages computed using this method have been used in several policy studies, including one by the OECD.

8. There is however a basic problem with this method. If labour force participation rates are increasing with each age cohort, the difference between adjacent cohorts in any one year will reflect this. When age groups are compared in any one year, there will appear to be a high age of withdrawal. If participation is falling, the age of withdrawal will appear to be lower.

9. But the participation rate of those 45-49 will be greater than those age 50-54 because 45-49 year olds are members of a cohort with a greater participation rate at all ages than those born five years earlier. If participation rates are higher for each cohort, the data will show an apparent withdrawal between ages 45-49 and 50-54 even if there is no withdrawal from the labour force between the two age groups. In fact, they can suggest a fall even if women are still entering the labour force (so far from there being net rate of withdrawal, participation rates are increasing).

10. Latulippe argues against the comparison of participation rates over time by observing that this encounters difficulties where participation rates are rising in the age groups 45 to 55 , due to the entry of women into the labour force after raising their children. But this effect exists in reality: it can be observed even for estimates using the static estimation method he derived when participation rates are stable or rising only slowly (Japan is a case in point). However, it is masked if age-specific participation rates are rising significantly from one cohort to the next, which has been the pattern in most OECD countries over the past three decades. This masking of the effect is not an advantage of the static method, it is symptom of the systematic bias it entails. Other people who have used the estimates he derived have recognised this problem, and have concentrated on the male rates. However, as will be discussed below, these also are inaccurate as a guide to fluctuations in withdrawal rates over time.

11. This observation about females illustrates a fundamental feature of the method proposed by Latulippe. It will only measure net retirement rates correctly if participation rates are stable between one cohort and another. Since the calculation of the average requires comparisons (as will be argued further below) from age 45 to 75 : that is, for people born over a 30 year period, this will not in general be the case.

12. The method proposed by Latulippe is equivalent to estimating mortality tables by comparing the number of people in each age cohort in any particular year. A mortality table based on this assumption would only be meaningful if the population structure were stationary (that is, deaths in each age group were exactly proportional to the number of people reaching that age). Demographers frequently need to estimate birth and death rates in populations for which there are no registration data, but they almost never make such an extreme assumption. 
13. Mortality rates are, ideally, measured by direct observation of the age of those who die. However, in the absence of registration data, estimates of death rates can be derived from two successive censuses or surveys which classify the population by age. On the assumption of zero net migration, the difference over time can be assumed to be due to deaths, and so death rates per age category can be derived.

14. The counterpart of direct data on age at death for retirement would be longitudinal data on transition from labour force activity to retirement. In the absence of such longitudinal data, comparisons of labour force participation rates can be used - provided that retirement is independent of population changes (that is, provided the following assumption holds.

Participation in the labour force is not correlated with mortality (those in the labour force are as likely to die as those outside it) nor with net migration (immigrants and emigrants are as likely to be in the labour force as those who stay).

\section{DYNAMIC ESTIMATES}

15. This paper proposes and illustrates a method for estimating net age of withdrawal from the labour force which uses comparisons of labour force participation rates over time. Table 1, which presents a hypothetical example, illustrates the approach, and in particular has been constructed to illustrate the differences between the outcomes to be expected from the "static" approach and those which result from a "dynamic" analysis. In it, column 3 shows participation rates for a hypothetical country at five-year intervals. All the cases show the same 'static' estimate of average retirement age (56.6: column 8, row 9), since the ratio of participation rates is constructed to be identical in each case. However in the first block of data (Block A "Men") participation is actually falling at all age groups. The 'dynamic' estimate of the retirement age, which compares each cohort at an interval of five years, is lower than the static estimate (54.6: column 13). By contrast, for Block B ("Women") the participation rate is rising. In this case, the "dynamic" estimate, which follows through each cohort, has an average retirement age that is higher than the static estimate.

16. In this example, it is clear that men are in fact retiring on average at a lower age than women. The "dynamic" estimate gives a more accurate summary of the situation than does the "static" one.

17. Panel "C" of the example shows a case which is more difficult to interpret. In this case, "female" participation rates are rising so fast that the earliest age at which these "women" can be observed to retire is age 60, and not 50. As a result of this higher growth in participation, the "dynamic" estimate is even higher. Undoubtedly, some of the women in the labour force aged 45 to 54 in "1995" would have retired over the following five years, but the number who do so are outweighed by new entrants. The "net" estimates show no retirement before age 60 . 


\section{Table 1. Hypothetical example}

\begin{tabular}{|c|c|c|c|c|c|c|c|c|c|c|c|c|c|c|c|c|c|c|c|}
\hline & 1 & 2 & $3 a$ & $3 b$ & $4 a$ & $4 \mathrm{~b}$ & $5 n$ & $5 b$ & 6 & ab & 7. & 76 & \& & s & 9 & 10 & 11 & 12 & 13 \\
\hline & \multirow{3}{*}{$\begin{array}{l}\text { Myt } \\
\text { dive }\end{array}$} & \multirow{3}{*}{$\begin{array}{c}\text { Age at } \\
\text { which } \\
\text { retrenent } \\
\text { in anened } \\
\text { bo octur }\end{array}$} & \multirow{2}{*}{\multicolumn{2}{|c|}{ Partiquintertat }} & \multicolumn{10}{|c|}{ Static estimates } & \multicolumn{5}{|c|}{ 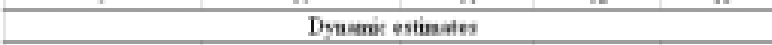 } \\
\hline & & & & & \multicolumn{2}{|c|}{ 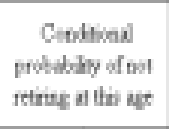 } & \multicolumn{2}{|c|}{ 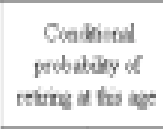 } & \multicolumn{2}{|c|}{ 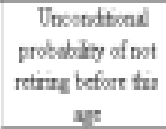 } & \multicolumn{2}{|c|}{ 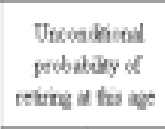 } & \multicolumn{2}{|c|}{ 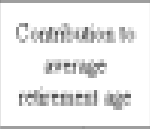 } & 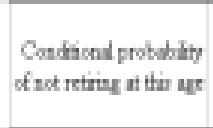 & 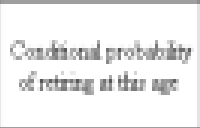 & 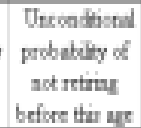 & 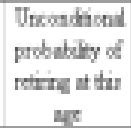 & $\begin{array}{l}\text { Conthace } \\
\text { lo wetayt } \\
\text { fetrenesl by }\end{array}$ \\
\hline & & & 1995 & 2000 & ty9s & 2000 & 195 & 200 & 1995 & 2000 & 195 & 2000 & 1995 & 2000 & & t95. & 2000 & & \\
\hline & & & & & & & & & & & & & & & & & & & \\
\hline \multicolumn{20}{|c|}{ 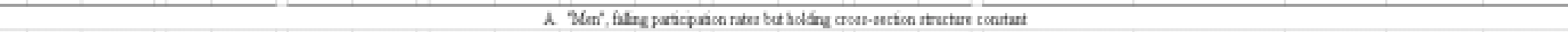 } \\
\hline 1 & $45-45$ & & 80 & 70 & & & & & 1 & 1 & & & & & & & 1 & & \\
\hline 2 & 50.54 & so & 60 & \$25 & 075 & 075 & 0.25 & 0.25 & a7s & 075 & 0.25 & 0.25 & 120 & 120 & 0.66 & 0.34 & 0.66 & 0.34 & 16.5 \\
\hline 3 & 55.53 & Ss & 40 & 35 & 067 & 067 & 0.53 & 0.33 & 0.50 & 050 & 0.25 & 0.25 & 133 & 13.3 & 0.58 & 0.42 & $0.8 \mathrm{~s}$ & 0.27 & 14.5 \\
\hline 4 & 60.64 & $\omega$ & 20 & $17 \mathrm{~s}$ & 0.50 & 0.50 & 0.50 & 0.50 & 025 & 025 & 0.25 & 0.25 & 14.5 & 14.5 & 0.44 & ass & 0.17 & 0.22 & 12.5 \\
\hline 5 & 65.65 & 65 & 10 & 275 & 0.50 & 0.50 & 0.50 & 0.50 & 013 & 0.13 & 0.13 & 0.13 & 79 & 79 & 0.44 & ass & 0.07 & 0.03 & 59 \\
\hline 6 & 70.74 & 70 & 1 & 4375 & 0.50 & 0.50 & 0.50 & 0.50 & 006 & 006 & 0.08 & 0.05 & 43 & 43 & 044 & $0.5 \%$ & 0.03 & 0.04 & $2 \mathrm{II}$ \\
\hline 7 & 75.72 & 79 & 2 & 175 & 0.40 & 040 & $O Q \infty$ & 060 & 0.03 & 0.03 & 0.04 & 0.04 & 27 & 27 & 035 & 0.65 & 0.01 & $O M$ & 15 \\
\hline 8 & 80-104 & $m$ & 0 & 0 & 000 & 000 & 100 & 100 & 000 & 000 & 001 & 007 & 20 & 20 & 000 & 100 & 000 & 001 & 09 \\
\hline 9 & $50 \mathrm{~s}$ & & & & & & & & & & 100 & 100 & 86 & 366 & & & & 100 & 546 \\
\hline & & & & & & & & & & & & & & & & & & & \\
\hline \multicolumn{20}{|c|}{ 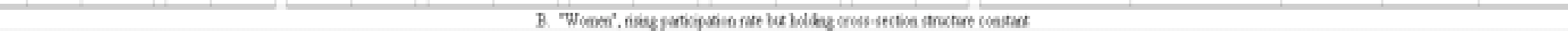 } \\
\hline 1 & 45.49 & & 60 & 70 & & & & & 1 & 1 & & & & & & & 1 & & \\
\hline 2 & 50.54 & 9) & 45 & 525 & 075 & 075 & 0.85 & 0.25 & 075 & 075 & 0.85 & 0.25 & 120 & 120 & 088 & 0.13 & 0.8 & 0.13 & 60 \\
\hline 3 & 55.99 & 55 & 30 & 35 & 0.67 & 0.67 & 0.33 & 0.33 & 050 & 050 & 0.8 & 0.25 & 13.3 & 13.3 & 0.78 & 0.22 & 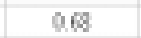 & 0.19 & 10.3 \\
\hline 4 & 60.64 & (6) & 15 & 175 & 050 & 050 & 0.90 & 0.90 & 0.25 & 025 & 0.88 & 0.25 & 14.5 & 14.5 & 0.58 & 0.42 & (0.4) & 088 & 164 \\
\hline 5 & 65.69 & 65 & 7.5 & 875 & 050 & 050 & 0.90 & 0.50 & 0.13 & 0.13 & 0.13 & 0.13 & 79 & 79 & 0.58 & 0.42 & 023 & 017 & 10.4 \\
\hline 6 & 70.74 & 70 & 375 & 4375 & 050 & 050 & 0.50 & 0.50 & 006 & 006 & 0.06 & 0.06 & 43 & 43 & 0.58 & 0.42 & 0.14 & 0.10 & 66 \\
\hline 7 & 75.79 & 75 & 1.5 & 175 & 040 & 040 & 0.60 & 0.60 & 0.03 & 0.03 & 0.04 & 0.04 & 27 & 27 & 0.47 & 0.53 & 0.05 & 0.07 & 53 \\
\hline 8 & 80-84 & () & 0 & 0 & 000 & 000 & 100 & 100 & 000 & 000 & 0.03 & 0.03 & 20 & 20 & 00 & 100 & 0,00 & 0.05 & 4.9 \\
\hline 9 & $8 \mathrm{en}$ & & & & & & & & & & 1.00 & 100 & 566 & 56.6 & & & & 100 & 99 \\
\hline & & & & & & & & & & & & & & & & & & & \\
\hline \multicolumn{20}{|c|}{ 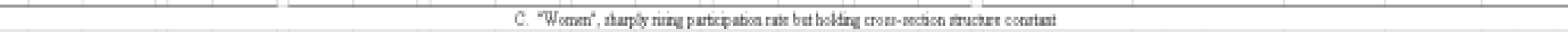 } \\
\hline 1 & $45-49$ & & 60 & 90 & & & & & 100 & 100 & & & & & & & 1.00 & & \\
\hline 2 & 50.54 & so & 45 & 675 & 075 & 0.75 & 0.25 & 0.25 & 075 & 075 & 0.25 & 0.25 & 120 & 120 & 10 & 000 & 1.00 & 0.00 & 0.0 \\
\hline 3 & 55.52 & 55 & 30 & 45 & 067 & 0.67 & 0.33 & 0.33 & 050 & 050 & 0.25 & 0.25 & 133 & 133 & 10 & 0.00 & 1.00 & 0.00 & 0.0 \\
\hline 4 & 60.64 & $\omega$ & 15 & 225 & 0.50 & 0.50 & 0.50 & aso & 025 & 025 & 0.25 & 0.25 & 14.5 & 14.5 & 0.8 & 0.25 & 0.75 & 0.25 & 14.5 \\
\hline 5 & 65.62 & 65 & 3.5 & 118 & 0.50 & 0.50 & 0.50 & 0.50 & 013 & 0.13 & 0.13 & 0.13 & 79 & 7.9 & 0.75 & 0.25 & 0.58 & 0.15 & 118 \\
\hline 6 & 70.74 & 70 & 375 & 5688 & 0.50 & 0.50 & 0.50 & aso & 006 & 006 & 0.08 & 0.05 & 43 & 43 & a.s & 0.25 & 0.42 & 0.14 & 9.6 \\
\hline 7 & 75.72 & 75 & 15 & 225 & 040 & 040 & $0 \omega$ & $0 \omega$ & 003 & 0.03 & 0.04 & 0.04 & 27 & 27 & 060 & 0.40 & 0.25 & 0.17 & 123 \\
\hline II & $10-1 / 4$ & D & 0 & 0 & 000 & 000 & 100 & 100 & 000 & 000 & 0.03 & 003 & 20 & 20 & 000 & 100 & 0.00 & 0.28 & 197 \\
\hline 9 & Swa & & & & & & & & & & 100 & 100 & 86 & 566 & & & & 100 & 679 \\
\hline
\end{tabular}

Note: The participation rates are constructed for illustrative purposes. The formulae used are set out in Table 2. 
18. This effect poses problems for comparisons. Suppose one wishes to compare "men" with "women". At first sight, a "fair" comparison would suggest the exclusion of all cases of retirement before age 60. If that is done, the average retirement age for men is automatically higher: in the case of this hypothetical example, it rises to 61.7, but with actual data it can easily rise to be equal to or exceed the estimate for women.

19. However, such an adjustment would be an error. The averages here represent net withdrawal rates. All the estimates are over-estimates of gross retirement ages, as they all include in the activity rates people who are late entrants. In the case of men, these are retirees who return to work part time or in second jobs. The (more numerous) women are largely (re-) entering the labour force after childbearing. In this hypothetical example, a net total $62 \%$ of men would have retired by age 60 , yet this early retirement would be excluded from such a censored estimate for them. At the same time, the impact of the entry of women aged 45-54 into the labour force should itself be reflected in a figure that summarises net movement. If anything, the practice adapted here of imposing a zero net exit rate when women are still entering the labour force itself imposes a downward bias on the estimate, since actual net entry rates at younger ages are (in a sense) negative.

20. The difference between the "static" and the "dynamic" estimates shown in the illustrative Table demonstrate the true nature of the "static" average retirement rates. The static rates are the average withdrawal rates that would prevail in the population in question if the age-specific participation structure remained stable over time. In other words, they show what the average withdrawal age that would be required to keep unchanged the participation distribution by age. In an age in which participation structures are changing markedly, such an estimate has little intrinsic interest.

\section{CROSS-SECTIONAL AND COHORT ESTIMATES}

21. In neither case is the actual retirement experience of a particular cohort being estimated. The issue here is similar to that which obtains with summary demographic statistics. Estimates of life expectancy and of gross and net reproduction rates sum together the mortality and birth-rates of different cohorts in a particular year. They show what the actual average lifespan and the actual average number of children would be if the one cohort experienced over the entire lifespan the rates observed in the year in question.

22. Such estimates can be misleading. For example, if a generation of women is deferring childbearing, gross reproduction rates will be low for a period even if the eventual number of children born per woman does not fall. And the age specific death rates of older generations who had poorer nourishment and care when young may be a poor guide to the longevity of those who are still young.

23. In the case of withdrawal from the labour force, it is an open question whether current early withdrawal by some middle aged men is a process which involves a selection bias (so that the survivors, who are men who like their jobs, will be more likely to work longer). Withdrawal could also be a Markov process in which the probability is not affected by the size of the remaining cohort. Similarly, nor can we know from these data alone whether the low (or negative) withdrawal rate amongst 45 year old women will be followed by net withdrawal at rate as fast as that of men, or by a longer worklife to compensate for the time lost when child-raising. These issues can be explored for past generations, but any projections of the conclusions into the future is necessarily speculative. Understanding such trends involves hypothesising and then modelling behaviour, for which the data used here are at best a starting point. 
24. The estimates are summary indicators. They summarise the latest information available for each cohort in one average. The method implies (though it does not assume) that withdrawal is a Markov process, in which the probability of withdrawal is independent of past experience. As is shown by the example of birth deferment, such assumptions can be misleading. But the alternative would be to wait forty years until the last of those currently aged 40 move out of the labour force: a useless approach for tracking current trends.

\section{ANALYTIC BASIS OF THE ESTIMATES}

25. Consider those in the labour force at age $(a-1)$. Let $W_{a}$ be the probability that each person will withdraw from the labour force at age $a$, and $S_{a} \equiv\left(1-W_{a}\right)$ its supplement: the probability that each person will stay in the labour force at age $a$. If $m$ is the minimum age at which withdrawal occurs (so that $W_{j} \equiv 0$, $j<m)$, then the overall probability that any person will still be in the labour force at age $(a-1)$ will be

$$
s_{a}=\Pi_{j=m}^{a-1} S_{j}, \quad \text { where } \quad S_{j} \equiv 1 \quad \text { for } \quad j<m
$$

Then the probability that any individual will withdraw from the labour force at age $a$ will be

$$
\begin{aligned}
& w_{a}=W_{a} \quad S_{a} \\
& \quad \equiv\left(1-S_{a}\right) \Pi_{j=1}^{a-1} S_{j}
\end{aligned}
$$

26. Now assume that there is a maximum age, $n$, above which no one remains in the labour force. This implies $W_{n}=1$ : everyone still in the labour force at age $(n-1)$ withdraws at age $n$, so that $S_{n}=0$

In this case, it is easy to show that

$$
\sum_{a=m}^{n} w_{a}=1
$$

and the expected age of withdrawal, $G$, is the sum of the retirement ages weighed by the probability of withdrawal, i.e.

$$
G=\sum_{a=m}^{n} a w_{a}
$$

\section{EMPIRICAL ESTIMATION}

27. Data on participation in the labour force held in the OECD labour force database are currently available for five-year age groups. It is therefore necessary to assume that withdrawal from the labour force occurs at a uniform rate over five year age groups. For purposes of calculation, this amounts to the assumption that all withdrawal is at the intersection between five year age groups: for example, those who withdraw between age 55-59 and 60-64 all do so at age $60^{4}$.

3 see endnote (a)

4 Arithmetically, this is equivalent to assuming that withdrawal occurs at a uniform rate over the five years in question, so the average (and nedian) age is the mid-point between the age groups: 60 in this case. This assumption is occasionally close to reality (people often do move into retirement at age 60 or 65 , since this is 
On this basis:

"y" refers to a particular calendar year

"a" is a five year age group which, for convenience, is written as the first of the five year group. Thus " $a=65$ " in fact means "the age group 65-69".

Then define

$L_{a}^{y}$ as the number of people in the labour force in year y and age group a

( $L_{65}^{1977}$ is the number of 65-69 year olds in the labour force in 1977).

$P_{a}^{y}$ as the population in year y and age group a

$A_{a}^{y} \equiv L_{a}^{y} / P_{a}^{y}$ as the activity rate (labour force participation rate) for age group a in year y

$\hat{S}_{a}^{y}=A_{a}^{y} / A_{a-5}^{y-5}$ as the proportion of those who were in the labour force five years ago who have stayed in it in age group a in year y

28. By the convention described above, all those who did withdraw are assumed to have done so at the age "a" which we have used to label the five year age range. For the dynamic estimate of net withdrawal age, the overall probability in the population of staying in the labour force at age a in year $y$, $S_{a}^{y}$, is then estimated by the observed withdrawal rate $\widehat{S}_{a}^{y}$.

29. The corresponding static estimate of the probability of staying in the labour force (as estimated by Latulippe) is $A_{a}^{y} / A_{a-5}^{y}$. The minimum age at which anyone withdraws from the labour force in Table 1 is 45 , and the maximum age is 80 : ie. $m=45$ and $n=80$. The relation between the theoretical probabilities, the empirical estimates and the illustration in Table 1 is set out in Table $2^{5}$.

often the age at which the public pension become available). However, often this assumption is not correct (e.g. in the United States, the first age at which old age social security is payable is 62). (I am grateful to Denis Latulippe for pointing out that such differences, if not taken into account, can lead to an illusion of precision) Future work will need to adjust for such effects to derive more accurate estimates.

5 Column 3 of Table 2 shows one of the attractions of Latulippe's method: using only current year data simplifies the calculations. The implicit assumption that the structure of activity rates is invariant means the unconditional probabilities cancel out when multiplied together. However, such computational simplicity is not a reason for adhering to a method that yields misleading results.

The method also has the apparently seductive advantage of only requiring one years' data for each estimate: Latulippe's paper includes estimates of activity rates at 10 year intervals (five sets of data are given for each country, running from 1950 to 1990). However, this is similar to using single-year census data to derive net (death plus emigration) rates: the method only has validity if activity rate structures are stable. But if they were stable, the time series would be of no interest! 
Table 2. Formulae used for empirical estimates

\begin{tabular}{|c|c|c|c|c|c|c|c|}
\hline \multirow[b]{2}{*}{1} & \multirow{2}{*}{$\begin{array}{c}\text { Symbolic Form } \\
2\end{array}$} & \multicolumn{2}{|c|}{ Estimates } & \multicolumn{4}{|c|}{ Corresponding Column in Table 1} \\
\hline & & 3 & 4 & 5 & & 6 & \\
\hline & & Static & Dynamic & Static & & Dyna & \\
\hline $\begin{array}{l}\text { of staying in the } \\
\text { labour force }\end{array}$ & $S_{a}^{y}$ & $A_{a}^{y} / A_{a-5}^{y}$ & $A_{a}^{y} / A_{a-5}^{y-5}$ & $\begin{array}{l}\text { Column } \\
4\end{array}$ & $\begin{array}{l}\text { Row } \\
1-8\end{array}$ & $\begin{array}{l}\text { Column } \\
\quad 9\end{array}$ & $\begin{array}{l}\text { Row } \\
1-8\end{array}$ \\
\hline $\begin{array}{l}\text { of not staying in } \\
\text { the labour force }\end{array}$ & $W_{a}^{y} \equiv 1-S_{a}^{y}$ & $1-\left(A_{a}^{y} / A_{a-5}^{y}\right)$ & $1-A_{a}^{y} / A_{a-5}^{y-5}$ & 5 & $1-8$ & 10 & $1-8$ \\
\hline $\begin{array}{l}\text { of still being in } \\
\text { the labour force }\end{array}$ & $S_{a}^{y}=\prod_{j=9}^{a / 5-1} S_{5 j}^{y}$ & $A_{a-5}^{y} / A_{40}^{y}$ & $\prod_{k=9}^{a / 5-1}\left(A_{5 k}^{y} / A_{5 k-5}^{y-5}\right)$ & 6 & $1-8$ & 11 & $1-8$ \\
\hline $\begin{array}{l}\text { of withdrawing at } \\
\text { this particular age }\end{array}$ & $W_{a}^{y}=W_{a}^{y} s_{a}^{y}$ & $\left(A_{y}^{a-5}-A_{y}^{a}\right) / A_{y}^{40}$ & $W_{a}^{y} \boldsymbol{S}_{a}^{y}$ & 7 & $1-8$ & 12 & $1-8$ \\
\hline $\begin{array}{l}\text { Expected (mean) age } \\
\text { of withdrawal from } \\
\text { the labour force in } \\
\text { year y }\end{array}$ & $G_{y}=\sum_{a=9}^{14}(5 a) w_{5 a}^{y}$ & $\sum_{k=9}^{14}(5 k)\left(A_{y}^{a-5}-A_{y}^{a}\right) / A_{y}^{40}$ & $\sum_{k=9}^{14}(5 k) \cdot w_{5 k}^{y}$ & 8 & 9 & 13 & 9 \\
\hline
\end{tabular}


30. Data on participation rates until age 70-74 were available for three countries (France, the USA and Japan) for some years. When combined with the assumption that no-one is in the labour force above age 80, this allows retirement at ages 65, 70, 75 and 80 to be taken into account. Estimates of average net withdrawal ages $\left(\mathrm{G}_{\mathrm{y}}\right)$ can then be derived.

31. However, for most countries (and for most years for the USA and Japan) data on participation rates by age are only available up to age 65 . However, the total number in the labour force above this age is available. This total number is an important indicator of the extent of late retirement, but cannot directly be integrated into the approach described in the above illustration.

32. The Annex describes a method for using this total to derive an estimate of $S_{a}$ for age groups above the age of 65 . Because only one figure is available, this is done by assuming that the value of $S_{a}$ does not vary by age for $a \geq 65$. The Annex compares the estimates of average net withdrawal ages $\left(G_{y}\right)$ which result from using this assumption with those calculated using data for activity rates above the age of 65 . Except for Japanese women (where the data used to derive rates for age groups above 65 is clearly inconsistent over time) the results are almost exactly the same.

33. The rest of this paper assumes that this method is valid, and uses it to calculate average net withdrawal ages for 17 countries. Because at least five years' data are needed, only countries with at least that many years' data are included. In some cases ${ }^{6}$, data are only available for ten-year age groups for ages below 55. In these cases, activity rates in five-year groups have been devised by interpolation, and then the formulae given above have been used. This does not influence the accuracy of the results greatly, as the ages at which most retirement occurs are the ages between 55 and 65 .

34. Finally, if the simplifying assumption of all retirements occurring at the boundary between two age groups is dropped, and a more realistic (though arithmetically similar) uniform transition between each age range is substituted, it is possible by interpolation to derive the quartiles of the distribution of net withdrawal. To do this, it is necessary to assume that movement out of the labour force continues until the age 82.5. These estimates are less affected by the assumed truncation of employment at this age, except for Japan where the final quartile of the distribution is at a very high age.

\section{RESULTS}

35. Figure 1 shows the "dynamic" and "static" estimates of average age of withdrawal over time for 16 countries. Figure 2 shows the three quartiles for dynamic estimates for both genders. It should be born in mind that all these estimates have been obtained from data truncated at age 65, using the method described in Annex 1. This particularly affects the upper quartile. In the cases of Japan and Korea, it is also directly affected by the imposed assumption that all labour force participation ceases above age 82: this assumption is strictly not correct anywhere, and clearly produces a downward bias in the estimate of the upper quartile in these two cases.

\section{Difference in levels between "Static" and "Dynamic" estimates}

36. The pattern suggested in the hypothetical example (Table 1) is confirmed by the empirical data. Out of 16 countries, for 13 the "dynamic" estimate of average age of withdrawal for women is consistently

6 Australia, Canada, Finland, the United Kingdom and (before 1983) Italy 
higher than the static estimate, since it eliminates the bias due to the secular increase in female participation in the labour force over time. This bias is not present, of course, when female participation ceases to increase, and so the systematic difference in the two series disappears in Sweden and Denmark from 1995 and in Finland from 1990.

37. The fall in male labour force participation has been less pronounced and less general than the rise in female participation. However, it is sufficiently widespread to cause the male dynamic estimate to be generally lower than the static estimate in about nine of the 16 countries.

38. The dynamic estimates therefore show female withdrawal rates to be closer to male rates than do the static estimates. In four cases (the US, France, Spain and Portugal) the average age of withdrawal for females is in fact consistently above that for men. For five other countries, the two genders are not consistently different, but in seven countries the estimate of average age of withdrawal for men remains consistently above that for women.

39. The estimates for women are influenced by the fact that within each cohort, participation often increases up to age 45-49 and even 50-54. The method adopted imposes a zero rate of withdrawal from the labour force for these age groups when this happens, and so does not result in a relatively higher age for women unless men do start to withdraw in these age groups. The quartile estimates can be used to see whether men "catch up" to women after these ages are passed: in most cases this does not occur.

\section{Trends}

40. Trends over time in the static and dynamic series can be very different. While in most cases both show a fall from relatively high average ages in the 1960's and 1970's to lower ones more recently, this is by no means general. The static series for women can be particularly misleading. However, the static series for men is generally similar in trend to the dynamic one.

41. Chart 2 shows the changes over the last decade in the "dynamic" estimates. It will be seen that on average there has been no trend to earlier retirement over this period for these OECD countries: increases in some countries have been matched by falls in others.

\section{Cyclical Fluctuations}

42. Unlike the static series, the dynamic series show strong cyclical fluctuations, showing clearly that withdrawal from the labour force by both genders is strongly responsive to general labour market trends. However, this pattern is by no means uniform: for example, the strong increase since the period 1995-1994 in the average age in the US for men is not reflected at all in the series for women, and by 1993-1998 the average for men in the US had risen above that for women for the first time in 20 years.

43. Some of the changes over time show trends which are different to popular perceptions. For example, there has been a great deal of policy concern on Norway over growth in early retirement. But whatever is happening to the age of payment of state pensions, the data show that increasingly premature withdrawal from the labour force in that country ceased for both genders as from the period 1987-1992. The average age of withdrawal has increased by about three years for both men and women since then. 


\section{Data problems}

44. All this is not to say the dynamic estimates are free of faults. They share with static estimates the approximations due to the use of censored data, but because they are more sensitive to the data they more strongly reflect its inadequacies. These are particularly pronounced in Europe, particularly in years prior to 1983 and for countries (such as Belgium and Denmark) where labour force surveys are only carried out to fulfil a mandate from Eurostat. On the first issue, the strong increase in average age in the estimates for Italy from 1971-76 and for the following five years are due to a doubling in one year of the reported number in the labour force above age 65 , a doubling which is certainly a data inconsistency. Similar unlikely fluctuations in that and other age groups for Belgium and Denmark influence their series.

45. Many of the difficulties addressed in this paper - and particularly in Annex 1 - derive from the use of grouped and truncated data. Unit record data or detailed tabulations from labour force surveys can now allow data showing single years of age to be used. Preliminary trials using such data show that the annual variation in the resultant estimates is higher than for the grouped data used for this paper. This appears to reflect annual changes in labour market conditions. Further work on the correlates of these annual variations is needed ${ }^{7}$.

46. Finally, while it would clearly be possible to make data available in a more detailed manner for future surveys, it may be difficult to do so retrospectively in all cases. Hence the estimation processes described in this paper will necessary for several decades, even if data were released from now on in a more comprehensive form.

\section{CONCLUSION}

47. In spite of the inevitable problems in interpretation, the dynamic series are a much better guide to both secular and cyclical trends in withdrawal from the labour force. They provide a more accurate guide for current policy. This methodology should therefore be used as the basis for future data development in this field.

7 Such detailed data could certainly be used for future work to address the issue raised in note 3 above: the "bunching" of withdrawal at the age of eligibility for pensions. Where this age does not coincide with the dividing point between five-year age ranges, estimates based on the assumption of "uniform" rates over the five-year range will be biased. 


\section{DEELSA/ELSA/WD(2001)2}

(a) End note.

$$
\begin{aligned}
\sum_{a=m}^{n} W_{a}=\sum_{a=m}^{n}\left(1-S_{a}\right) \Pi_{j=1}^{a-1} S_{j} \\
=1-S_{m} \\
\quad+S_{m}-S_{m+1} S_{m} \\
\quad+S_{m+1} S_{m}-S_{m+2} S_{m+1} S_{m} \\
\quad---------- \\
\quad+\Pi_{j=1}^{h-2} S_{j}-\Pi_{j=1}^{n-1} S_{j} \\
+\prod_{j=1}^{h-2} S_{j}-S_{n} \Pi_{j=1}^{n-1} S_{j}
\end{aligned}
$$

$=1$ as $S_{n}=0$ by assumption. 


\section{BIBLIOGRAPHY}

Australian Bureau of Statistics (ABS) (1994)

Australian Social Trends Canberra: ABS (cat 4102.0).

GENDELL, Murray (1998)

"Trends in retirement age in four countries, 1965-95", Monthly Labor Review, August, pp: 20-30.

GENDELL, Murray (2001)

"Retirement age declines again in 1990s", Monthly Labor Review, October, pp: 12-21.

GENDELL, M. and SIEGEL J. S. (1992)

"Trends in retirement age by sex, 1950-2005", Monthly Labor Review, July, pp: 22-29.

LATULIPPE, Denis (1996)

Effective retirement age and the duration of retirement in the industrial countries between 1950 and 1990 (Issues in Social Protection, Discussion Paper 2) ILO: Geneva. 
Chart 1. Average age of withdrawal from the labour force

USA

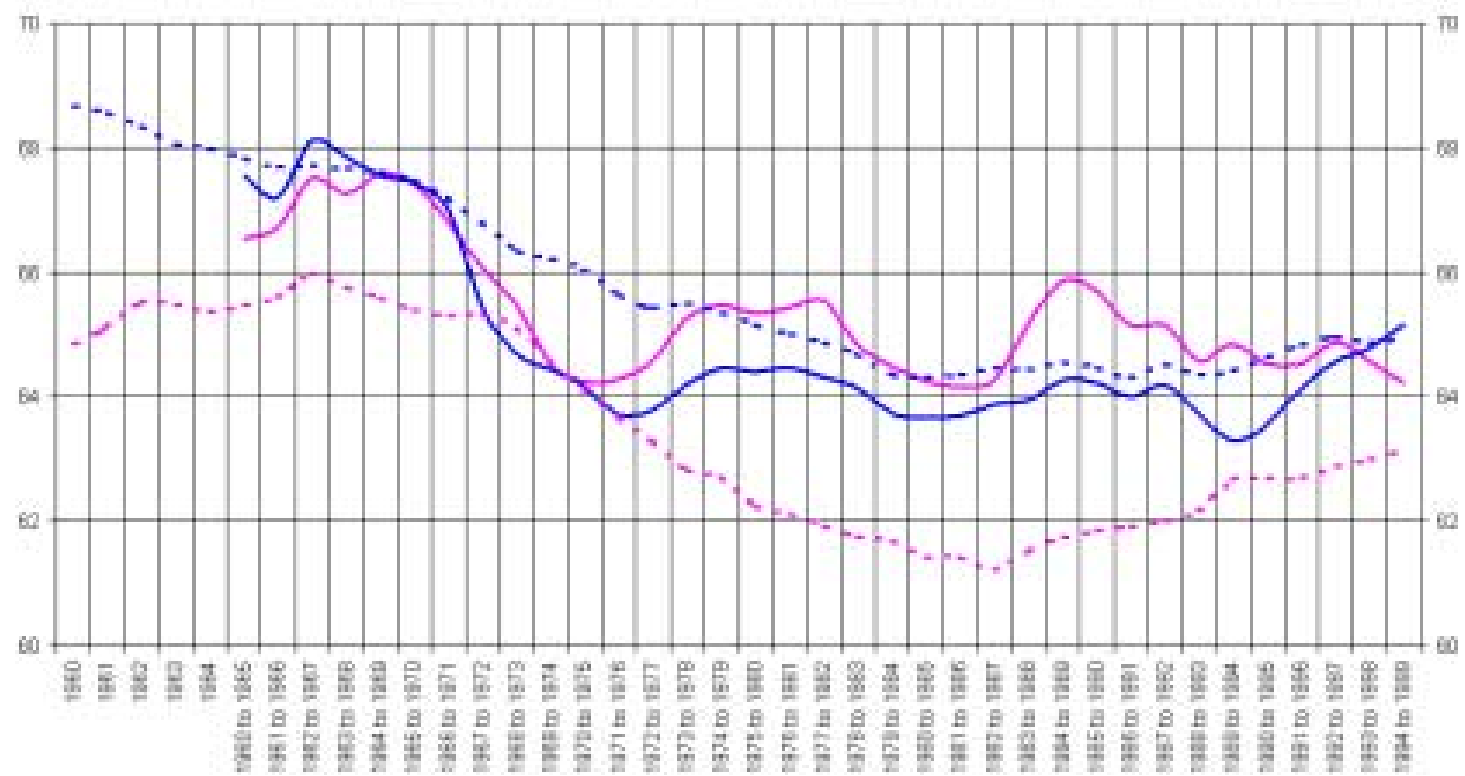

JAPAN

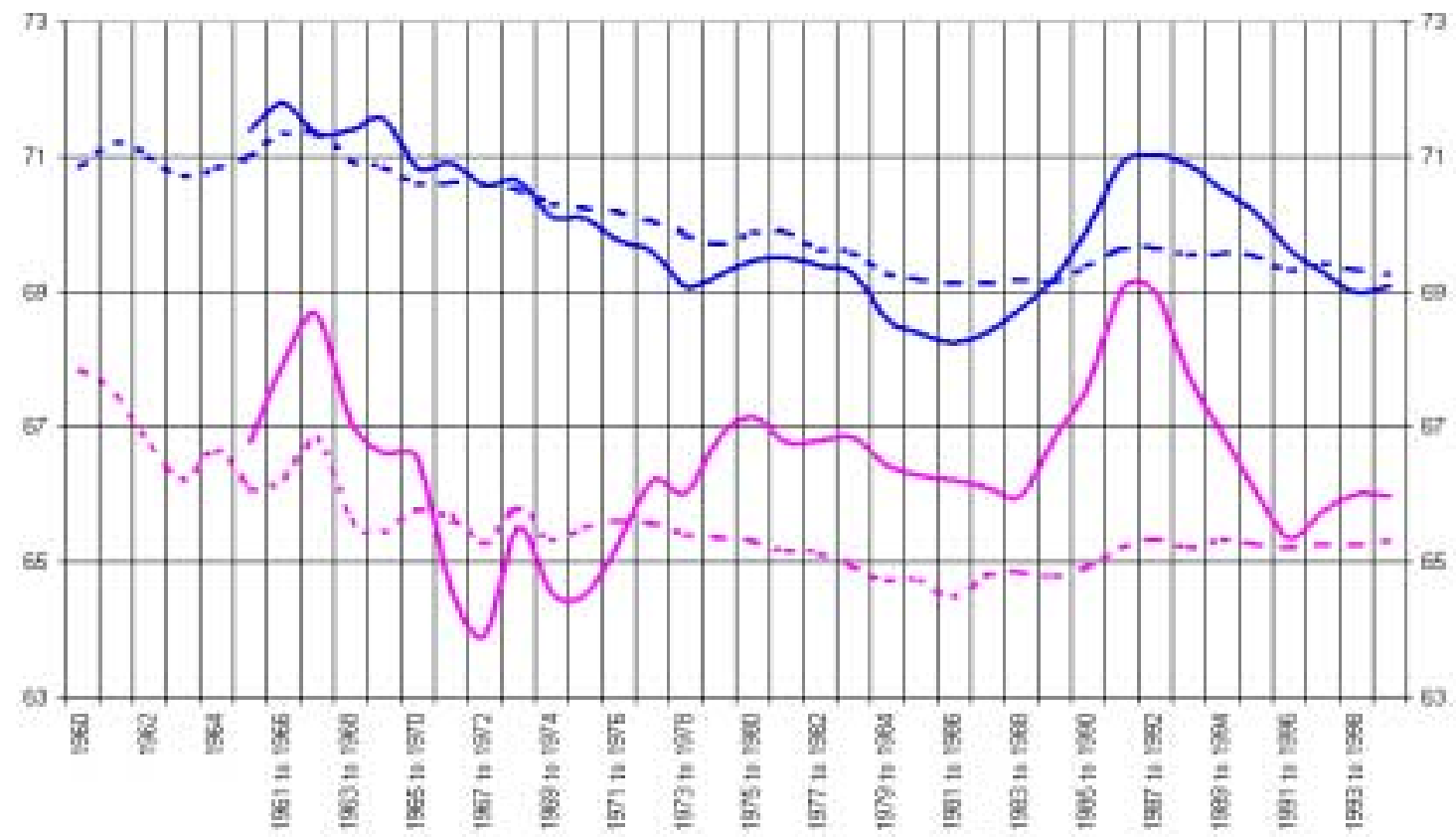

Men Dynamic Estimate

Women Dynamic Estimate - - - Men Static Estimate = - = Women Static Estimate 
Chart 1. Average age of withdrawal from the labour force (cont.) WEST GERMANY

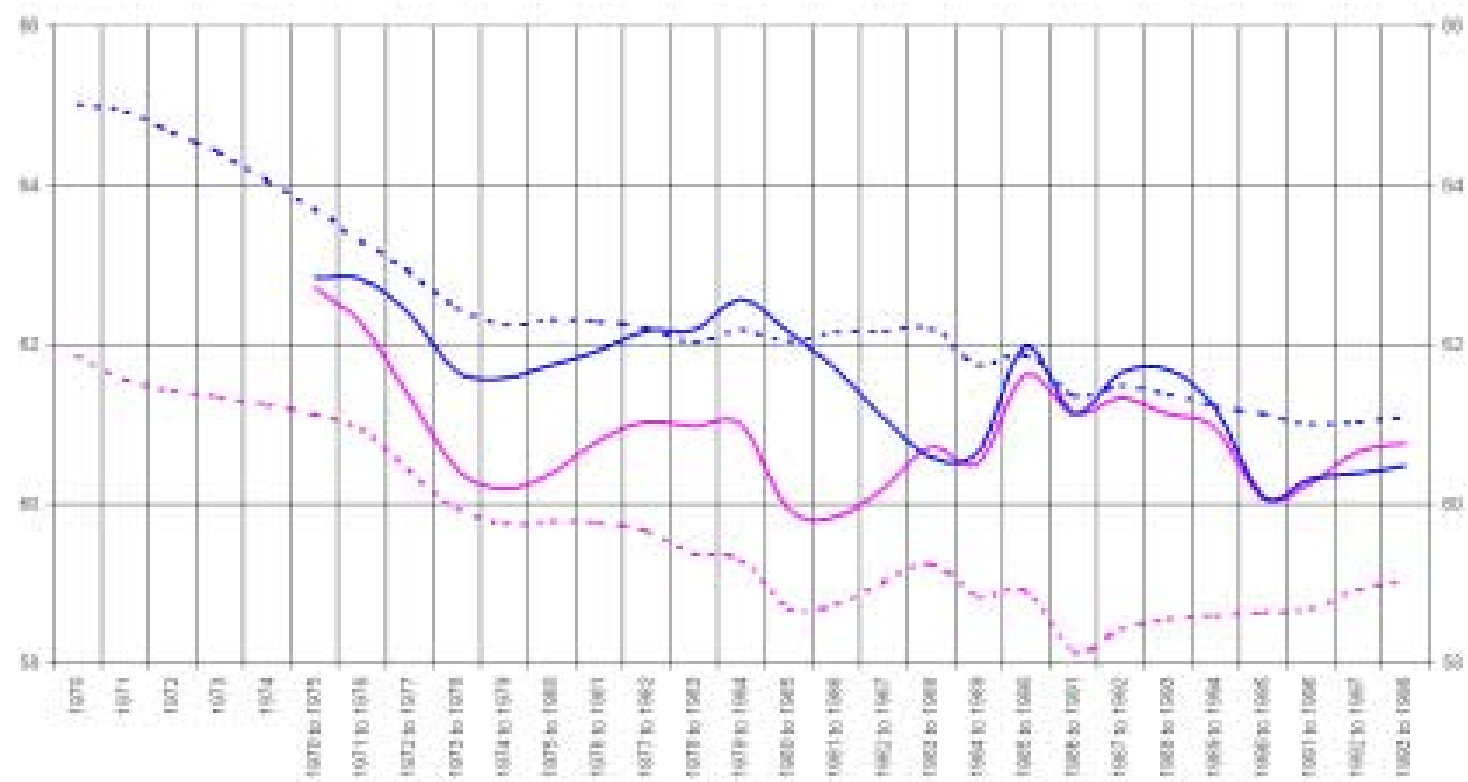

FRANCE

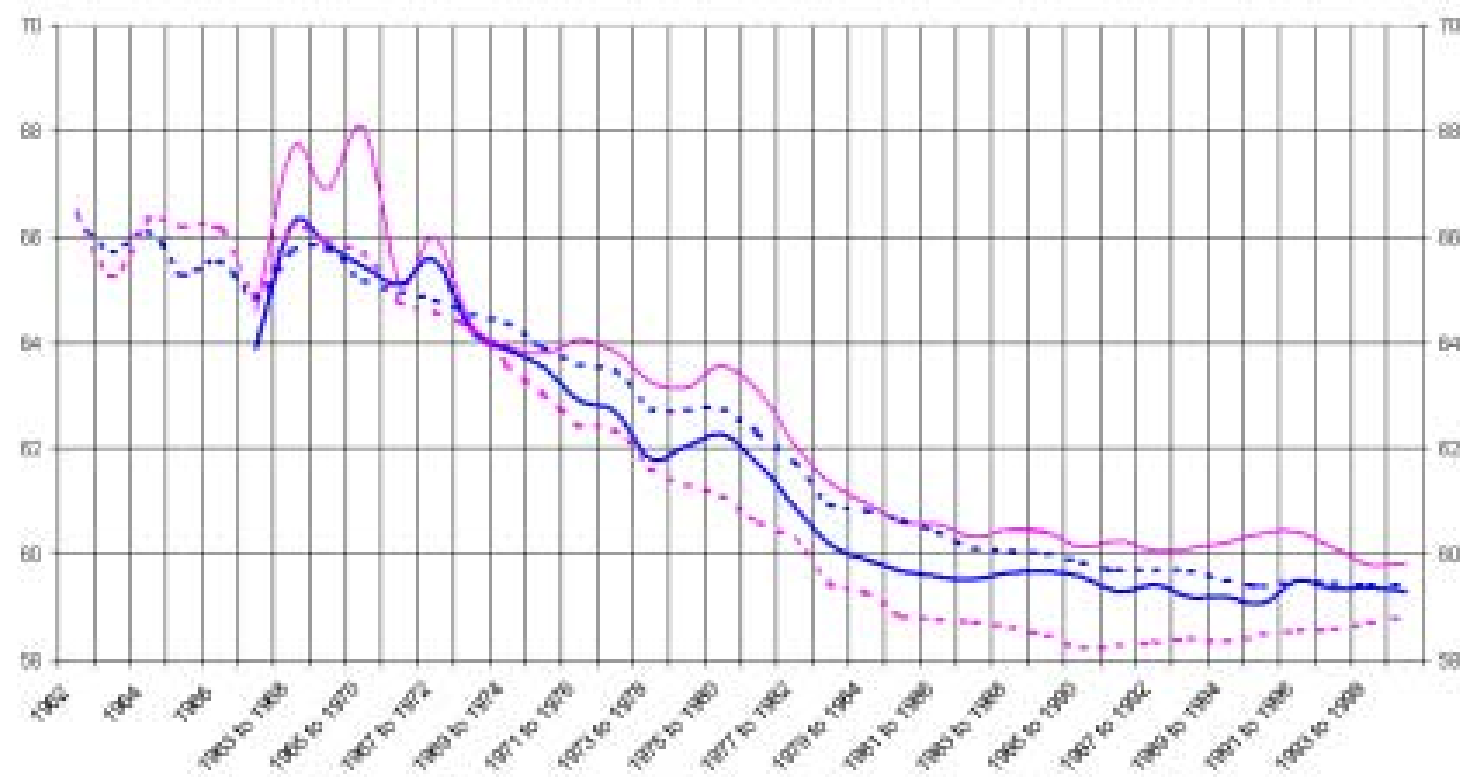

Men Dynamic Estimate — Women Dynamic Estimate - - - Men Static Estimate - - - Women Static Estimate 
Chart 1. Average age of withdrawal from the labour force (cont.)

ITALIE

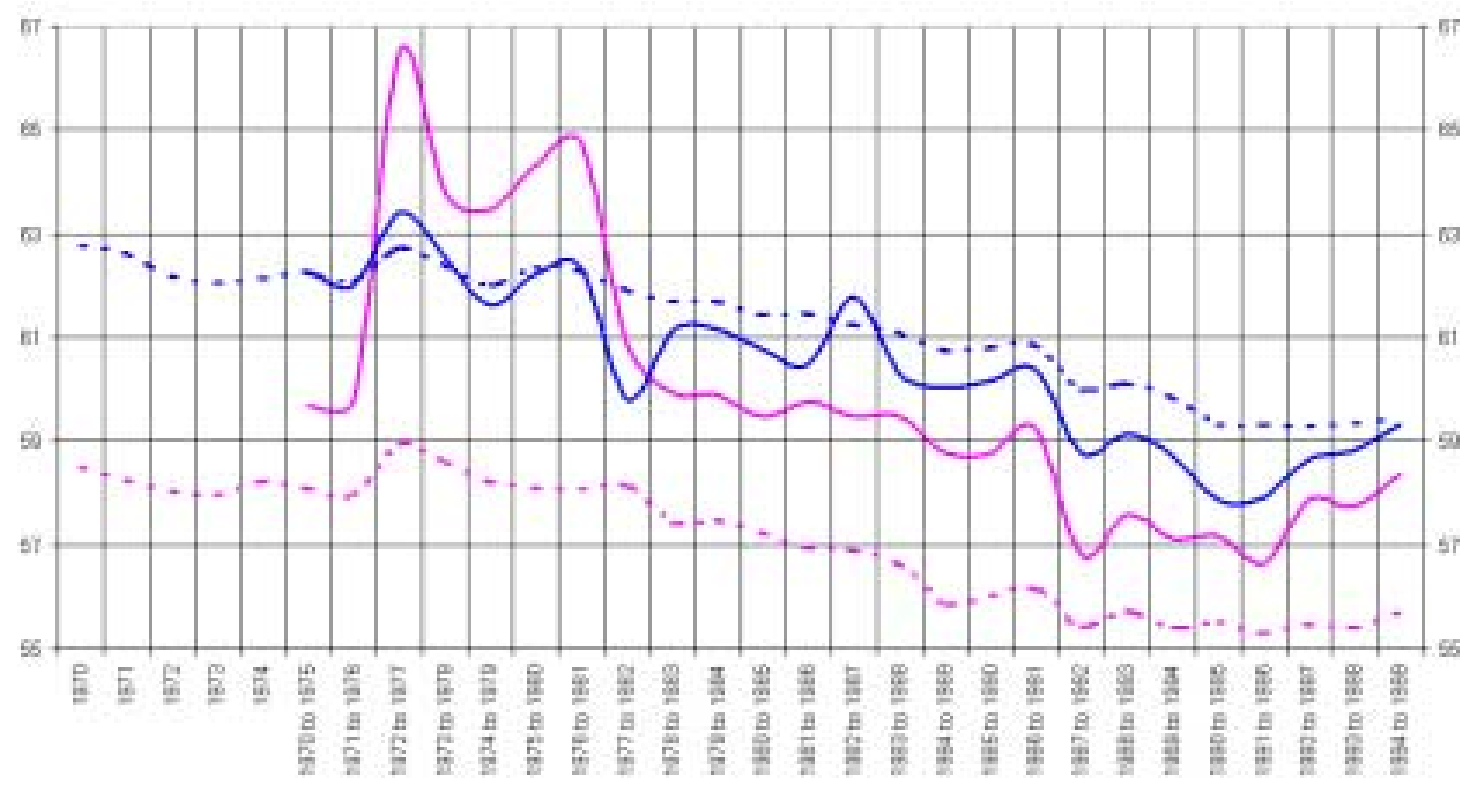

UNITED KINGDOM

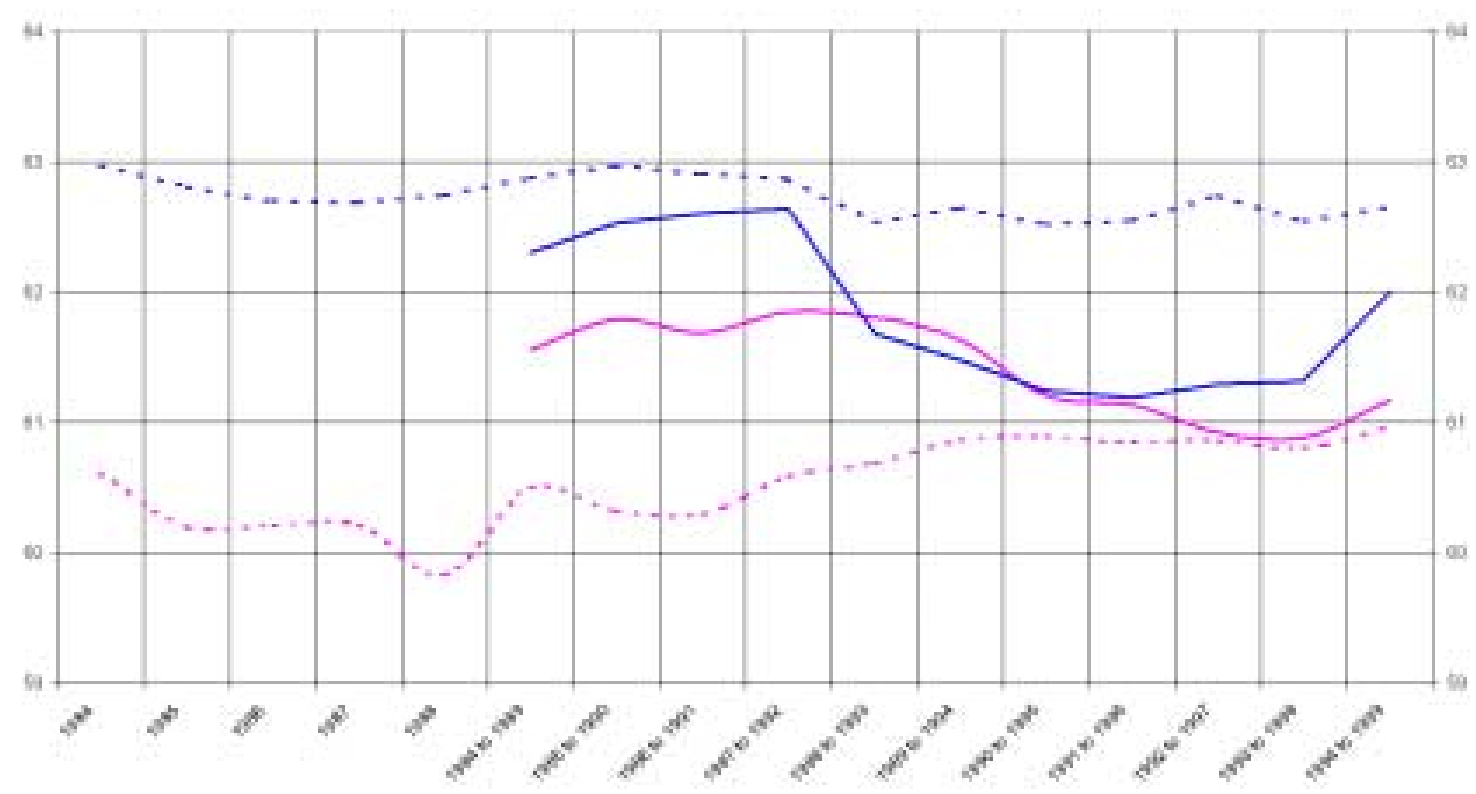


Chart 1. Average age of withdrawal from the labour force (cont.)

CANADA

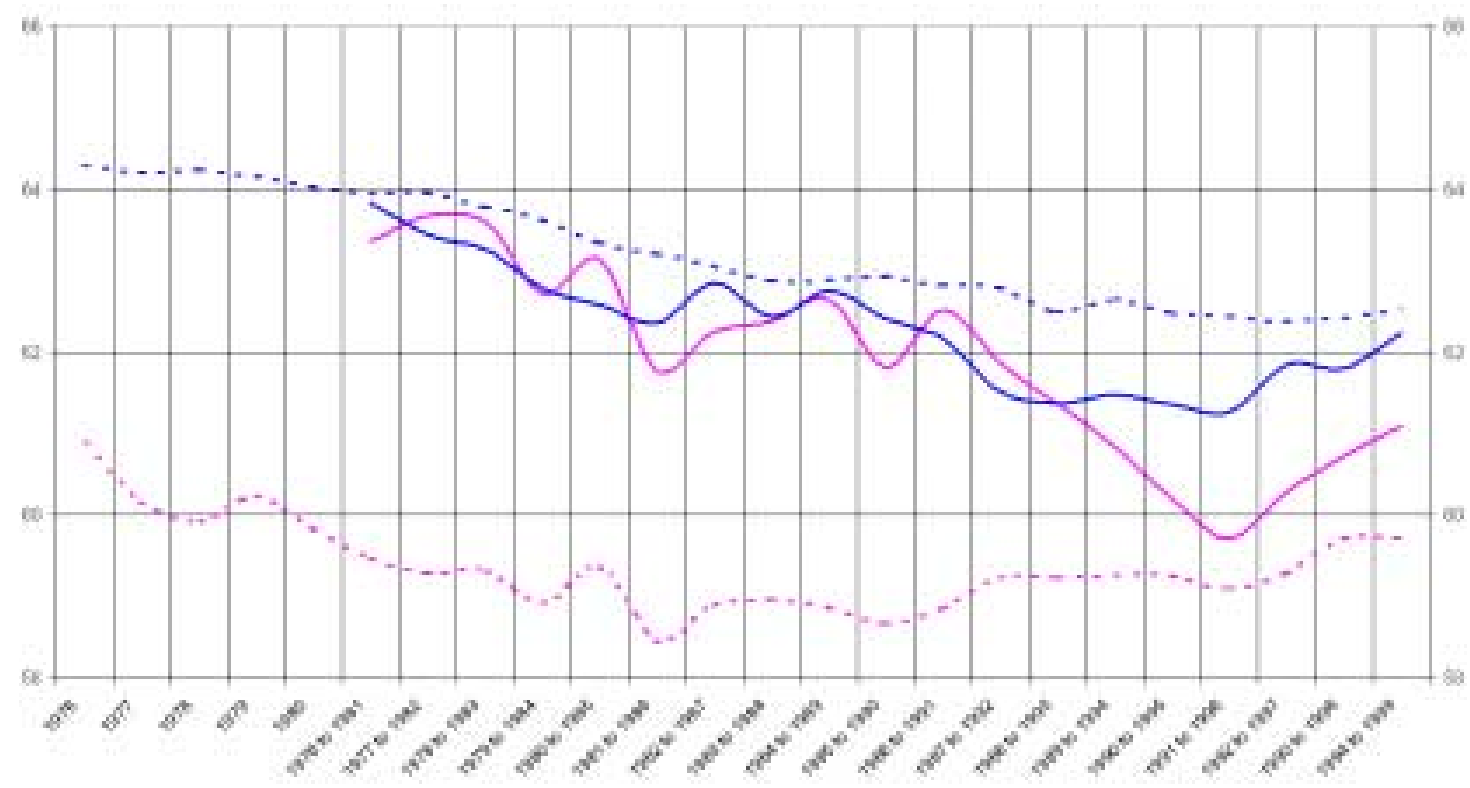

AUSTRALIA

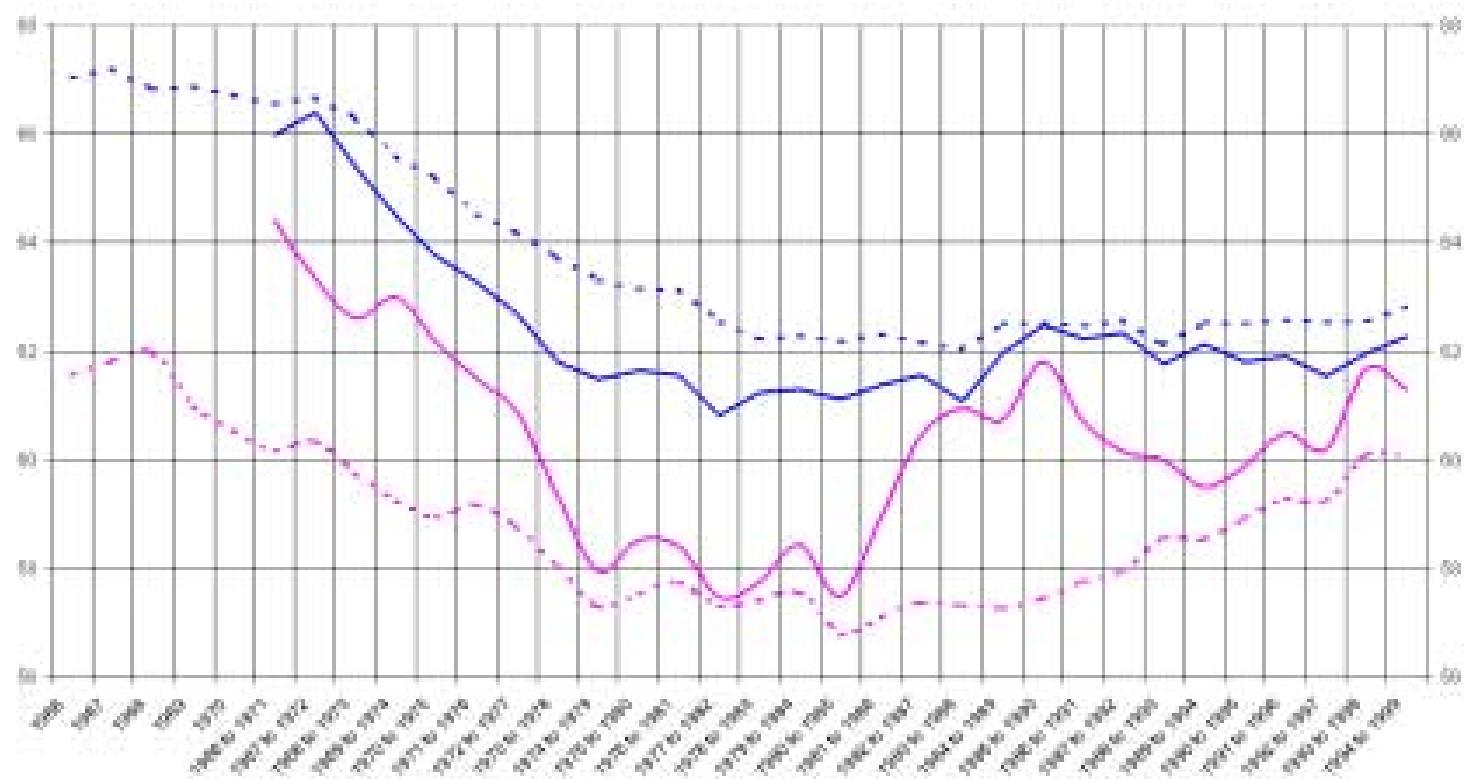

- Men Dynamic Estimate —Women Dynamic Estimate - - - Men Static Estimate - = - Women Static Estimate 
Chart 1. Average age of withdrawal from the labour force (cont.)

BELGIUM
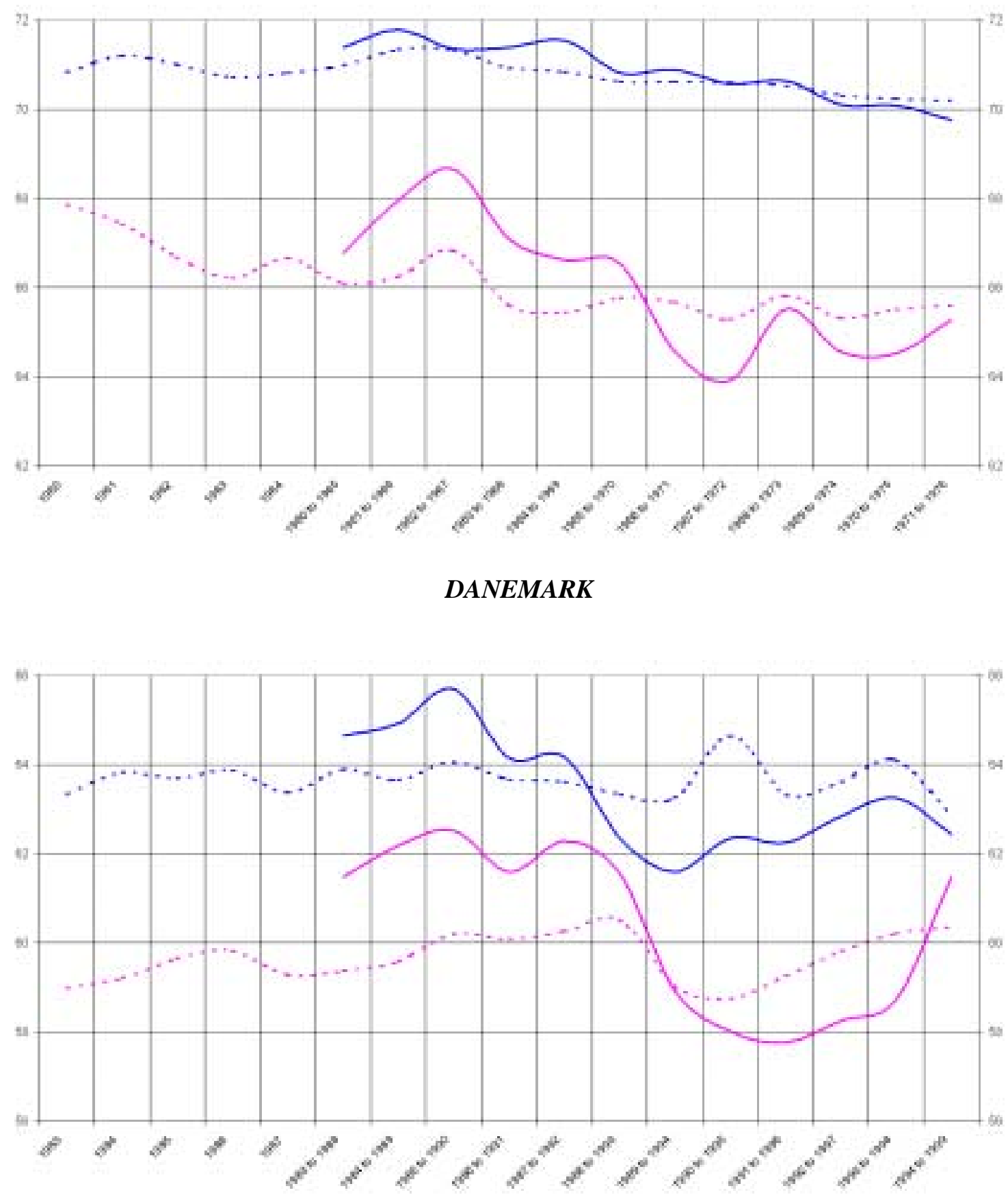

- Men Dynamic Estimate —Women Dynamic Estimate - - - Men Static Estimate = - = Women Static Estimate 
Chart 1. Average age of withdrawal from the labour force (cont.)

FINLAND
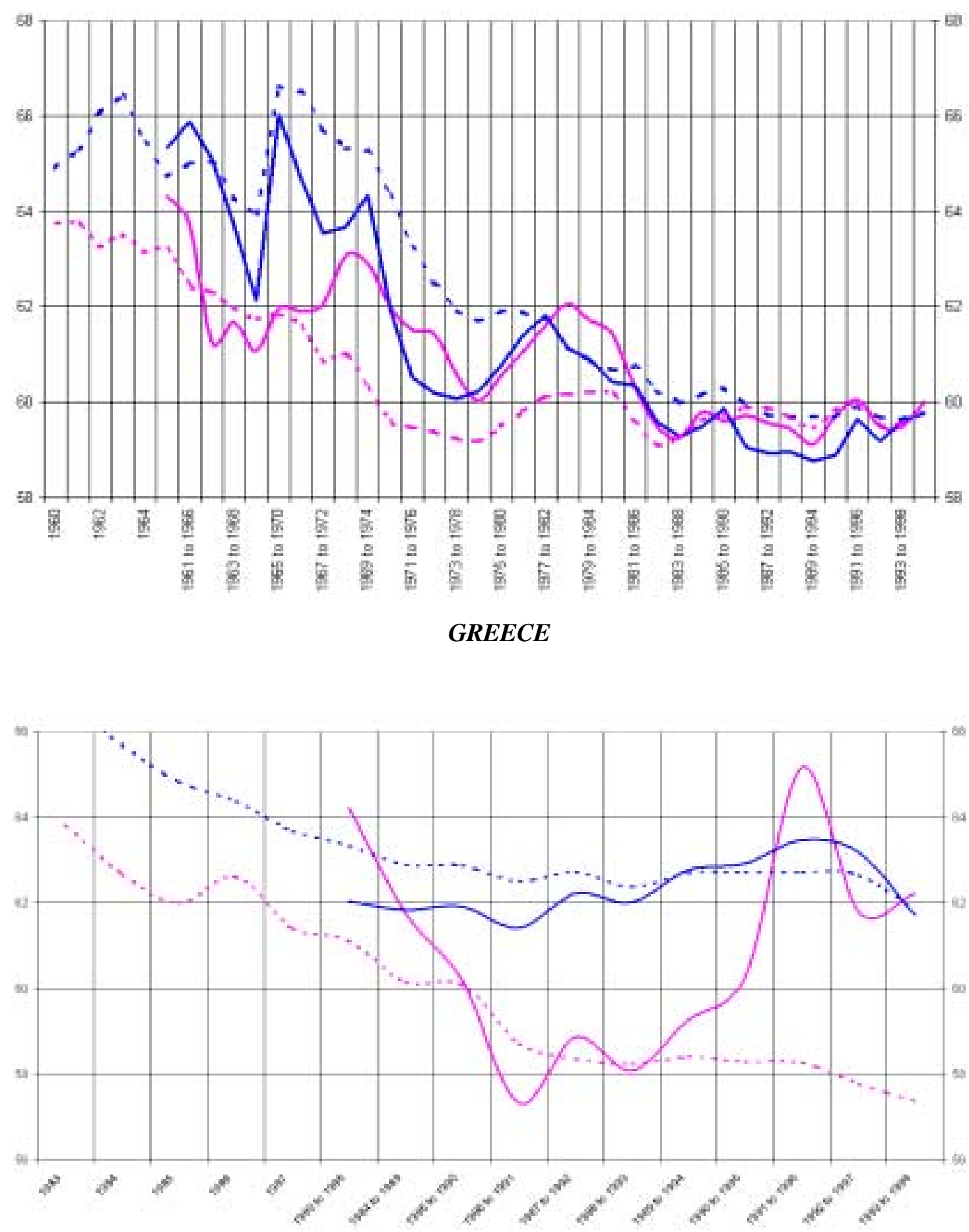
Chart 1. Average age of withdrawal from the labour force (cont.)

KOREA

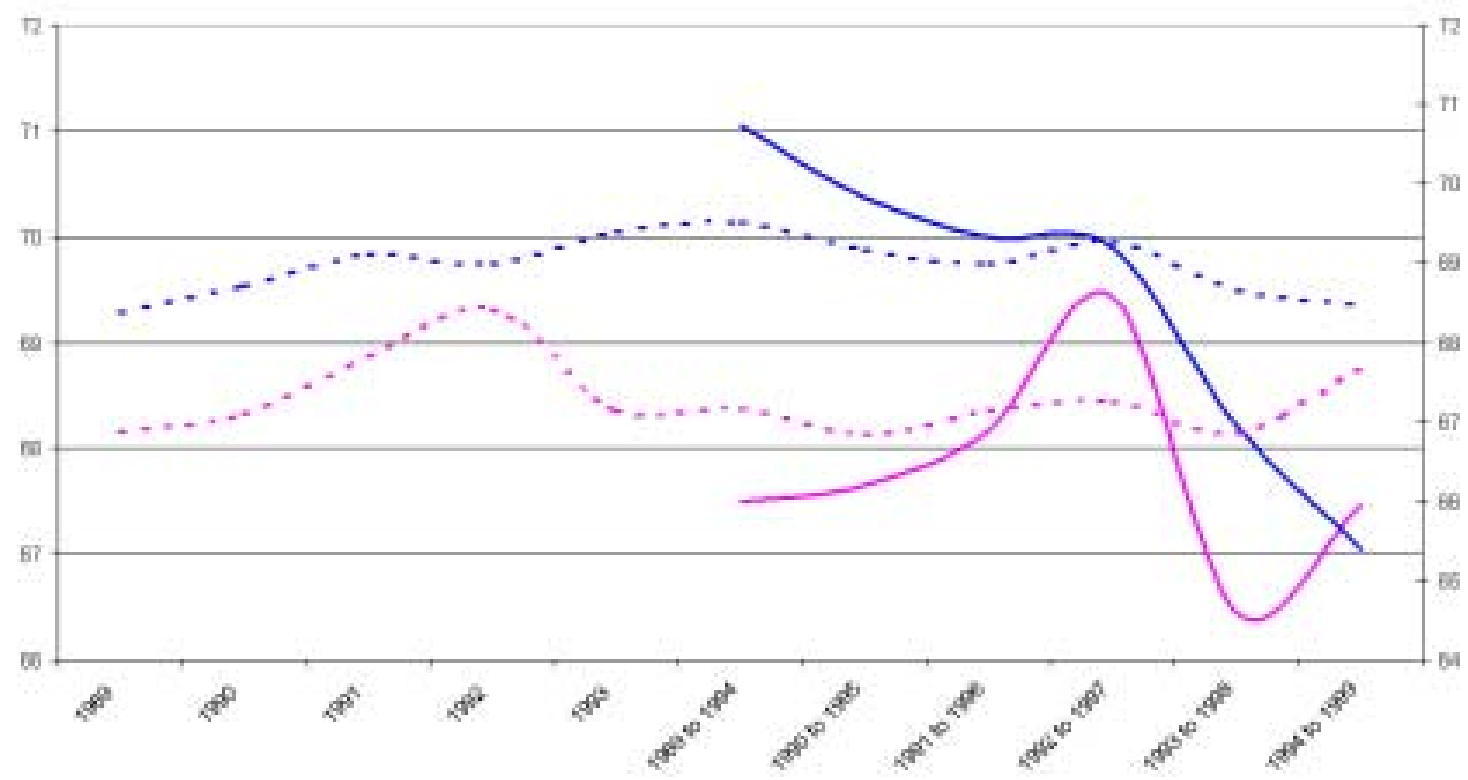

NETHERLANDS

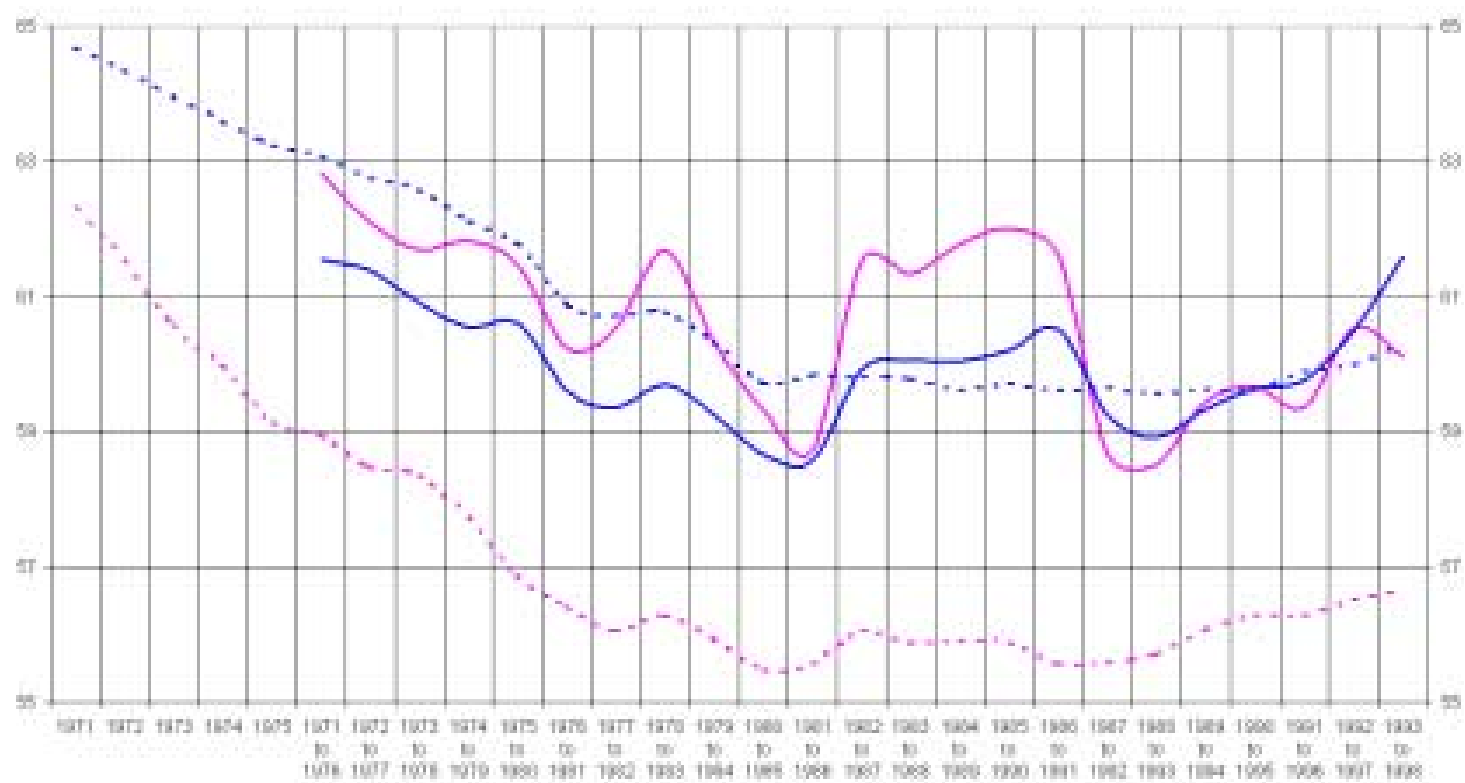

Men Dynamic Estimate

Women Dynamic Estimate - - - Men Static Estimate = - - Women Static Estimate 
Chart 1. Average age of withdrawal from the labour force (cont.)

NORWAY

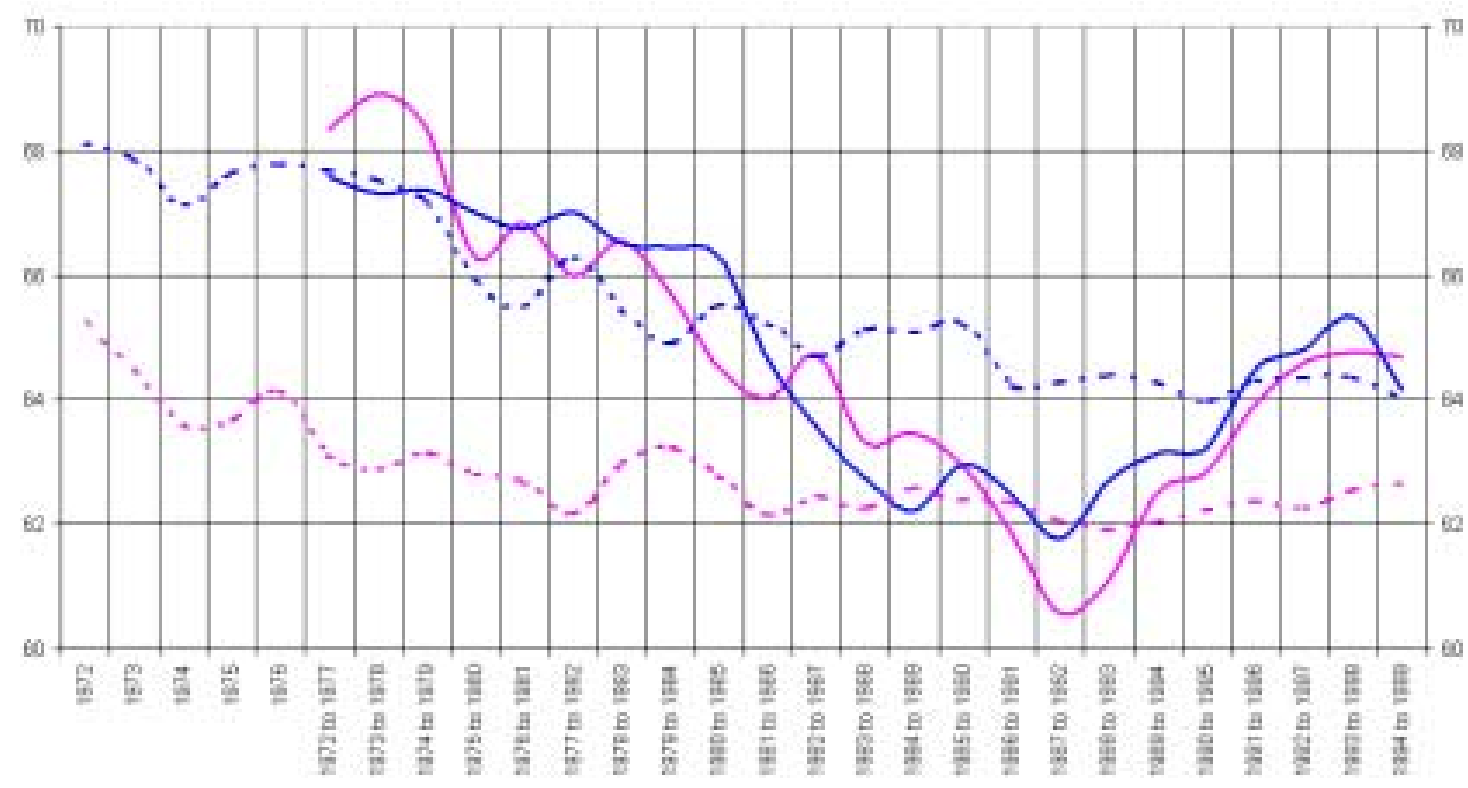

POLAND

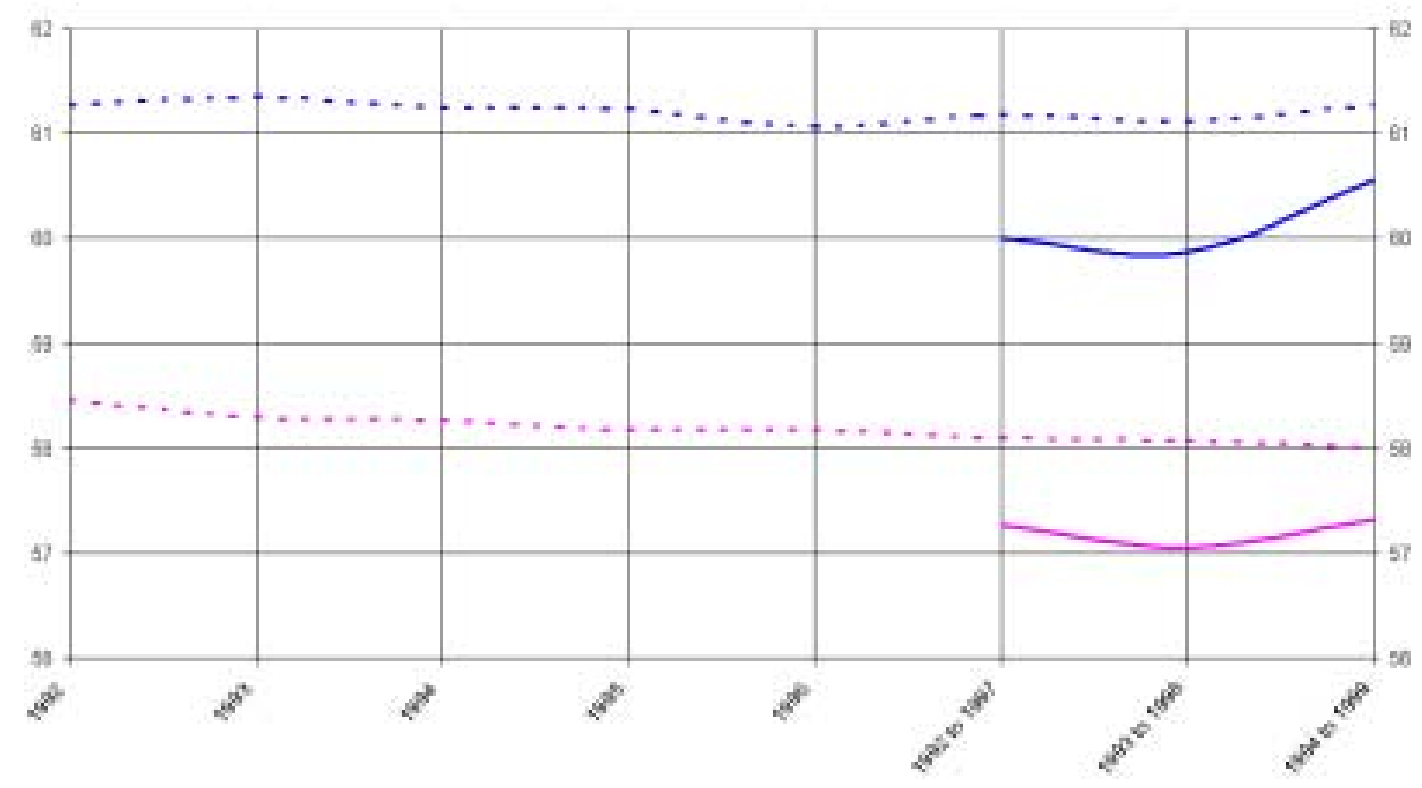


Chart 1. Average age of withdrawal from the labour force (cont.)

PORTUGAL

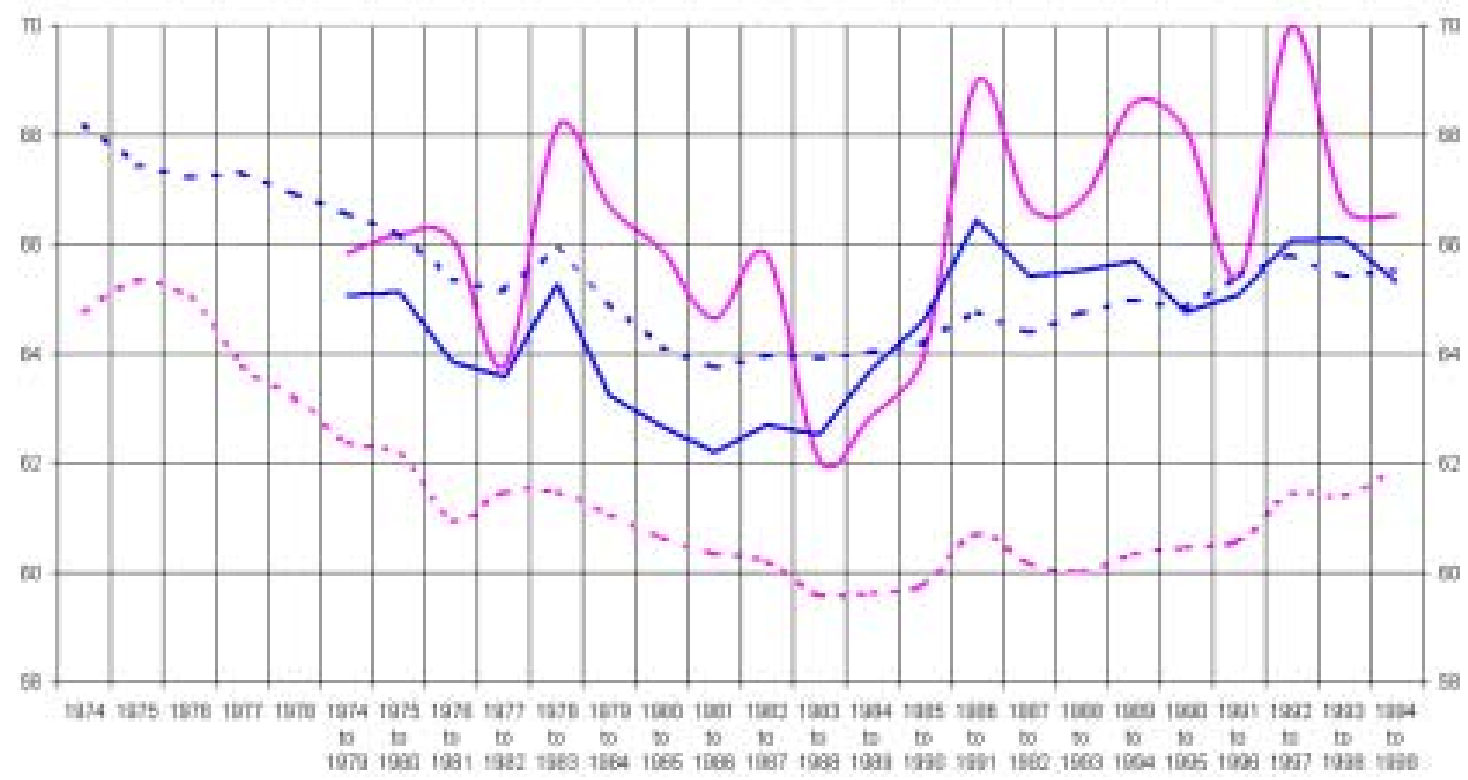

SPAIN

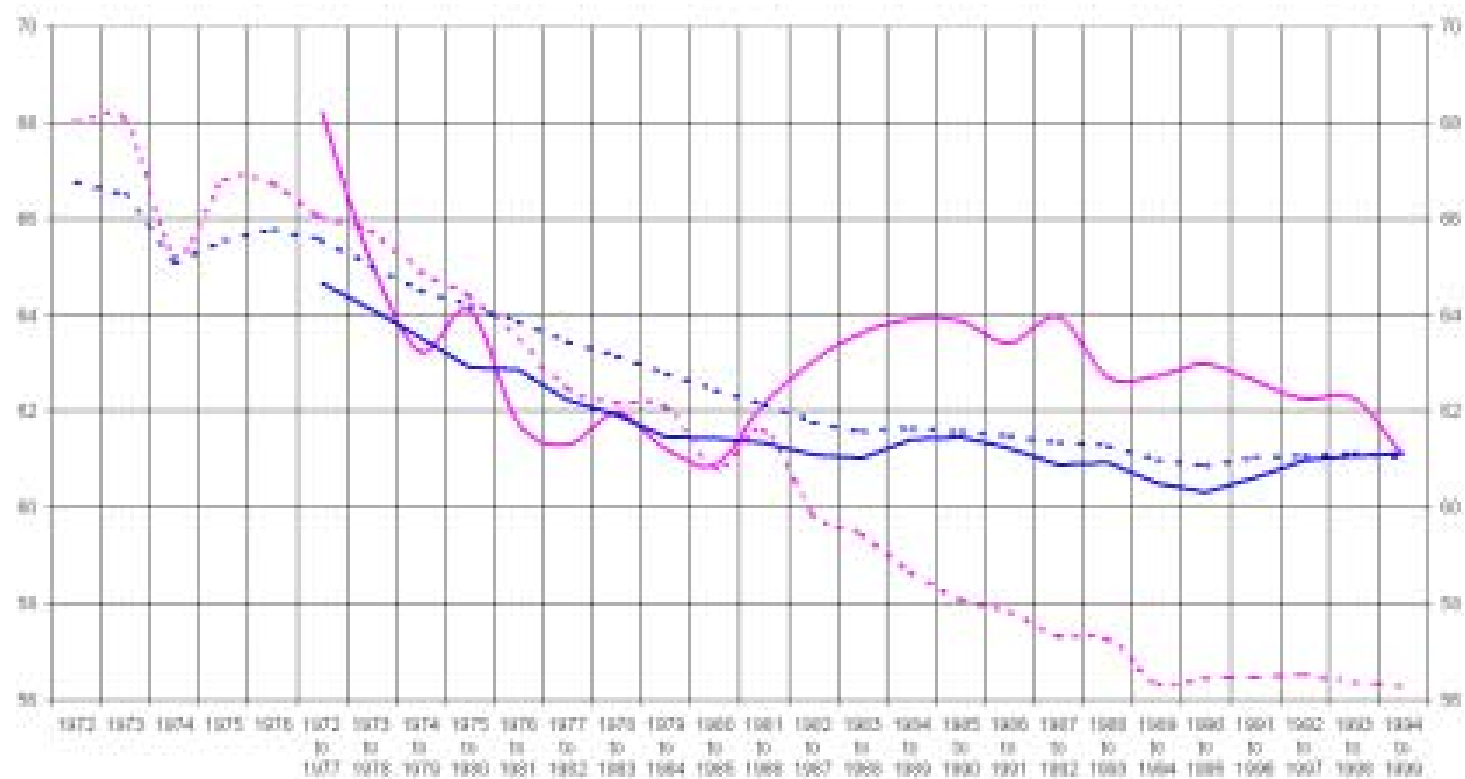

Men Dynamic Estimate

Women Dynamic Estimate - - - Men Static Estimate = - - Women Static Estimate 
Chart 1. Average age of withdrawal from the labour force (cont.)

SWEDEN

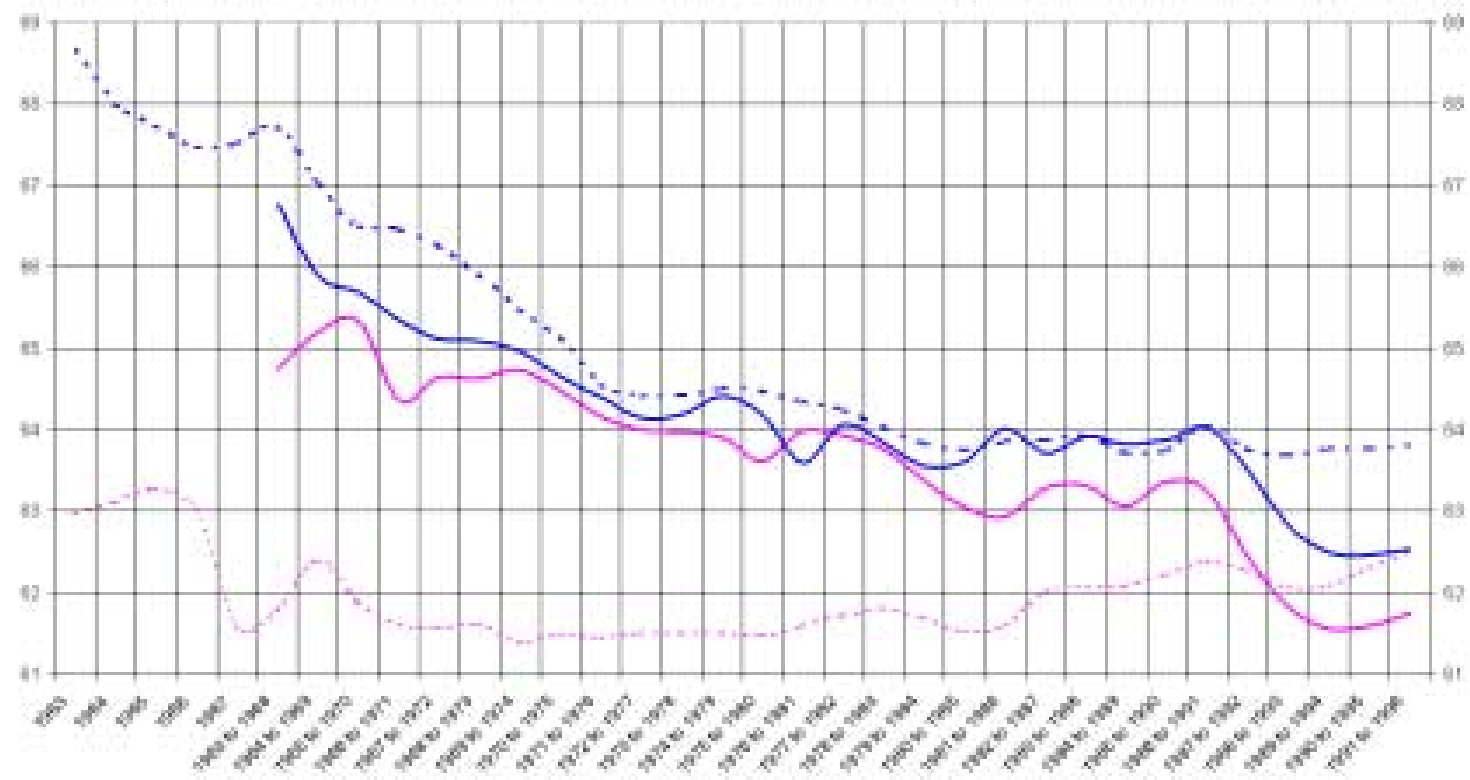


Chart 2. Average age of withdrawal from the labour force since 1983

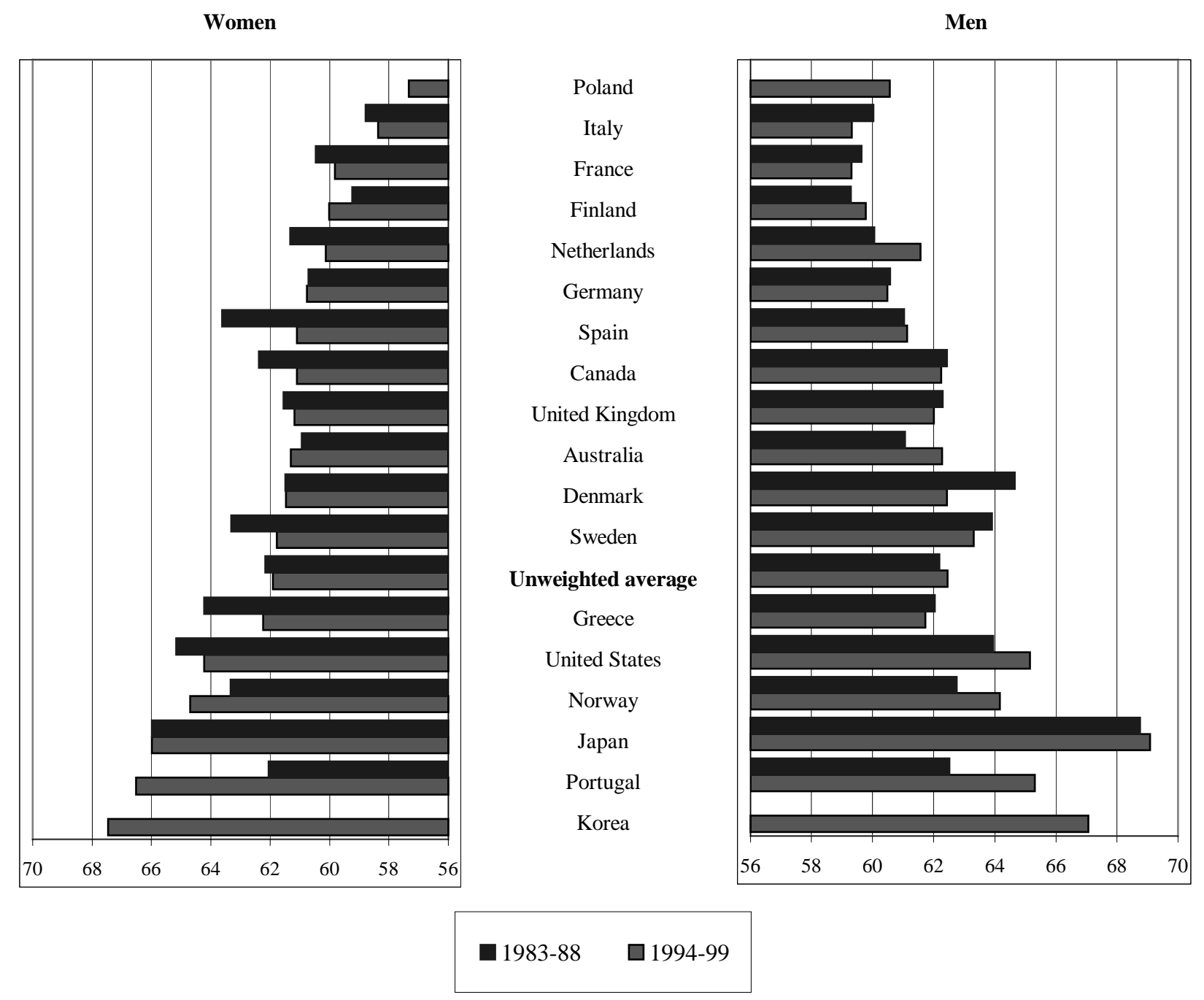


DEELSA/ELSA/WD(2001)2

Table 3. Estimates of average age of withdrawal from the labour force

\begin{tabular}{|c|c|c|c|c|c|c|c|c|c|c|c|c|c|c|c|c|c|c|c|c|}
\hline & \multicolumn{4}{|c|}{ United States } & \multicolumn{4}{|c|}{ Japan } & \multicolumn{4}{|c|}{ Western Germany } & \multicolumn{4}{|c|}{ France } & \multicolumn{4}{|c|}{ Italy } \\
\hline & \multicolumn{2}{|c|}{ Men } & \multicolumn{2}{|c|}{ Women } & \multicolumn{2}{|c|}{ Men } & \multicolumn{2}{|c|}{ Women } & \multicolumn{2}{|c|}{ Men } & \multicolumn{2}{|c|}{ Women } & \multicolumn{2}{|c|}{ Men } & \multicolumn{2}{|c|}{ Women } & \multicolumn{2}{|c|}{ Men } & \multicolumn{2}{|c|}{ Women } \\
\hline & 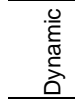 & 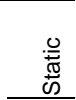 & 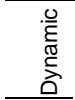 & $\begin{array}{l}\frac{0}{\bar{T}} \\
\frac{\pi}{\omega 0}\end{array}$ & 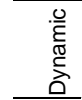 & $\begin{array}{l}\frac{0}{\bar{T}} \\
\frac{\pi}{\omega 0}\end{array}$ & 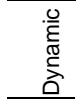 & 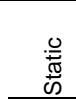 & 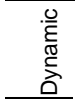 & 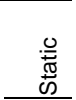 & 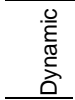 & $\begin{array}{l}\frac{0}{\bar{T}} \\
\frac{\pi}{i n} \\
\end{array}$ & 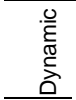 & $\begin{array}{l}\frac{0}{\bar{T}} \\
\frac{\pi}{\omega}\end{array}$ & 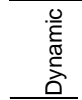 & 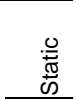 & 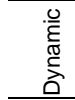 & $\begin{array}{l}\frac{0}{\bar{T}} \\
\frac{\pi}{\omega}\end{array}$ & 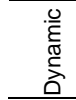 & $\begin{array}{l}\frac{0}{\bar{T}} \\
\frac{\pi}{\omega}\end{array}$ \\
\hline 1960 & & 68.7 & & 64.8 & & 70.8 & & 67.9 & & & & & & & & & & & & \\
\hline 1961 & & 68.6 & & 65.1 & & 71.2 & & 67.4 & & & & & & & & & & & & \\
\hline 1962 & & 68.4 & & 65.5 & & 71.0 & & 66.7 & & & & & & 66.4 & & 66.4 & & & & \\
\hline 1963 & & 68.1 & & 65.5 & & 70.7 & & 66.2 & & & & & & 65.7 & & 65.3 & & & & \\
\hline 1964 & & 68.0 & & 65.4 & & 70.8 & & 66.7 & & & & & & 66.1 & & 66.3 & & & & \\
\hline 1960 to 1965 & 67.5 & 67.8 & 66.5 & 65.5 & 71.4 & 71.0 & 66.8 & 66.1 & & & & & & 65.3 & & 66.2 & & & & \\
\hline 1961 to 1966 & 67.2 & 67.7 & 66.7 & 65.6 & 71.8 & 71.3 & 67.9 & 66.3 & & & & & & 65.6 & & 66.2 & & & & \\
\hline 1963 to 1968 & 67.8 & 67.7 & 67.3 & 65.8 & 71.4 & 70.9 & 67.1 & 65.6 & & & & & 66.3 & 65.7 & 67.7 & 66.2 & & & & \\
\hline 1964 to 1969 & 67.5 & 67.6 & 67.6 & 65.6 & 71.5 & 70.9 & 66.6 & 65.4 & & & & & 65.8 & 65.8 & 66.9 & 65.9 & & & & \\
\hline 1965 to 1970 & 67.4 & 67.5 & 67.4 & 65.4 & 70.8 & 70.6 & 66.5 & 65.8 & & 65.0 & & 61.9 & 65.4 & 65.2 & 68.1 & 65.7 & & 62.8 & & 58.5 \\
\hline 1966 to 1971 & 67.0 & 67.2 & 66.8 & 65.3 & 70.9 & 70.6 & 64.6 & 65.7 & & 64.9 & & 61.6 & 65.1 & 65.0 & 65.1 & 64.8 & & 62.6 & & 58.3 \\
\hline 1967 to 1972 & 65.4 & 66.8 & 66.1 & 65.3 & 70.6 & 70.6 & 63.9 & 65.3 & & 64.7 & & 61.4 & 65.6 & 64.8 & 66.0 & 64.6 & & 62.2 & & 58.0 \\
\hline 1968 to 1973 & 64.7 & 66.3 & 65.4 & 65.1 & 70.6 & 70.5 & 65.5 & 65.8 & & 64.4 & & 61.3 & 64.3 & 64.5 & 64.4 & 64.3 & & 62.1 & & 58.0 \\
\hline 1969 to 1974 & 64.4 & 66.2 & 64.5 & 64.6 & 70.1 & 70.3 & 64.5 & 65.3 & & 64.1 & & 61.2 & 63.8 & 64.4 & 63.9 & 63.6 & & 62.1 & & 58.2 \\
\hline 1970 to 1975 & 64.2 & 66.0 & 64.3 & 64.1 & 70.1 & 70.2 & 64.5 & 65.5 & 62.8 & 63.7 & 62.7 & 61.1 & 63.5 & 63.9 & 63.8 & 63.1 & 62.3 & 62.3 & 59.7 & 58.1 \\
\hline 1971 to 1976 & 63.7 & 65.7 & 64.3 & 63.7 & 69.8 & 70.2 & 65.3 & 65.6 & 62.8 & 63.3 & 62.2 & 60.9 & 62.9 & 63.6 & 64.0 & 62.4 & 62.0 & 62.1 & 59.8 & 58.0 \\
\hline 1972 to 1977 & 63.8 & 65.4 & 64.6 & 63.3 & 69.6 & 70.1 & 66.2 & 65.6 & 62.4 & 62.9 & 61.3 & 60.4 & 62.7 & 63.5 & 63.8 & 62.4 & 63.4 & 62.7 & 66.5 & 59.0 \\
\hline 1973 to 1978 & 64.2 & 65.5 & 65.3 & 62.8 & 69.1 & 69.9 & 66.0 & 65.4 & 61.7 & 62.5 & 60.4 & 59.9 & 61.8 & 62.8 & 63.2 & 61.6 & 62.5 & 62.4 & 63.8 & 58.6 \\
\hline 1974 to 1979 & 64.5 & 65.4 & 65.5 & 62.7 & 69.2 & 69.7 & 66.8 & 65.4 & 61.6 & 62.2 & 60.2 & 59.8 & 62.0 & 62.7 & 63.2 & 61.3 & 61.6 & 62.0 & 63.5 & 58.2 \\
\hline 1977 to 1982 & 64.3 & 64.9 & 65.5 & 61.9 & 69.4 & 69.7 & 66.8 & 65.1 & 62.2 & 62.2 & 61.0 & 59.7 & 60.9 & 61.7 & 62.1 & 60.3 & 59.8 & 61.9 & 60.9 & 58.2 \\
\hline 1978 to 1983 & 64.1 & 64.7 & 64.8 & 61.8 & 69.3 & 69.6 & 66.8 & 65.0 & 62.2 & 62.0 & 61.0 & 59.4 & 60.2 & 61.0 & 61.4 & 59.5 & 61.1 & 61.7 & 59.9 & 57.4 \\
\hline 1979 to 1984 & 63.7 & 64.4 & 64.5 & 61.7 & 68.6 & 69.3 & 66.4 & 64.7 & 62.6 & 62.2 & 61.0 & 59.3 & 59.9 & 60.8 & 61.0 & 59.3 & 61.2 & 61.7 & 59.9 & 57.5 \\
\hline 1980 to 1985 & 63.7 & 64.3 & 64.2 & 61.5 & 68.4 & 69.2 & 66.3 & 64.8 & 62.2 & 62.0 & 59.9 & 58.7 & 59.7 & 60.7 & 60.6 & 58.8 & 60.8 & 61.5 & 59.5 & 57.2 \\
\hline 1981 to 1986 & 63.7 & 64.4 & 64.2 & 61.4 & 68.2 & 69.1 & 66.2 & 64.5 & 61.7 & 62.1 & 59.8 & 58.7 & 59.6 & 60.4 & 60.6 & 58.8 & 60.5 & 61.5 & 59.8 & 57.0 \\
\hline 1982 to 1987 & 63.9 & 64.5 & 64.3 & 61.2 & 68.4 & 69.1 & 66.1 & 64.8 & 61.1 & 62.2 & 60.2 & 59.0 & 59.5 & 60.1 & 60.3 & 58.7 & 61.8 & 61.3 & 59.5 & 56.9 \\
\hline 1983 to 1988 & 63.9 & 64.4 & 65.2 & 61.5 & 68.7 & 69.2 & 66.0 & 64.9 & 60.6 & 62.2 & 60.7 & 59.2 & 59.6 & 60.1 & 60.5 & 58.6 & 60.3 & 61.1 & 59.5 & 56.7 \\
\hline 1984 to 1989 & 64.3 & 64.5 & 65.9 & 61.7 & 69.2 & 69.2 & 66.9 & 64.8 & 60.6 & 61.8 & 60.5 & 58.8 & 59.7 & 60.0 & 60.4 & 58.5 & 60.0 & 60.8 & 58.8 & 55.9 \\
\hline 1985 to 1990 & 64.2 & 64.5 & 65.7 & 61.8 & 69.9 & 69.4 & 67.6 & 64.9 & 62.0 & 61.9 & 61.6 & 58.9 & 59.6 & 59.9 & 60.1 & 58.2 & 60.2 & 60.8 & 58.8 & 56.0 \\
\hline 1986 to 1991 & 64.0 & 64.3 & 65.1 & 61.9 & 70.9 & 69.6 & 69.0 & 65.2 & 61.1 & 61.4 & 61.1 & 58.1 & 59.3 & 59.7 & 60.3 & 58.3 & 60.4 & 60.9 & 59.2 & 56.2 \\
\hline 1987 to 1992 & 64.2 & 64.5 & 65.1 & 62.0 & 71.0 & 69.7 & 69.0 & 65.4 & 61.6 & 61.5 & 61.3 & 58.4 & 59.4 & 59.7 & 60.1 & 58.3 & 58.8 & 60.0 & 56.8 & 55.4 \\
\hline 1988 to 1993 & 63.7 & 64.4 & 64.6 & 62.2 & 70.9 & 69.5 & 67.8 & 65.2 & 61.7 & 61.4 & 61.1 & 58.5 & 59.2 & 59.7 & 60.1 & 58.4 & 59.1 & 60.1 & 57.6 & 55.8 \\
\hline 1989 to 1994 & 63.3 & 64.4 & 64.9 & 62.7 & 70.5 & 69.6 & 66.9 & 65.3 & 61.2 & 61.2 & 60.9 & 58.6 & 59.2 & 59.5 & 60.2 & 58.4 & 58.7 & 59.9 & 57.1 & 55.4 \\
\hline 1990 to 1995 & 63.6 & 64.6 & 64.5 & 62.7 & 70.2 & 69.6 & 66.1 & 65.3 & 60.1 & 61.1 & 60.1 & 58.6 & 59.1 & 59.4 & 60.4 & 58.5 & 57.9 & 59.3 & 57.2 & 55.5 \\
\hline 1991 to 1996 & 64.1 & 64.8 & 64.5 & 62.7 & 69.6 & 69.3 & 65.4 & 65.2 & 60.3 & 61.0 & 60.3 & 58.7 & 59.5 & 59.5 & 60.4 & 58.6 & 57.9 & 59.3 & 56.7 & 55.3 \\
\hline 1992 to 1997 & 64.6 & 65.0 & 64.9 & 62.9 & 69.3 & 69.4 & 65.7 & 65.3 & 60.4 & 61.0 & 60.6 & 58.9 & 59.4 & 59.5 & 60.1 & 58.6 & 58.7 & 59.3 & 57.9 & 55.5 \\
\hline 1993 to 1998 & 64.8 & 64.9 & 64.6 & 63.0 & 69.0 & 69.3 & 66.0 & 65.3 & 60.5 & 61.1 & 60.8 & 59.0 & 59.4 & 59.4 & 59.8 & 58.7 & 58.8 & 59.3 & 57.7 & 55.4 \\
\hline 1994 to 1999 & 65.1 & 65.0 & 64.2 & 63.1 & 69.1 & 69.3 & 66.0 & 65.3 & & & & & 59.3 & 59.4 & 59.8 & 58.8 & 59.3 & 59.4 & 58.4 & 55.7 \\
\hline
\end{tabular}


Table 3. Estimates of average age of withdrawal from the labour force (cont.)

\begin{tabular}{|c|c|c|c|c|c|c|c|c|c|c|c|c|c|c|c|c|c|c|c|c|}
\hline & \multicolumn{4}{|c|}{ United Kingdom } & \multirow{2}{*}{\multicolumn{4}{|c|}{\begin{tabular}{|c|}
\multicolumn{2}{|c|}{ Canada } \\
Men
\end{tabular}}} & \multicolumn{4}{|c|}{ Austalia } & \multicolumn{4}{|c|}{ Belgium } & \multicolumn{4}{|c|}{ Denmark } \\
\hline & \multicolumn{2}{|c|}{ Men } & \multicolumn{2}{|c|}{ Women } & & Men & \multicolumn{2}{|c|}{ Women } & \multicolumn{2}{|c|}{ Men } & \multicolumn{2}{|c|}{ Women } & \multicolumn{2}{|c|}{ Men } & \multicolumn{2}{|c|}{ Women } & \multicolumn{2}{|c|}{ Men } & \multicolumn{2}{|c|}{ Women } \\
\hline & 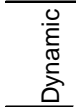 & 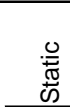 & 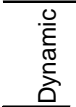 & $\begin{array}{l}\frac{0}{\overline{0}} \\
\frac{\pi}{\omega}\end{array}$ & 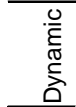 & 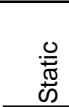 & 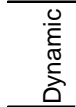 & 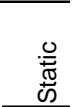 & 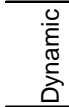 & $\begin{array}{l}\text { 莺 } \\
\text { in }\end{array}$ & 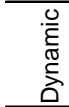 & $\begin{array}{l}\frac{0}{\bar{E}} \\
\dot{m}\end{array}$ & 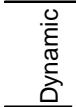 & $\begin{array}{l}\text { 莺 } \\
\text { in }\end{array}$ & 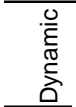 & $\begin{array}{l}\frac{0}{\overline{ \pm}} \\
\frac{\pi}{05}\end{array}$ & 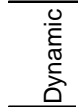 & $\begin{array}{l}\frac{0}{\overline{0}} \\
\frac{\pi}{\omega \infty}\end{array}$ & 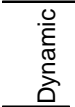 & $\begin{array}{l}\frac{0}{\bar{N}} \\
\dot{\pi n}\end{array}$ \\
\hline 1960 & & & & & & & & & & & & & & 60.2 & & 55.0 & & & & \\
\hline 1961 & & & & & & & & & & & & & & 59.7 & & 54.7 & & & & \\
\hline 1962 & & & & & & & & & & & & & & 59.4 & & 54.4 & & & & \\
\hline 1963 & & & & & & & & & & & & & & 58.8 & & 54.2 & & & & \\
\hline 1964 & & & & & & & & & & & & & & 58.3 & & 53.2 & & & & \\
\hline 1960 to 1965 & & & & & & & & & & & & & 57.2 & 58.3 & 55.0 & 53.6 & & & & \\
\hline 1961 to 1966 & & & & & & & & & & 67.0 & & 61.6 & 57.4 & 58.1 & 54.8 & 53.5 & & & & \\
\hline 1963 to 1968 & & & & & & & & & & 66.8 & & 62.0 & 57.6 & 58.1 & 56.0 & 53.5 & & & & \\
\hline 1964 to 1969 & & & & & & & & & & 66.9 & & 61.0 & 57.9 & 58.2 & 57.0 & 54.0 & & & & \\
\hline 1965 to 1970 & & & & & & & & & & 66.7 & & 60.6 & 57.4 & 57.9 & 58.4 & 53.9 & & & & \\
\hline 1966 to 1971 & & & & & & & & & 66.0 & 66.6 & 64.4 & 60.2 & 57.8 & 58.3 & 58.5 & 54.2 & & & & \\
\hline 1967 to 1972 & & & & & & & & & 66.4 & 66.7 & 63.3 & 60.4 & 58.6 & 58.5 & 59.4 & 54.6 & & & & \\
\hline 1968 to 1973 & & & & & & & & & 65.4 & 66.3 & 62.6 & 59.7 & 58.1 & 58.2 & 57.6 & 54.2 & & & & \\
\hline 1969 to 1974 & & & & & & & & & 64.5 & 65.6 & 63.0 & 59.3 & 58.1 & 58.2 & 57.7 & 54.5 & & & & \\
\hline 1970 to 1975 & & & & & & & & & 63.8 & 65.2 & 62.2 & 58.9 & 58.2 & 58.2 & 57.4 & 54.7 & & & & \\
\hline 1971 to 1976 & & & & & & 64.3 & & 60.9 & 63.3 & 64.5 & 61.5 & 59.2 & 59.0 & 58.7 & 58.9 & 55.1 & & & & \\
\hline 1972 to 1977 & & & & & & 64.2 & & 60.2 & 62.7 & 64.2 & 60.9 & 58.8 & & & & & & & & \\
\hline 1973 to 1978 & & & & & & 64.2 & & 59.9 & 61.8 & 63.7 & 59.3 & 58.0 & & & & & & & & \\
\hline 1976 to 1981 & & & & & 63.8 & 64.0 & 63.4 & 59.5 & 61.6 & 63.1 & 58.4 & 57.7 & & & & & & & & \\
\hline 1977 to 1982 & & & & & 63.4 & 64.0 & 63.7 & 59.3 & 60.8 & 62.6 & 57.5 & 57.3 & & & & & & & & \\
\hline 1978 to 1983 & & & & & 63.3 & 63.8 & 63.6 & 59.3 & 61.2 & 62.2 & 57.8 & 57.4 & & & & & & 63.3 & & 59.0 \\
\hline 1979 to 1984 & & 63.0 & & 60.6 & 62.8 & 63.6 & 62.7 & 58.9 & 61.3 & 62.3 & 58.4 & 57.6 & & & & & & 63.8 & & 59.2 \\
\hline 1980 to 1985 & & 62.8 & & 60.2 & 62.6 & 63.4 & 63.1 & 59.4 & 61.1 & 62.2 & 57.5 & 56.8 & & & & & & 63.7 & & 59.6 \\
\hline 1981 to 1986 & & 62.7 & & 60.2 & 62.4 & 63.2 & 61.8 & 58.5 & 61.4 & 62.3 & 59.0 & 57.1 & & & & & & 63.9 & & 59.8 \\
\hline 1982 to 1987 & & 62.7 & & 60.2 & 62.9 & 63.1 & 62.2 & 58.9 & 61.6 & 62.2 & 60.5 & 57.4 & & & & & & 63.4 & & 59.3 \\
\hline 1983 to 1988 & & 62.7 & & 59.8 & 62.4 & 62.9 & 62.4 & 59.0 & 61.1 & 62.0 & 60.9 & 57.3 & & & & & 64.7 & 63.9 & 61.5 & 59.4 \\
\hline 1984 to 1989 & 62.3 & 62.9 & 61.6 & 60.5 & 62.8 & 62.9 & 62.7 & 58.9 & 62.0 & 62.5 & 60.7 & 57.3 & & & & & 64.9 & 63.7 & 62.2 & 59.6 \\
\hline 1985 to 1990 & 62.5 & 63.0 & 61.8 & 60.3 & 62.4 & 62.9 & 61.8 & 58.7 & 62.5 & 62.5 & 61.8 & 57.5 & & & & & 65.7 & 64.1 & 62.5 & 60.2 \\
\hline 1986 to 1991 & 62.6 & 62.9 & 61.7 & 60.3 & 62.2 & 62.8 & 62.5 & 58.9 & 62.2 & 62.5 & 60.7 & 57.8 & & & & & 64.1 & 63.7 & 61.6 & 60.1 \\
\hline 1987 to 1992 & 62.6 & 62.9 & 61.8 & 60.6 & 61.5 & 62.8 & 61.9 & 59.2 & 62.3 & 62.6 & 60.1 & 58.0 & & & & & 64.2 & 63.6 & 62.3 & 60.3 \\
\hline 1988 to 1993 & 61.7 & 62.5 & 61.8 & 60.7 & 61.4 & 62.5 & 61.4 & 59.2 & 61.8 & 62.1 & 60.0 & 58.6 & & & & & 62.4 & 63.4 & 61.5 & 60.5 \\
\hline 1989 to 1994 & 61.5 & 62.7 & 61.6 & 60.9 & 61.5 & 62.7 & 60.8 & 59.3 & 62.1 & 62.5 & 59.5 & 58.5 & & & & & 61.6 & 63.3 & 58.9 & 59.0 \\
\hline 1990 to 1995 & 61.2 & 62.5 & 61.2 & 60.9 & 61.4 & 62.5 & 60.2 & 59.3 & 61.8 & 62.5 & 59.9 & 58.9 & & & & & 62.3 & 64.7 & 58.0 & 58.8 \\
\hline 1991 to 1996 & 61.2 & 62.5 & 61.1 & 60.8 & 61.3 & 62.4 & 59.7 & 59.1 & 61.9 & 62.6 & 60.5 & 59.3 & & & & & 62.2 & 63.3 & 57.8 & 59.3 \\
\hline 1992 to 1997 & 61.3 & 62.7 & 60.9 & 60.9 & 61.8 & 62.4 & 60.3 & 59.3 & 61.6 & 62.5 & 60.2 & 59.2 & & & & & 62.8 & 63.6 & 58.3 & 59.8 \\
\hline 1993 to 1998 & 61.3 & 62.5 & 60.9 & 60.8 & 61.8 & 62.4 & 60.7 & 59.7 & 62.0 & 62.6 & 61.7 & 60.1 & & & & & 63.3 & 64.1 & 58.7 & 60.2 \\
\hline 1994 to 1999 & 62.0 & 62.7 & 61.2 & 61.0 & 62.2 & 62.5 & 61.1 & 59.7 & 62.3 & 62.8 & 61.3 & 60.1 & & & & & 62.4 & 62.8 & 61.5 & 60.4 \\
\hline
\end{tabular}


Table 3. Estimates of average age of withdrawal from the labour force (cont.)

DEELSA/ELSA/WD(2001)2

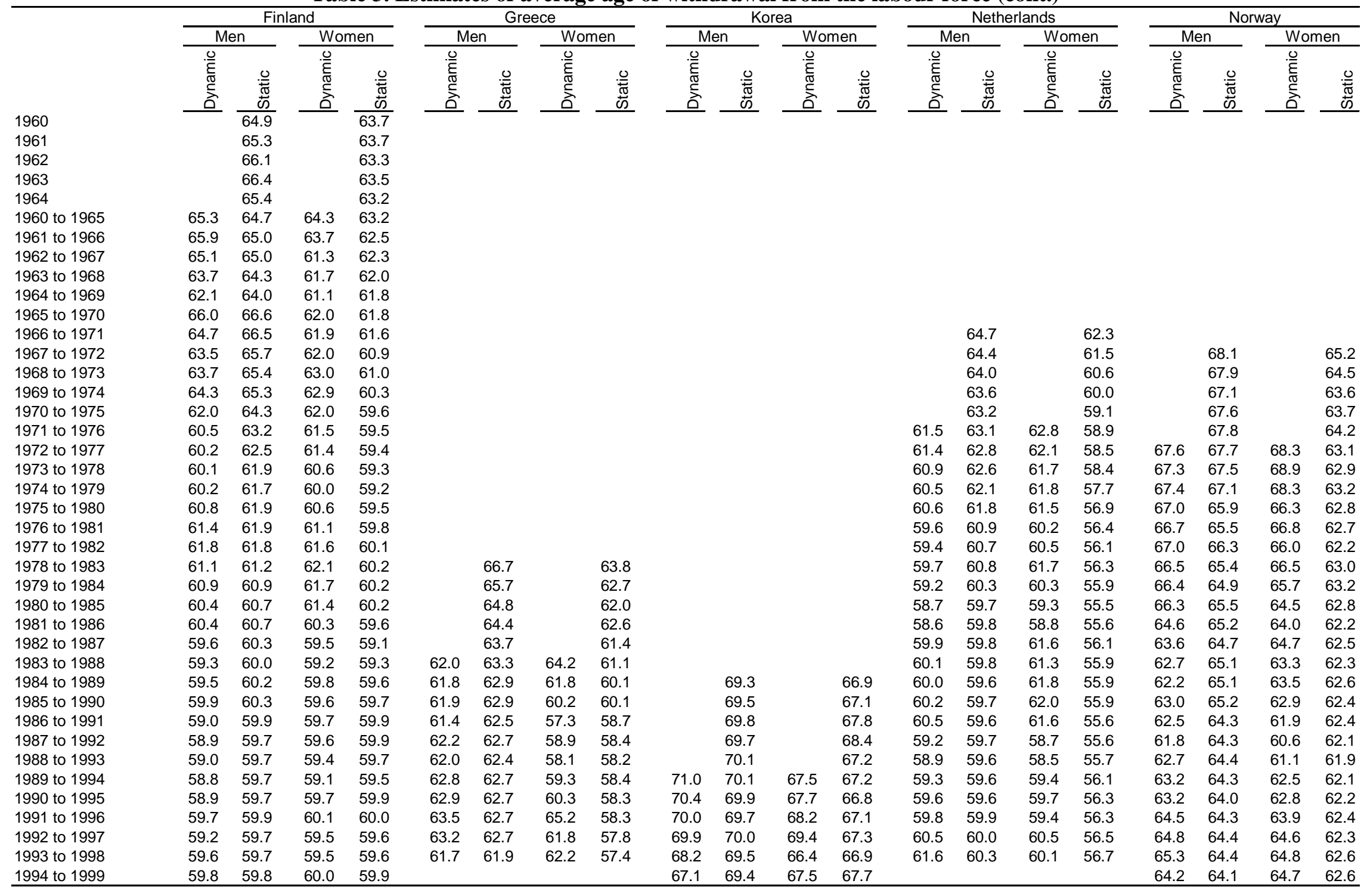


Table 3. Estimates of average age of withdrawal from the labour force (cont.)

\begin{tabular}{|c|c|c|c|c|c|c|c|c|c|c|c|c|c|c|c|c|}
\hline & \multicolumn{4}{|c|}{ Poland } & \multicolumn{4}{|c|}{ Portugal } & \multicolumn{4}{|c|}{ Spain } & \multicolumn{4}{|c|}{ Sweden } \\
\hline & \multicolumn{2}{|c|}{ Men } & \multicolumn{2}{|c|}{ Women } & \multicolumn{2}{|c|}{ Men } & \multicolumn{2}{|c|}{ Women } & \multicolumn{2}{|c|}{ Men } & \multicolumn{2}{|c|}{ Women } & \multicolumn{2}{|c|}{ Men } & \multicolumn{2}{|c|}{ Women } \\
\hline & 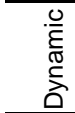 & 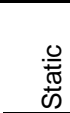 & 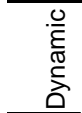 & 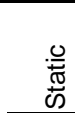 & 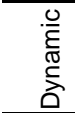 & $\begin{array}{l}\frac{0}{\overline{0}} \\
\stackrel{0}{\omega}\end{array}$ & 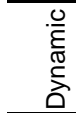 & $\begin{array}{l}\frac{0}{\bar{T}} \\
\dot{\omega}\end{array}$ & 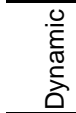 & $\begin{array}{l}\frac{0}{\bar{T}} \\
\dot{T n}\end{array}$ & 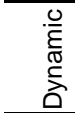 & $\begin{array}{l}\frac{0}{\overline{0}} \\
\dot{\omega}\end{array}$ & 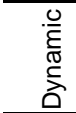 & $\begin{array}{l}\frac{0}{\bar{T}} \\
\frac{\pi}{\omega 0}\end{array}$ & 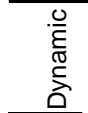 & $\begin{array}{l}\stackrel{0}{ \pm} \\
\stackrel{\pi}{\omega}\end{array}$ \\
\hline \multicolumn{17}{|l|}{1960} \\
\hline 1961 & & & & & & & & & & & & & & & & \\
\hline 1962 & & & & & & & & & & & & & & & & \\
\hline 1963 & & & & & & & & & & & & & & 68.6 & & 63.0 \\
\hline 1964 & & & & & & & & & & & & & & 68.0 & & 63.1 \\
\hline 1960 to 1965 & & & & & & & & & & & & & & 67.7 & & 63.3 \\
\hline 1961 to 1966 & & & & & & & & & & & & & & 67.5 & & 63.0 \\
\hline 1962 to 1967 & & & & & & & & & & & & & & 67.5 & & 61.6 \\
\hline 1963 to 1968 & & & & & & & & & & & & & 66.8 & 67.7 & 64.7 & 61.8 \\
\hline 1964 to 1969 & & & & & & & & & & & & & 65.9 & 67.0 & 65.2 & 62.4 \\
\hline 1965 to 1970 & & & & & & & & & & & & & 65.7 & 66.5 & 65.3 & 61.9 \\
\hline 1966 to 1971 & & & & & & & & & & & & & 65.3 & 66.5 & 64.4 & 61.6 \\
\hline 1967 to 1972 & & & & & & & & & & 66.8 & & 68.0 & 65.1 & 66.3 & 64.7 & 61.6 \\
\hline 1968 to 1973 & & & & & & & & & & 66.5 & & 68.1 & 65.1 & 65.9 & 64.6 & 61.6 \\
\hline 1969 to 1974 & & & & & & 68.2 & & 64.7 & & 65.1 & & 65.2 & 65.0 & 65.5 & 64.7 & 61.4 \\
\hline 1970 to 1975 & & & & & & 67.5 & & 65.3 & & 65.5 & & 66.8 & 64.7 & 65.1 & 64.5 & 61.5 \\
\hline 1971 to 1976 & & & & & & 67.2 & & 65.0 & & 65.8 & & 66.7 & 64.4 & 64.6 & 64.2 & 61.4 \\
\hline 1972 to 1977 & & & & & & 67.3 & & 63.8 & 64.7 & 65.6 & 68.2 & 66.0 & 64.1 & 64.4 & 64.0 & 61.5 \\
\hline 1973 to 1978 & & & & & & 66.9 & & 63.2 & 64.1 & 65.0 & 65.1 & 65.8 & 64.2 & 64.4 & 64.0 & 61.5 \\
\hline 1974 to 1979 & & & & & 65.1 & 66.6 & 65.8 & 62.4 & 63.5 & 64.5 & 63.2 & 64.9 & 64.4 & 64.5 & 63.9 & 61.5 \\
\hline 1975 to 1980 & & & & & 65.1 & 66.2 & 66.2 & 62.1 & 62.9 & 64.2 & 64.1 & 64.4 & 64.2 & 64.5 & 63.6 & 61.5 \\
\hline 1976 to 1981 & & & & & 63.8 & 65.4 & 66.1 & 61.0 & 62.9 & 63.9 & 61.8 & 63.5 & 63.6 & 64.3 & 64.0 & 61.6 \\
\hline 1977 to 1982 & & & & & 63.6 & 65.2 & 63.8 & 61.5 & 62.2 & 63.5 & 61.3 & 62.5 & 64.1 & 64.2 & 63.9 & 61.7 \\
\hline 1978 to 1983 & & & & & 65.3 & 65.9 & 68.1 & 61.5 & 61.9 & 63.2 & 62.0 & 62.2 & 63.8 & 64.0 & 63.8 & 61.8 \\
\hline 1979 to 1984 & & & & & 63.2 & 64.9 & 66.7 & 61.1 & 61.5 & 62.8 & 61.2 & 62.1 & 63.6 & 63.8 & 63.4 & 61.7 \\
\hline 1980 to 1985 & & & & & 62.7 & 64.1 & 65.9 & 60.7 & 61.4 & 62.5 & 60.9 & 60.8 & 63.6 & 63.8 & 63.0 & 61.5 \\
\hline 1981 to 1986 & & & & & 62.2 & 63.7 & 64.6 & 60.3 & 61.4 & 62.2 & 62.1 & 61.6 & 64.0 & 63.9 & 62.9 & 61.6 \\
\hline 1982 to 1987 & & & & & 62.7 & 64.0 & 65.8 & 60.2 & 61.1 & 61.8 & 63.0 & 59.9 & 63.7 & 63.9 & 63.3 & 62.0 \\
\hline 1983 to 1988 & & & & & 62.5 & 63.9 & 62.1 & 59.6 & 61.0 & 61.6 & 63.6 & 59.5 & 63.9 & 63.9 & 63.3 & 62.1 \\
\hline 1984 to 1989 & & & & & 63.7 & 64.0 & 62.9 & 59.6 & 61.4 & 61.7 & 63.9 & 58.7 & 63.8 & 63.7 & 63.1 & 62.1 \\
\hline 1985 to 1990 & & & & & 64.6 & 64.2 & 64.0 & 59.8 & 61.5 & 61.6 & 63.9 & 58.1 & 63.9 & 63.8 & 63.4 & 62.2 \\
\hline 1986 to 1991 & & & & & 66.4 & 64.8 & 69.0 & 60.7 & 61.2 & 61.5 & 63.4 & 57.8 & 64.0 & 64.0 & 63.3 & 62.4 \\
\hline 1987 to 1992 & & 61.3 & & 58.5 & 65.4 & 64.4 & 66.7 & 60.2 & 60.9 & 61.4 & 63.9 & 57.3 & 63.5 & 63.8 & 62.4 & 62.3 \\
\hline 1988 to 1993 & & 61.4 & & 58.3 & 65.5 & 64.7 & 66.8 & 60.0 & 60.9 & 61.3 & 62.7 & 57.3 & 62.8 & 63.7 & 61.8 & 62.1 \\
\hline 1989 to 1994 & & 61.2 & & 58.3 & 65.7 & 65.0 & 68.6 & 60.3 & 60.5 & 61.0 & 62.7 & 56.4 & 62.5 & 63.8 & 61.5 & 62.1 \\
\hline 1990 to 1995 & & 61.2 & & 58.2 & 64.7 & 64.8 & 68.1 & 60.5 & 60.3 & 60.9 & 63.0 & 56.4 & 62.5 & 63.8 & 61.6 & 62.3 \\
\hline 1991 to 1996 & & 61.1 & & 58.2 & 65.1 & 65.4 & 65.4 & 60.6 & 60.6 & 61.0 & 62.6 & 56.5 & 62.5 & 63.8 & 61.7 & 62.5 \\
\hline 1992 to 1997 & 60.0 & 61.2 & 57.3 & 58.1 & 66.1 & 65.8 & 70.0 & 61.4 & 61.0 & 61.1 & 62.3 & 56.5 & 62.6 & 63.8 & 61.6 & 62.4 \\
\hline 1993 to 1998 & 59.9 & 61.1 & 57.1 & 58.1 & 66.1 & 65.4 & 66.7 & 61.4 & 61.1 & 61.1 & 62.3 & 56.4 & 63.2 & 64.0 & 61.3 & 62.0 \\
\hline 1994 to 1999 & 60.6 & 61.3 & 57.3 & 58.0 & 65.3 & 65.5 & 66.5 & 61.9 & 61.1 & 61.0 & 61.1 & 56.3 & 63.3 & 55.1 & 61.8 & 62.2 \\
\hline
\end{tabular}


Chart 3. Age of withdrawal from the labour force: dynamic estimate USA

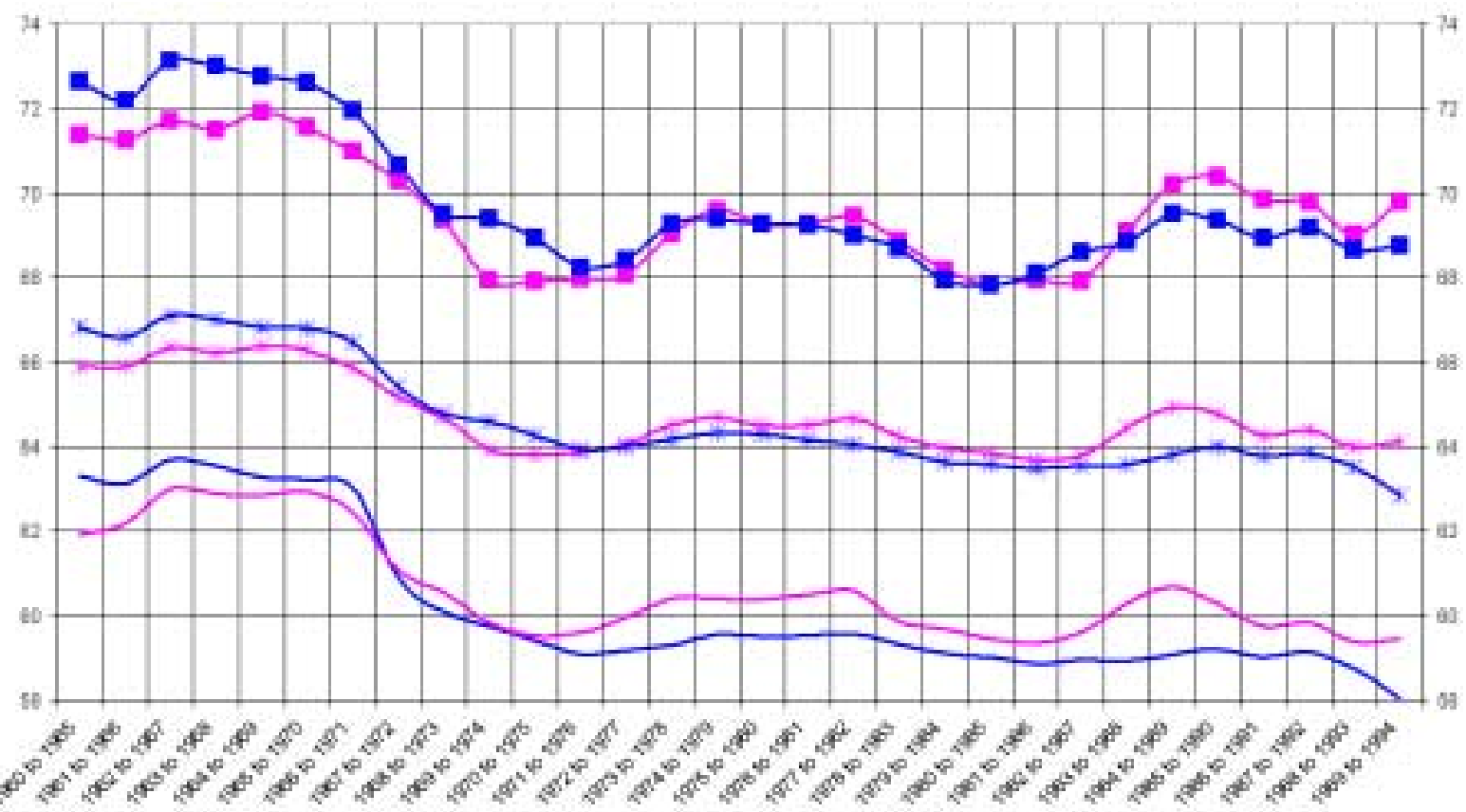

JAPAN

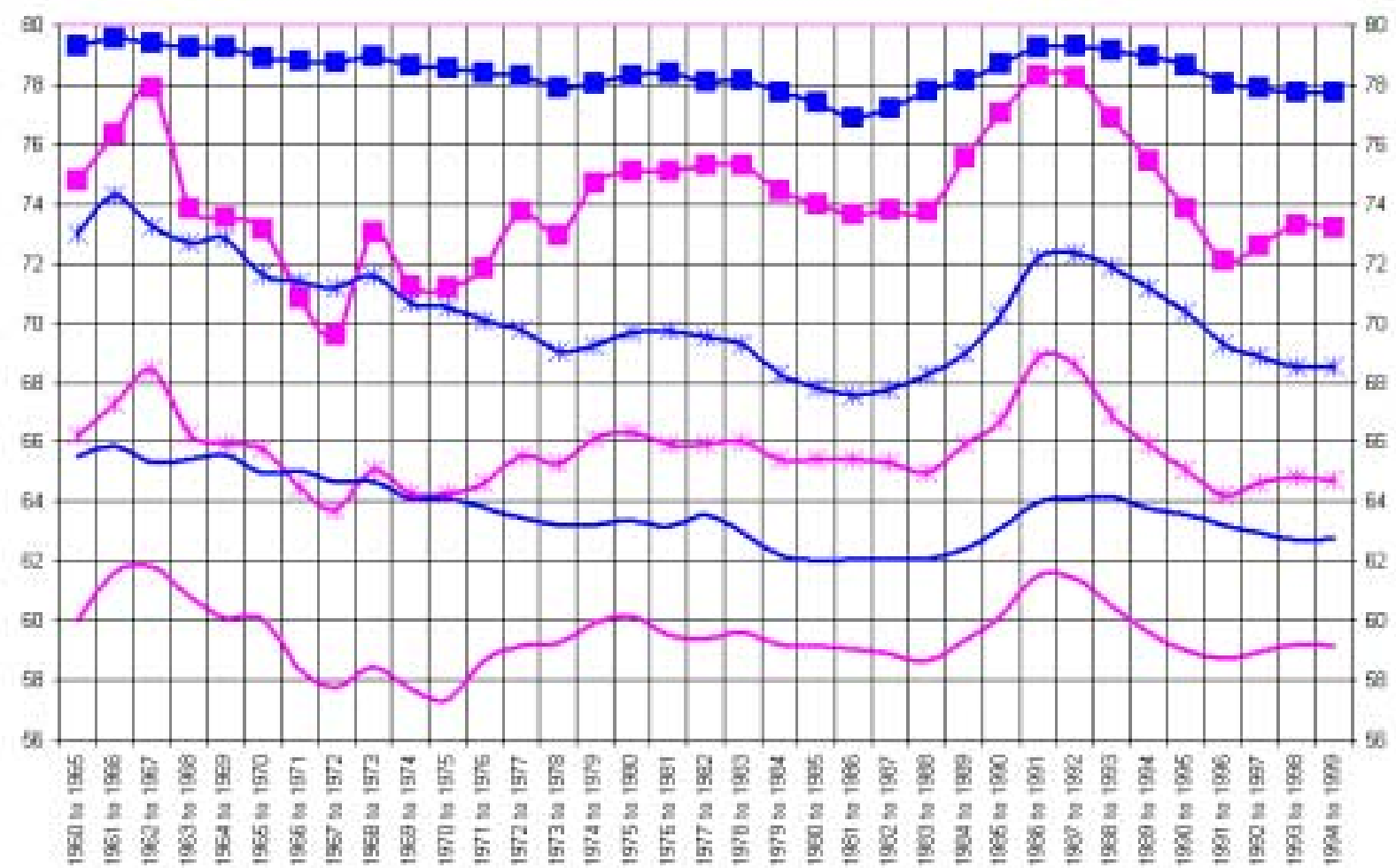

$\rightarrow$ Women: Third quartile $\rightarrow$ Men: Third quartile $\quad$ * Women: Median $\quad$ - Men: Median $\longrightarrow$ Men: First quartile $\quad$ Women: First quartile 
Chart 3. Age of withdrawal from the labour force: dynamic estimate (cont.) WEST GERMANY

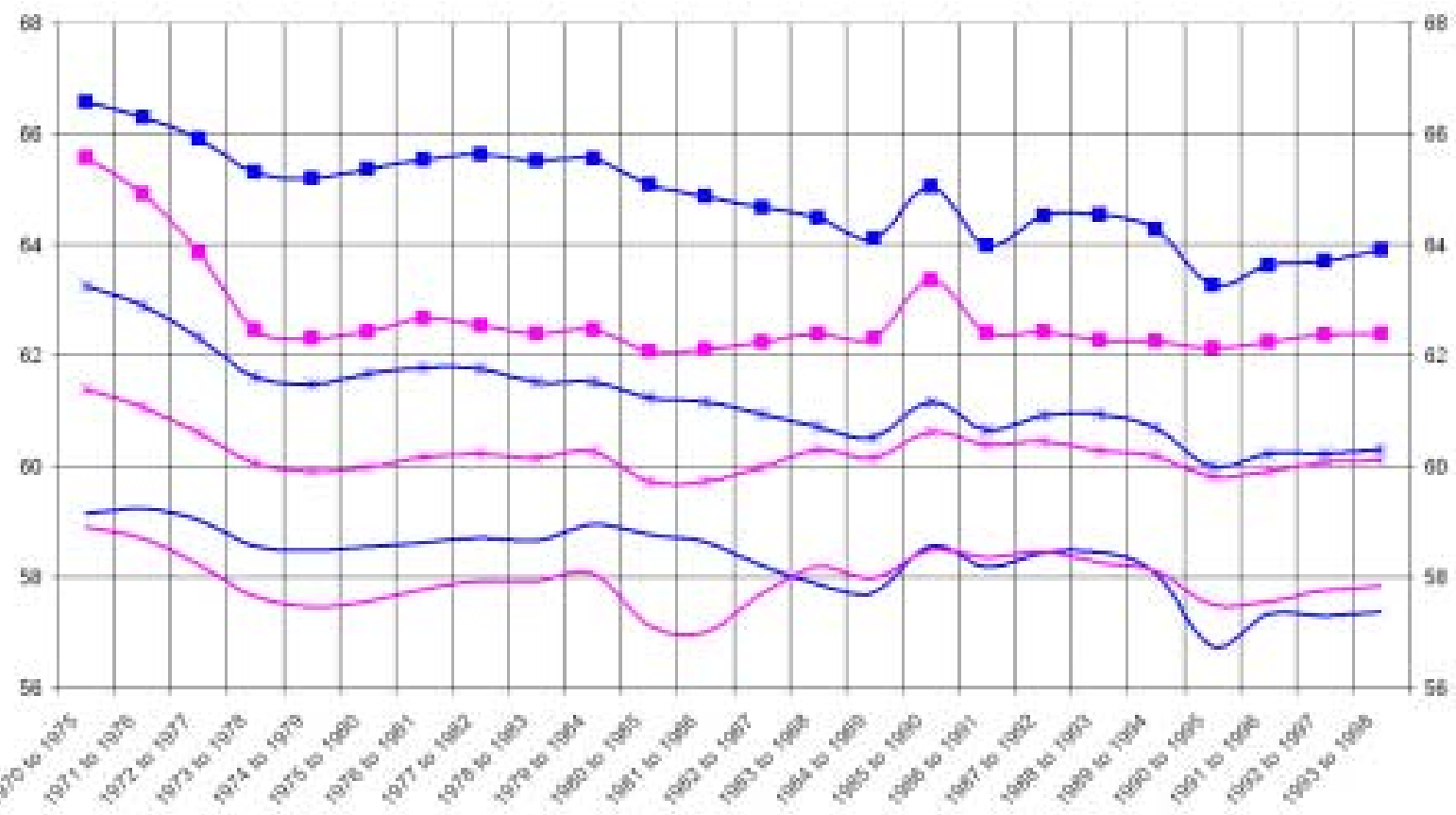

FRANCE

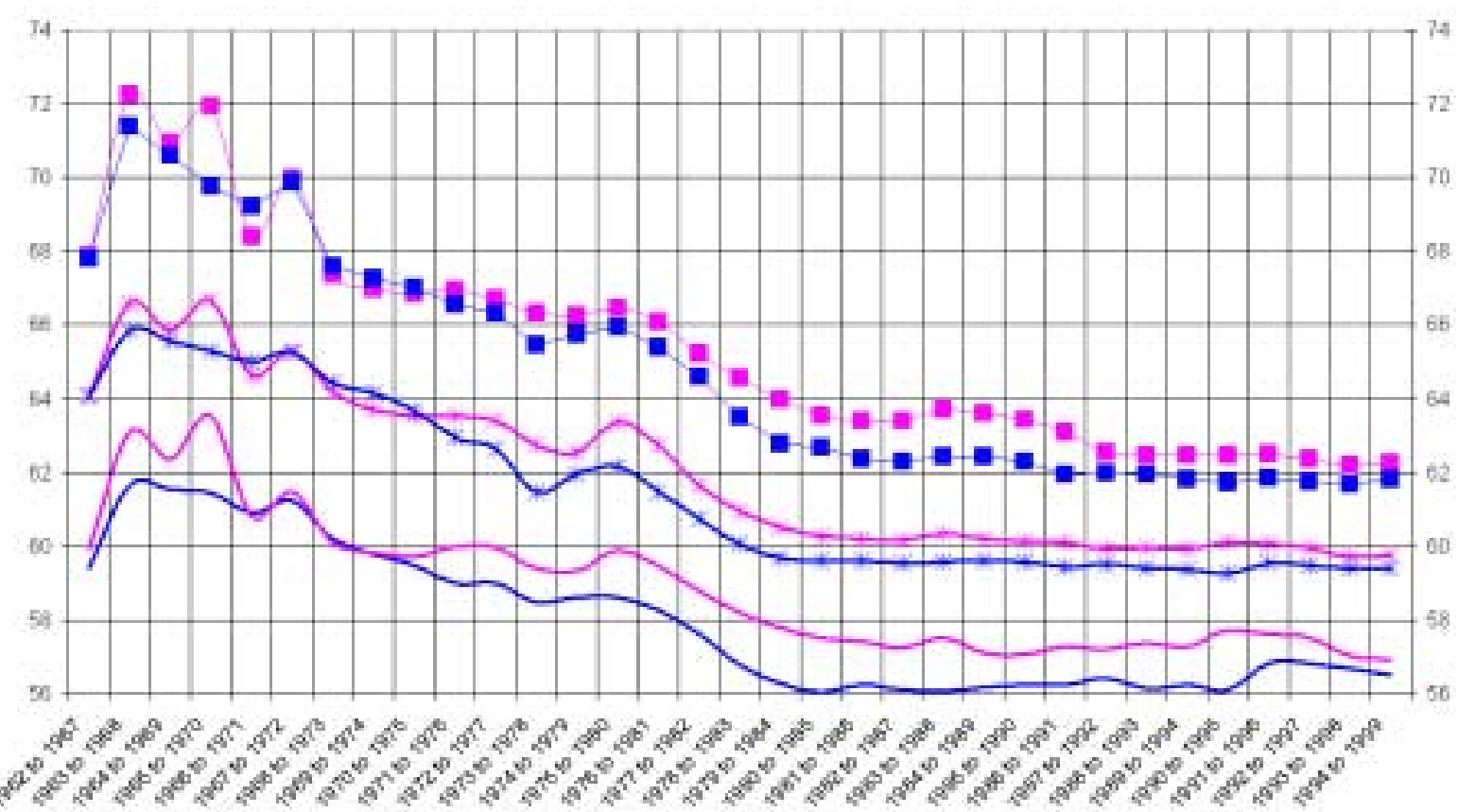


Chart 3. Age of withdrawal from the labour force: dynamic estimate (cont.)

ITALY

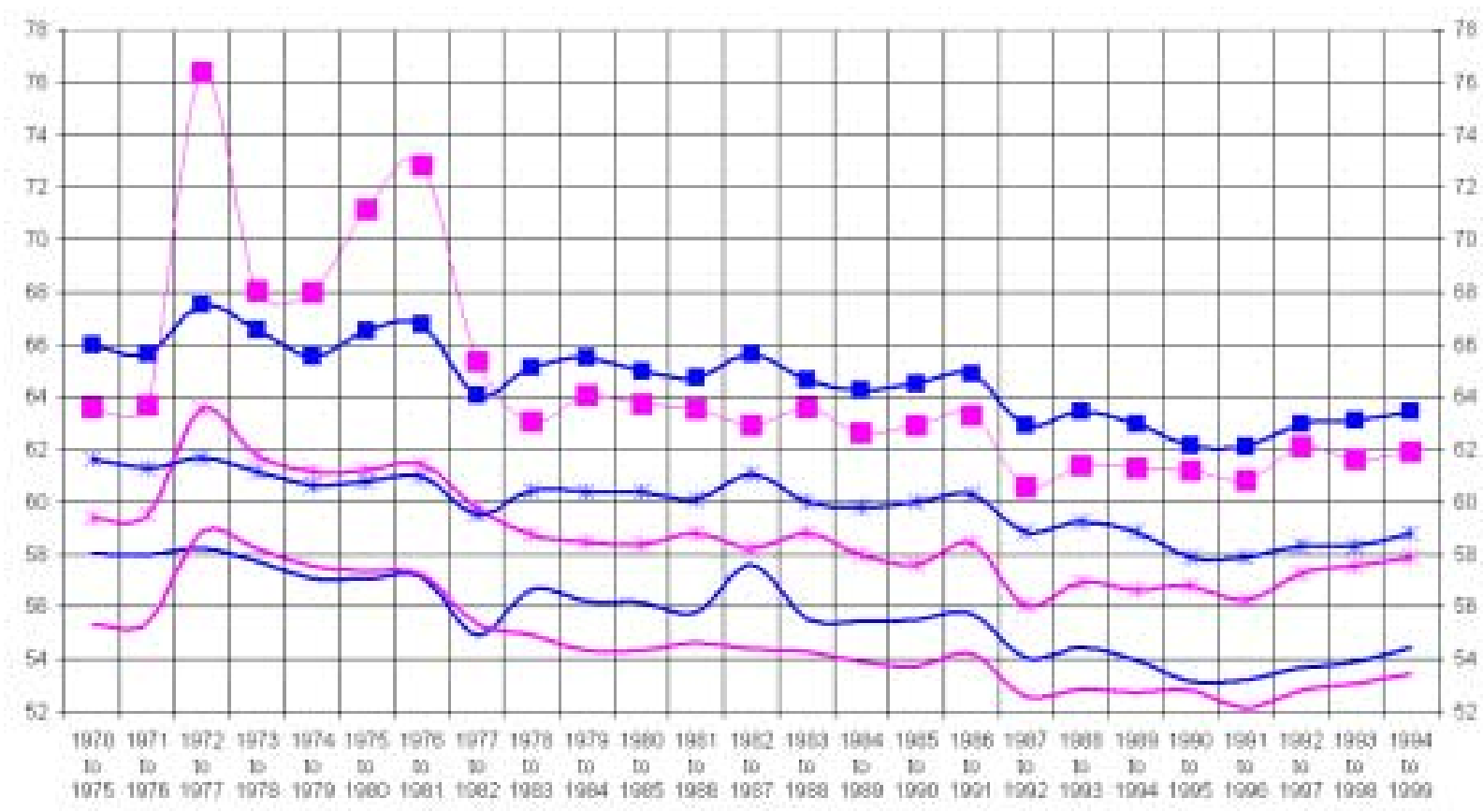

UNITED KINGDOM
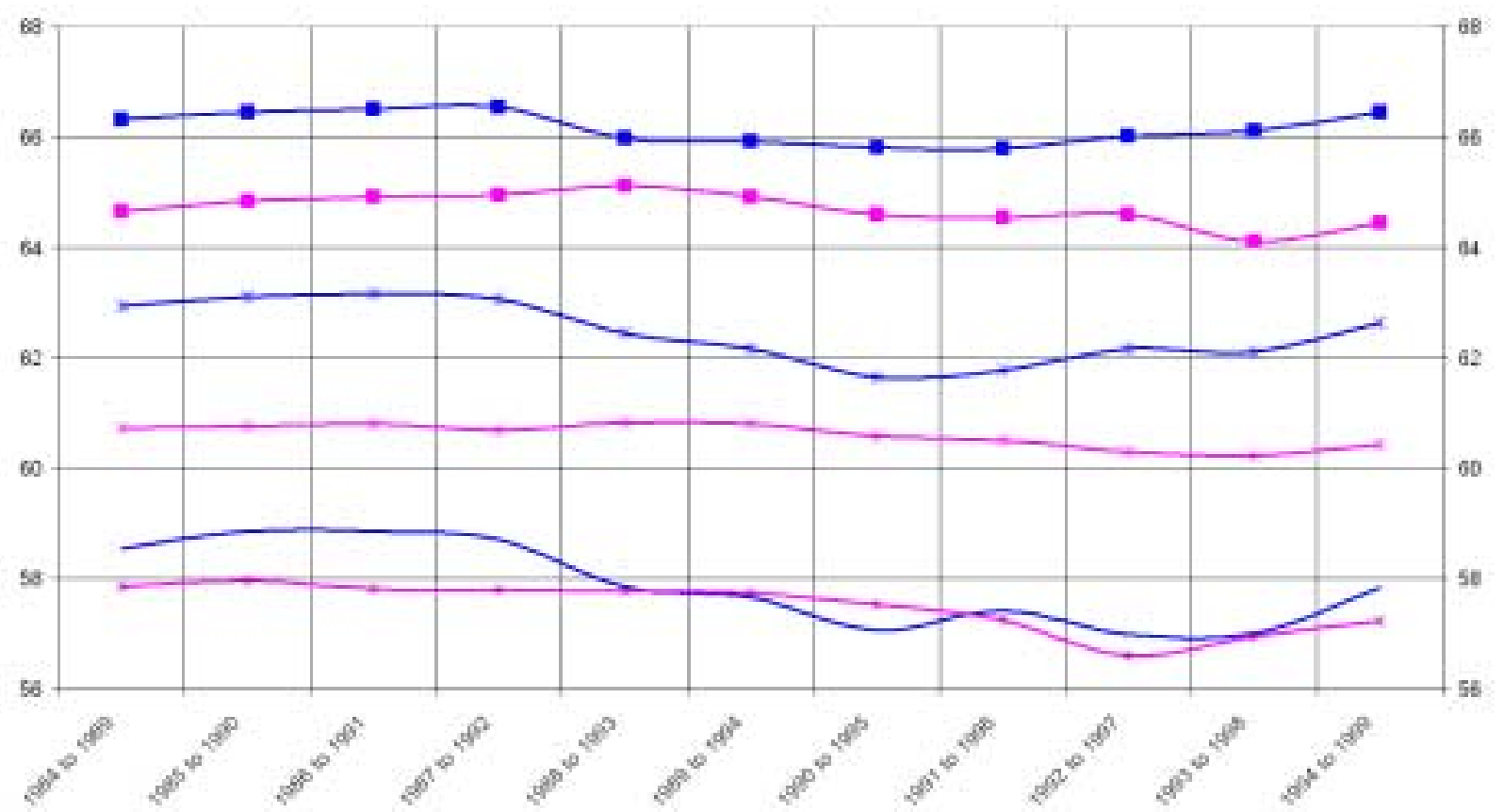

$\rightarrow$ Women: Third quartile $\rightarrow$ Men: Third quartile $\rightarrow$ Women: Median $\rightarrow$ Men: Median $\longrightarrow$ Men: First quartile $\longrightarrow$ Women: First quartile 
Chart 3. Age of withdrawal from the labour force: dynamic estimate (cont.)

CANADA

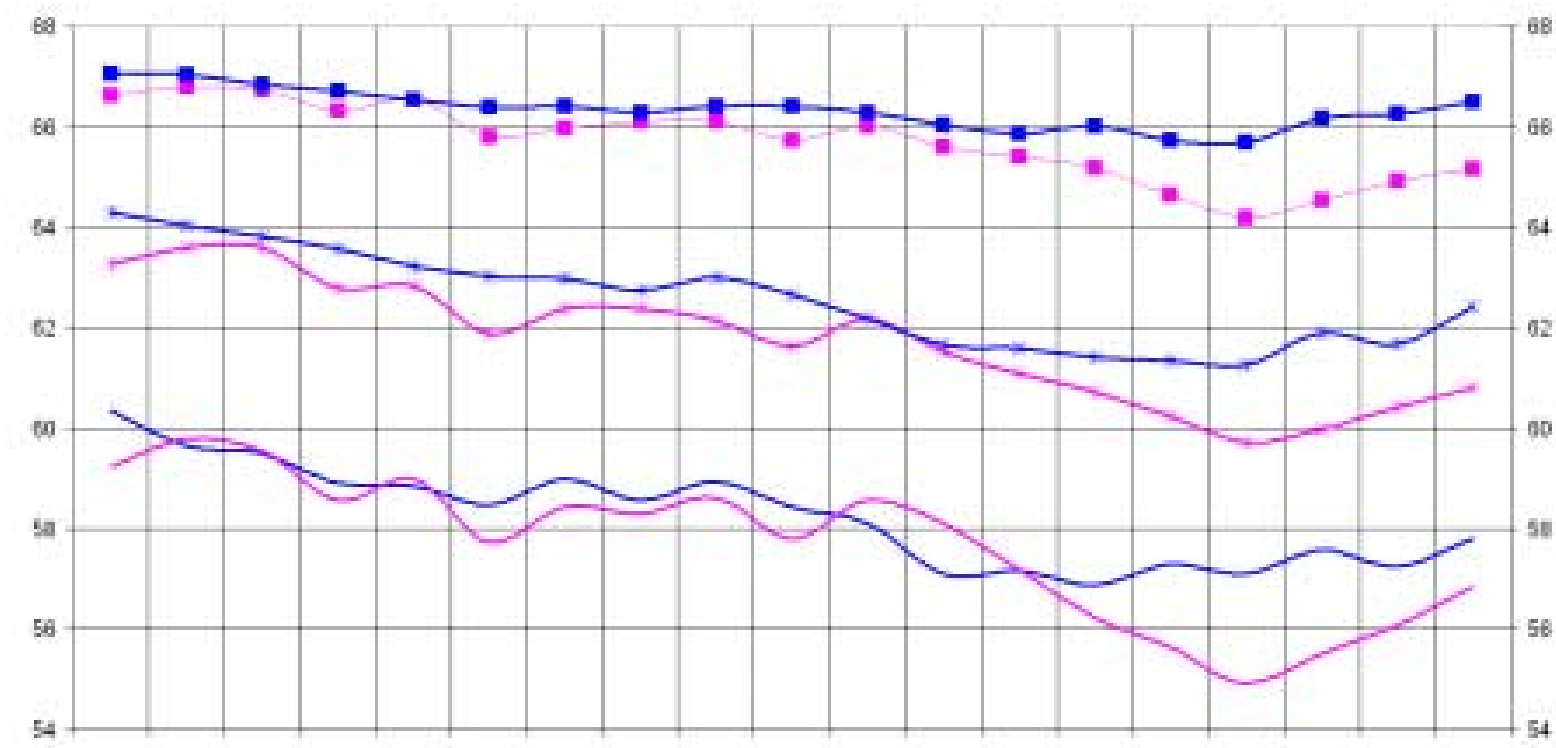

की

AUSTRALIA

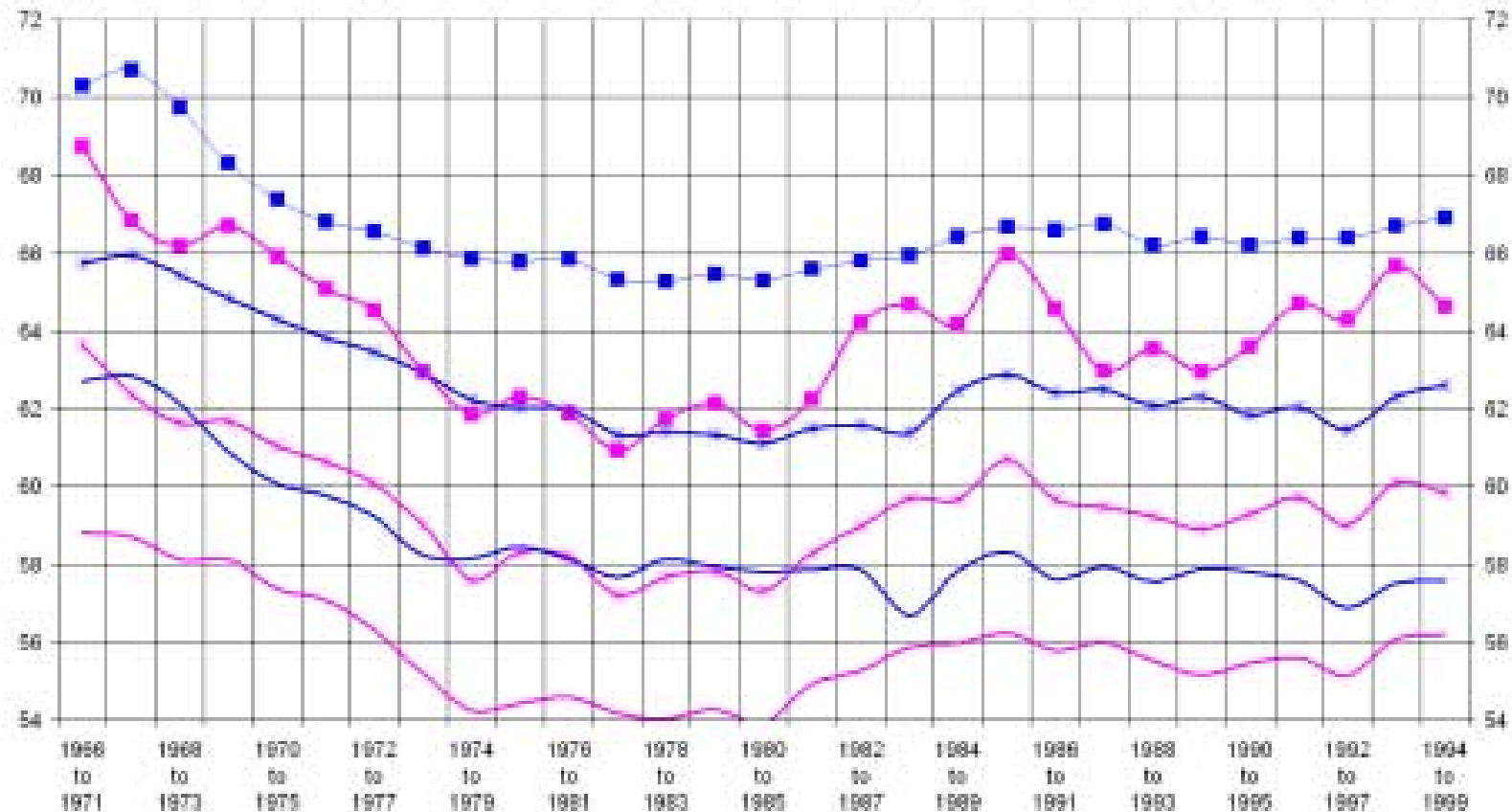

$\rightarrow$ Women: Third quartile $\rightarrow$ Men: Third quartile $\quad *$ Women: Median $\quad *$ Men: Median $\longrightarrow$ Men: First quartile $\longrightarrow$ Women: First quartile 
Chart 3. Age of withdrawal from the labour force: dynamic estimate (cont.)

BELGIUM

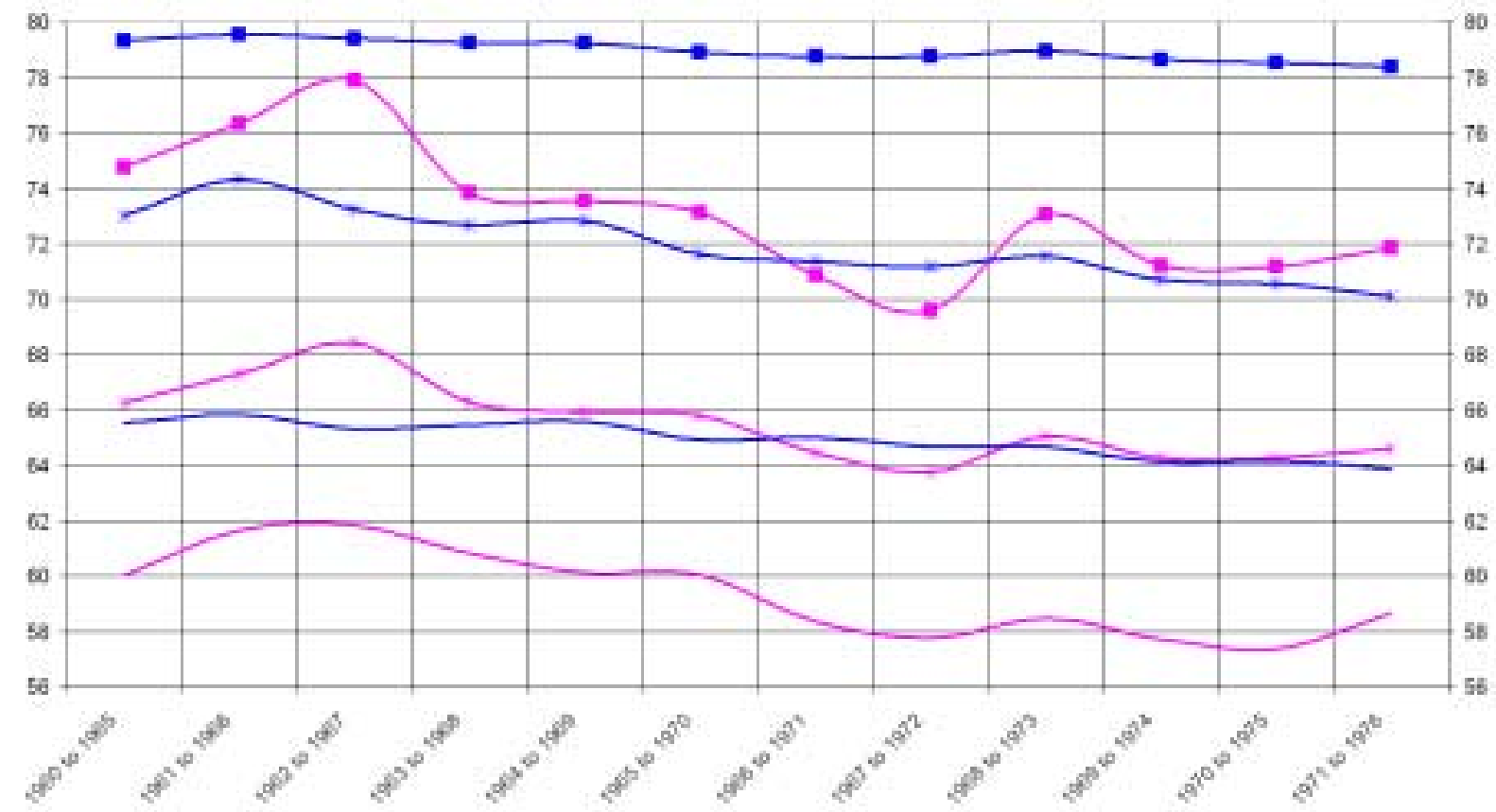

DANEMARK

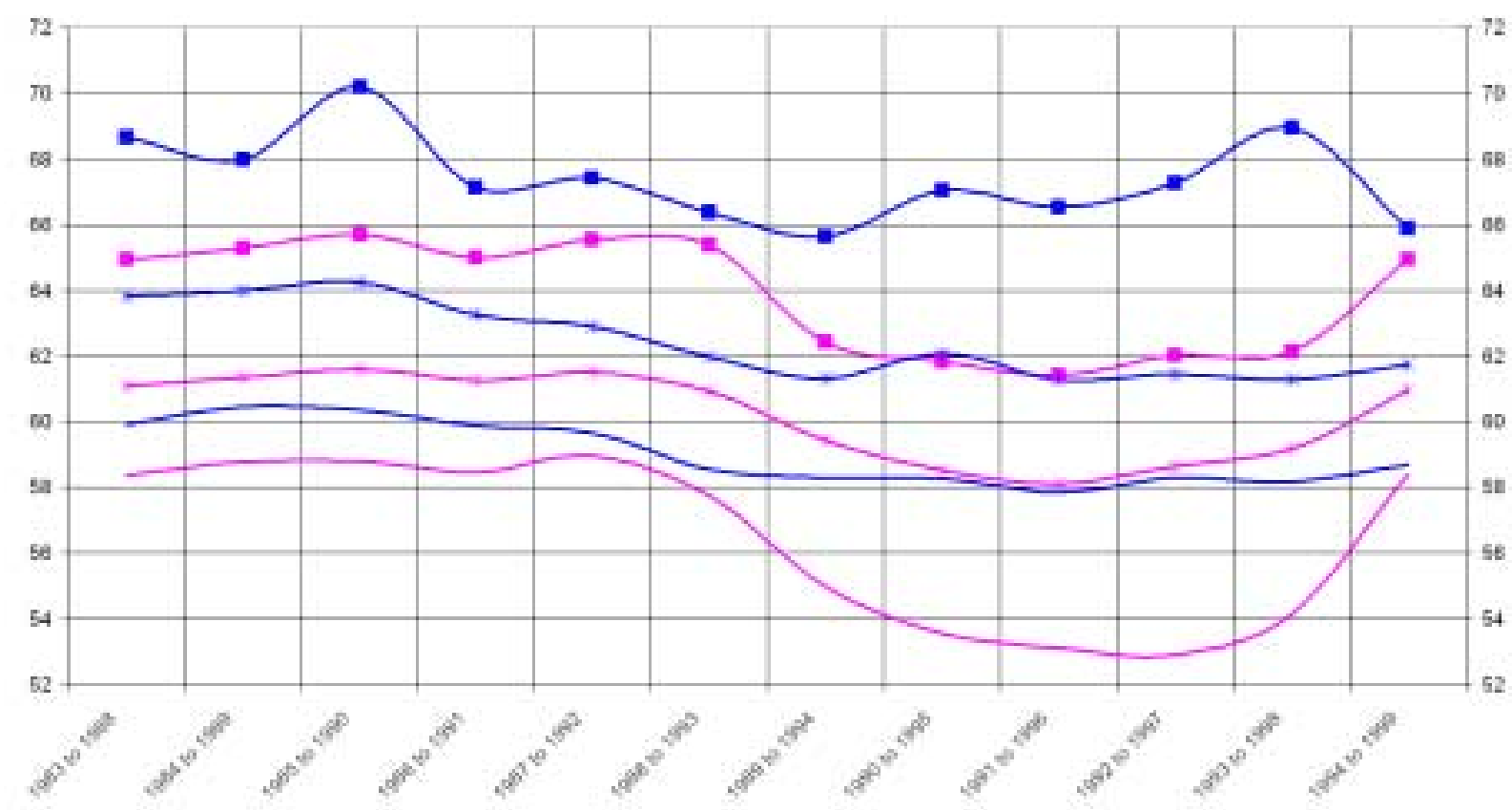

$\rightarrow$ Women: Third quartile $\rightarrow$ Men: Third quartile $\quad$ * $\rightarrow$ Women: Median $\rightarrow$ Men: Median $\longrightarrow$ Men: First quartile $\longrightarrow$ Women: First quartile 
Chart 3. Age of withdrawal from the labour force: dynamic estimate (cont.)

FINLAND

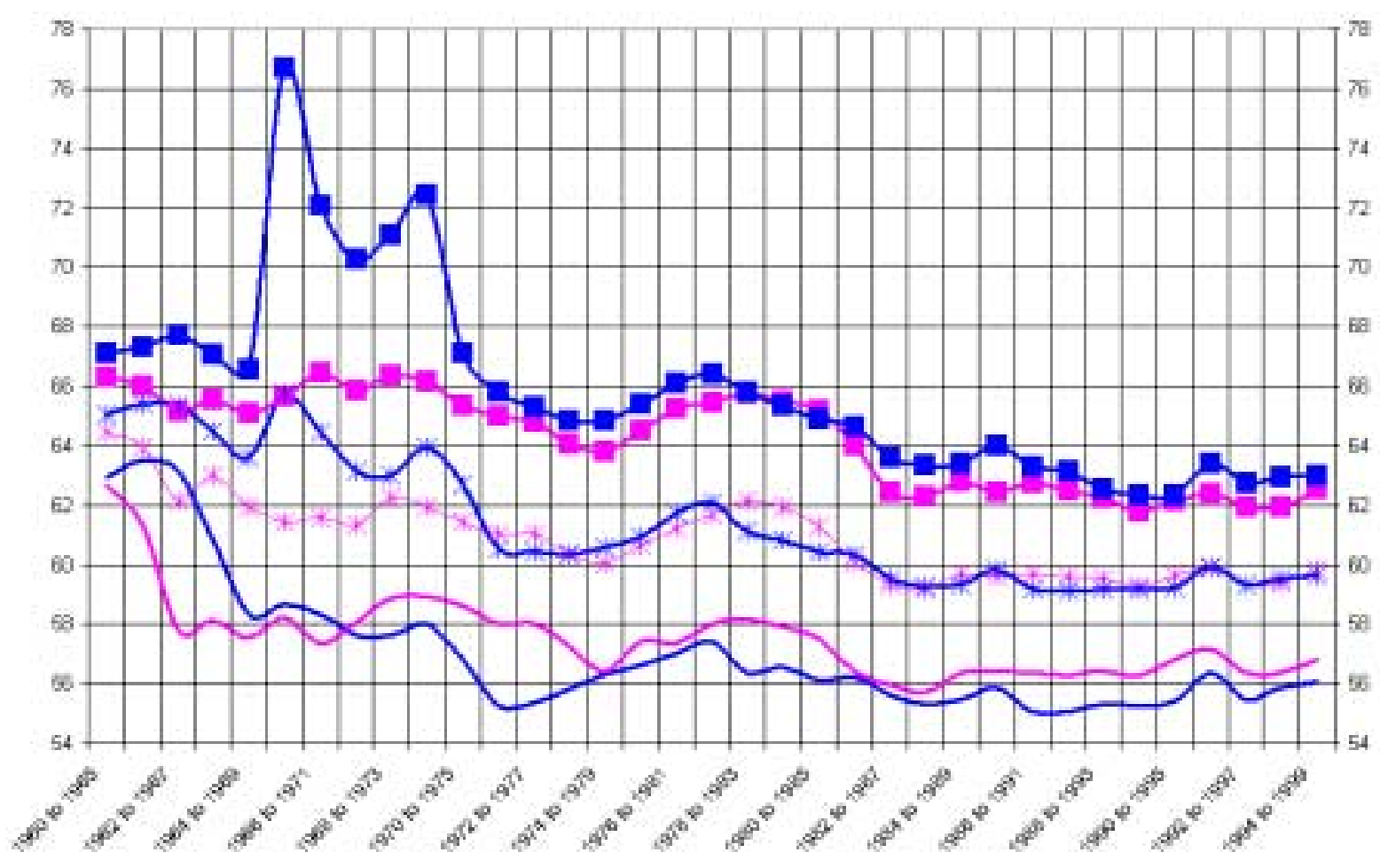

GREECE

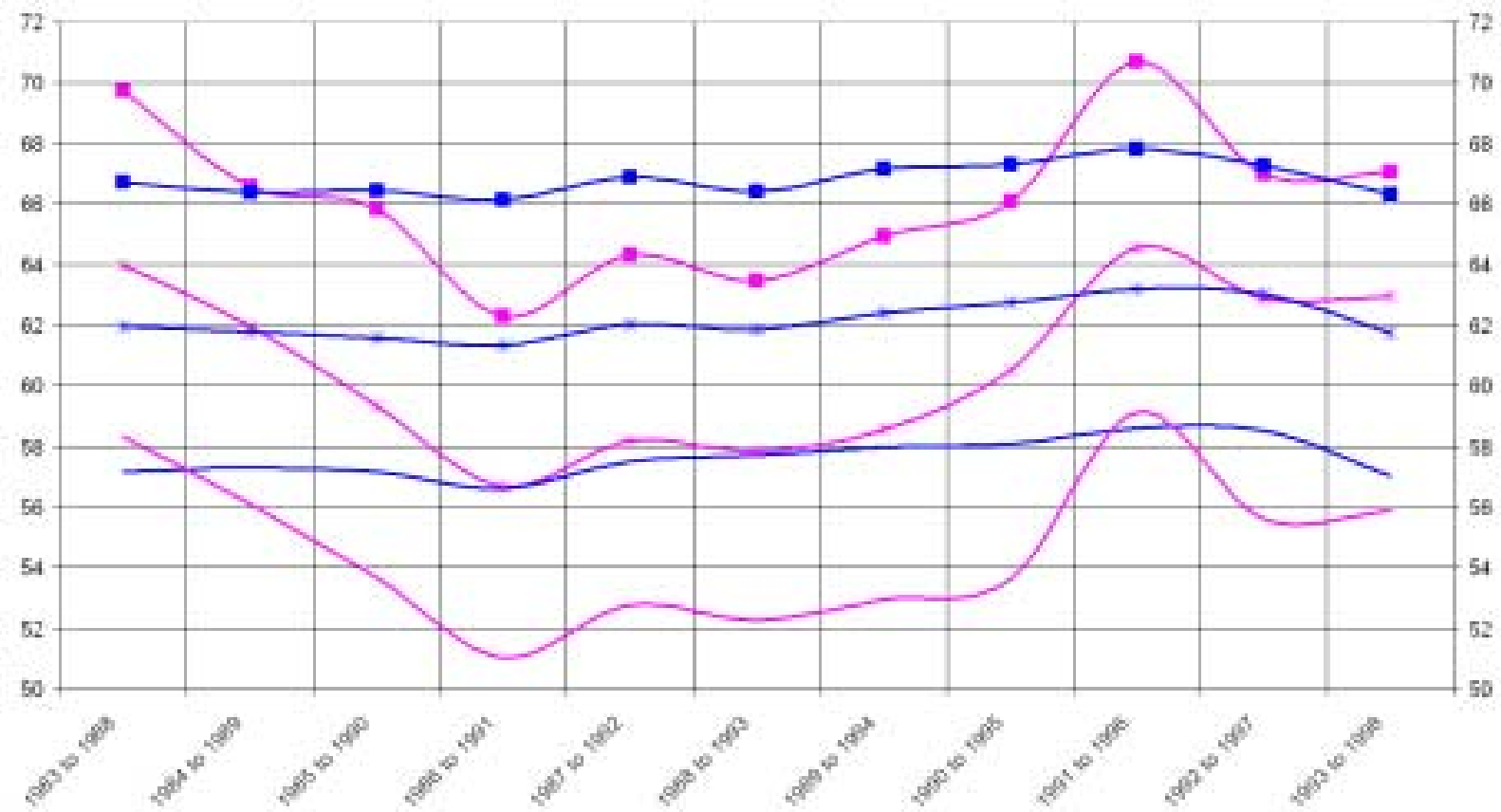

$\rightarrow$ Women: Third quartile $\rightarrow$ Men: Third quartile $\quad *$ Women: Median $\rightarrow$ Men: Median $\longrightarrow$ Men: First quartile $\longrightarrow$ Women: First quartile 
Chart 3. Age of withdrawal from the labour force: dynamic estimate (cont.)

KOREA

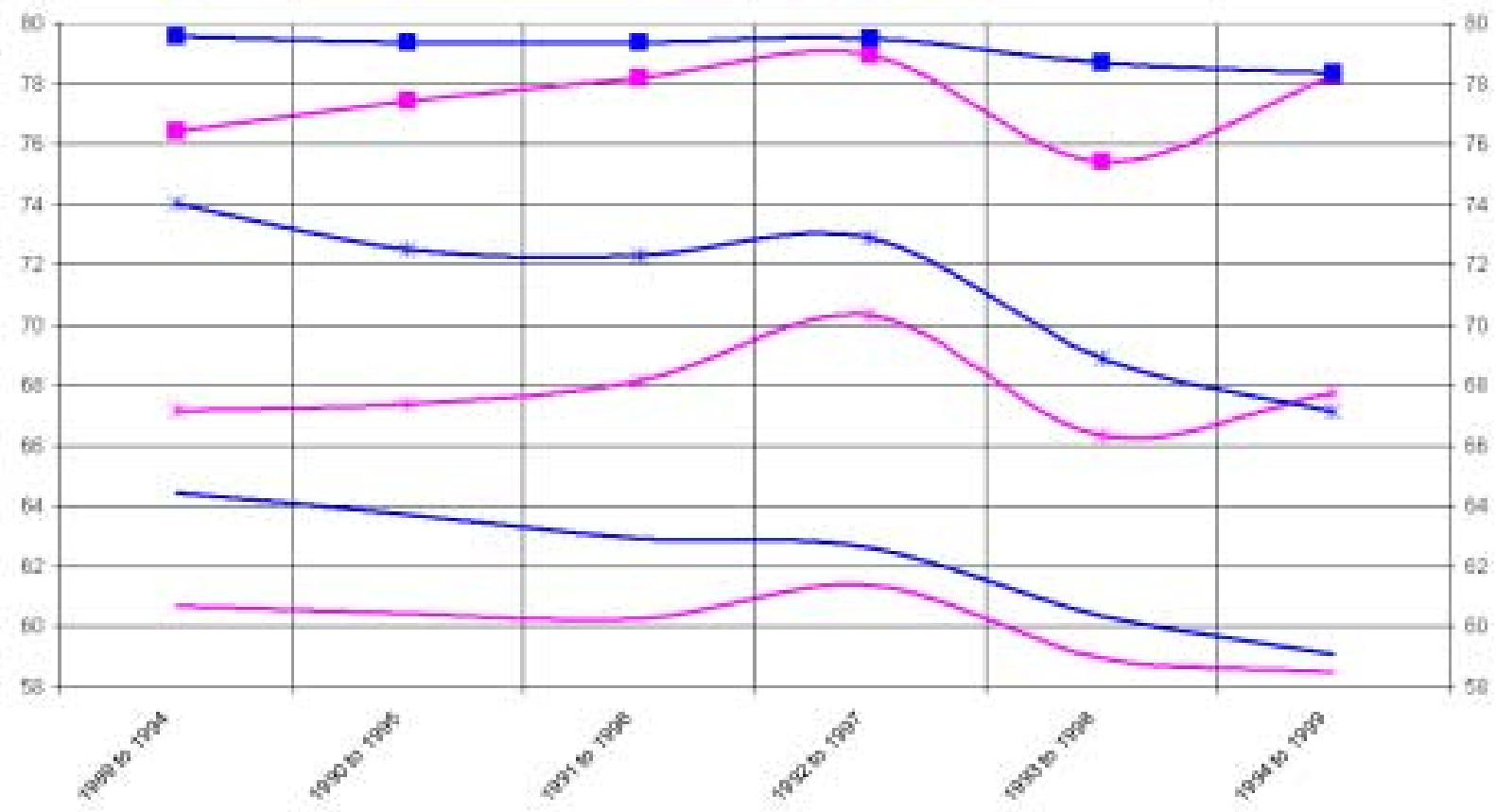

NETHERLANDS

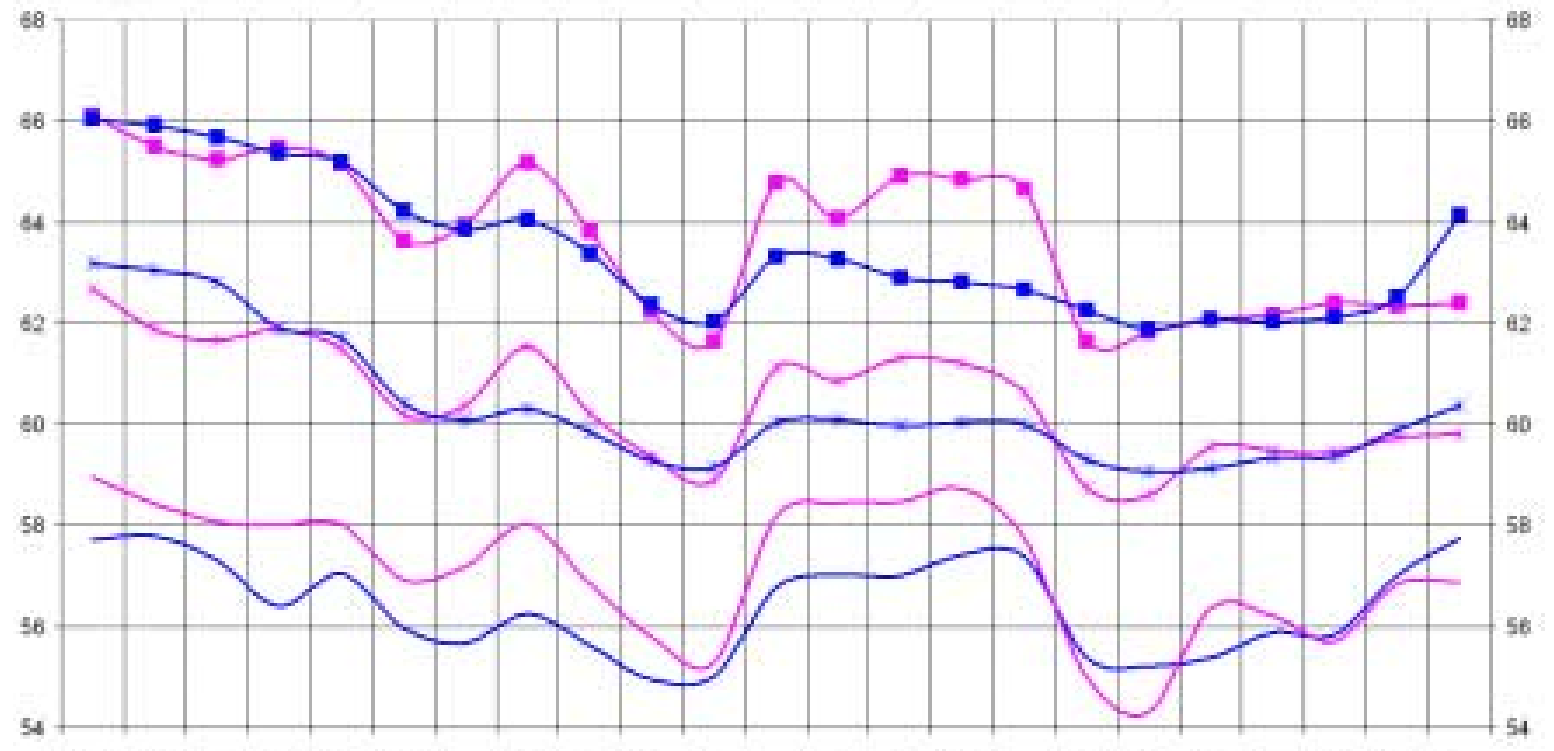

का

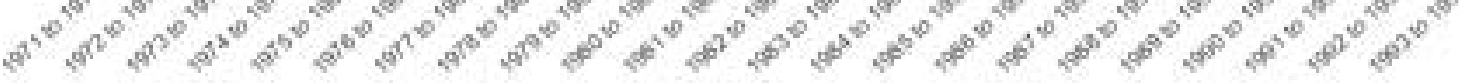


Chart 3. Age of withdrawal from the labour force: dynamic estimate (cont.)

NORWAY

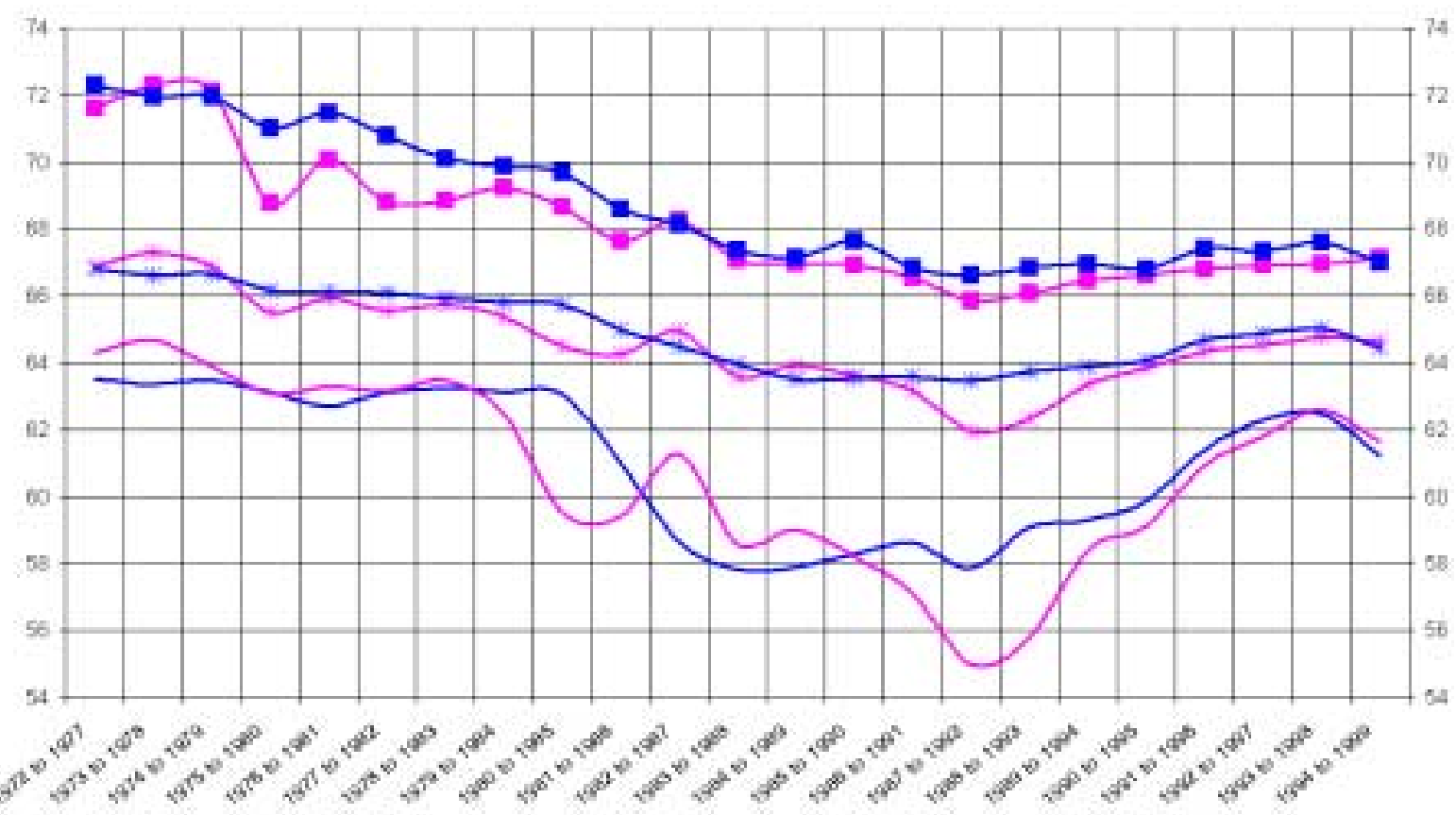

POLAND

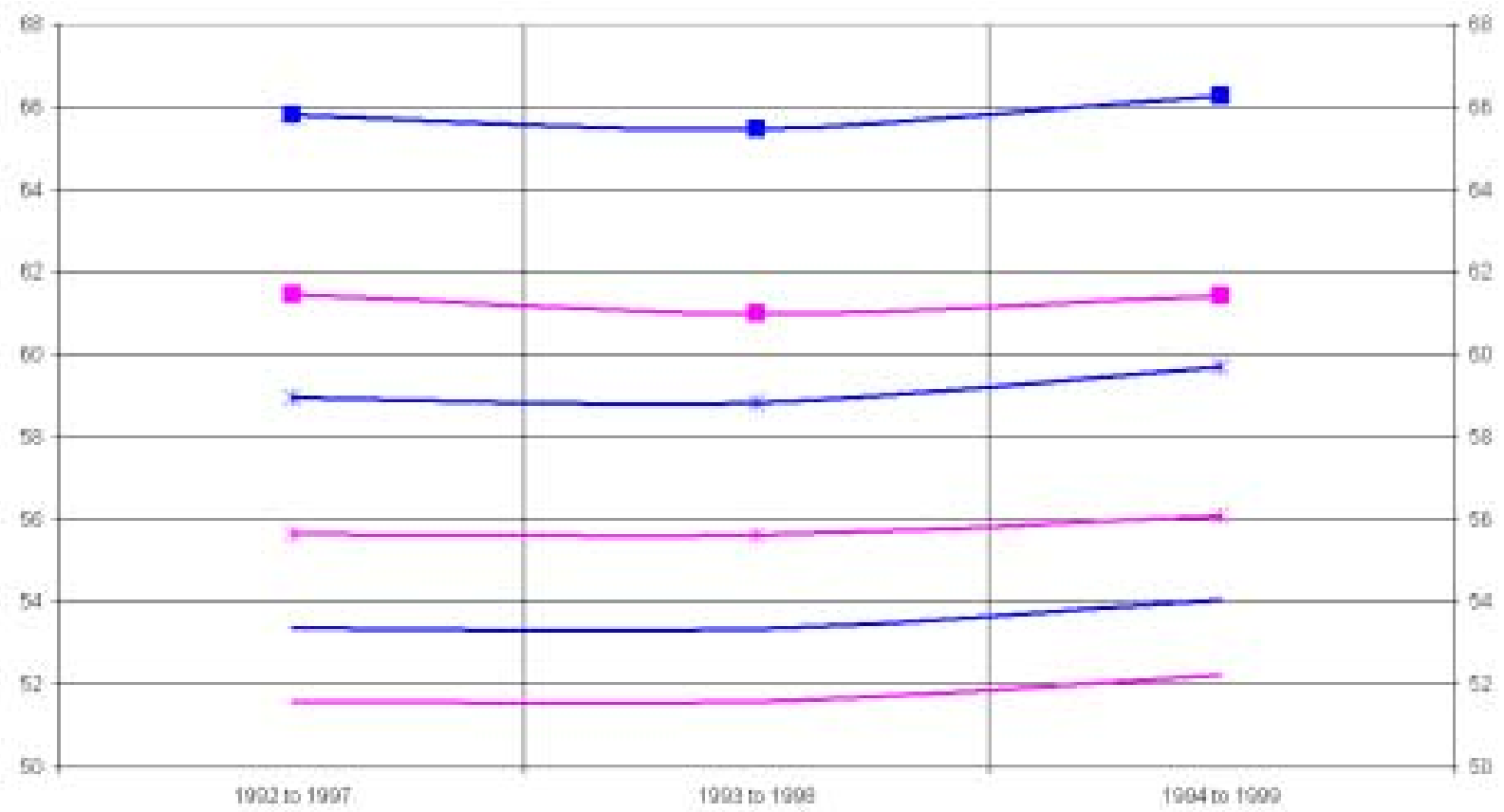

$\rightarrow$ Women: Third quartile $\rightarrow$ Men: Third quartile $\quad *$ Women: Median $\rightarrow$ Men: Median $\longrightarrow$ Men: First quartile $\longrightarrow$ Women: First quartile 
Chart 3. Age of withdrawal from the labour force: dynamic estimate (cont.)

PORTUGAL

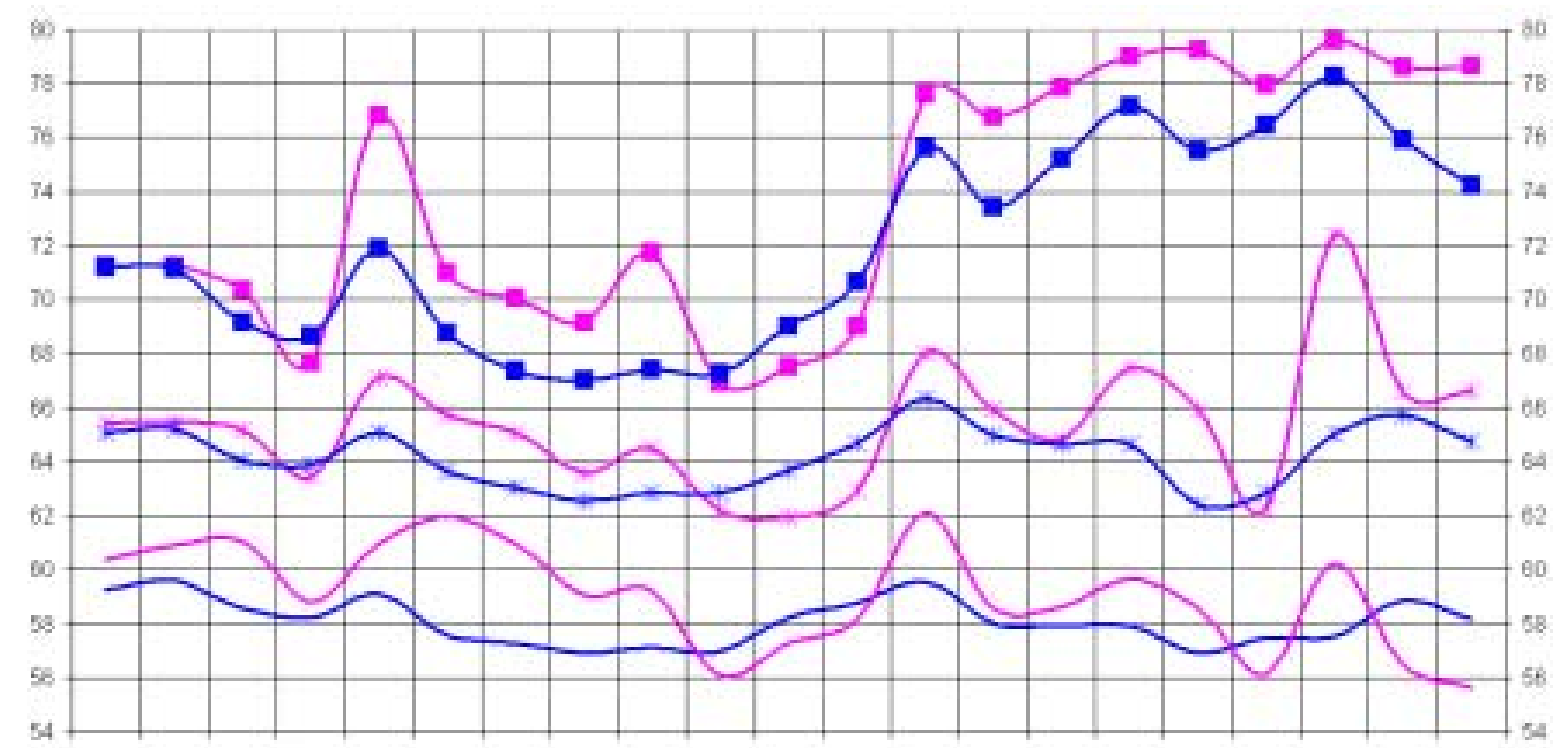

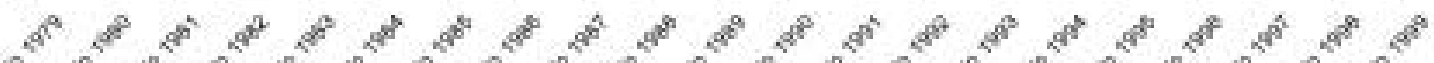

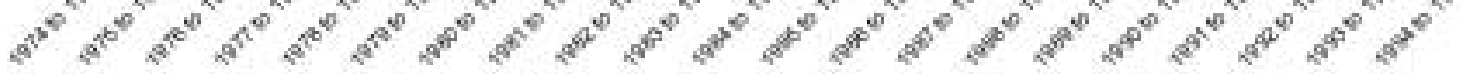

SPAIN

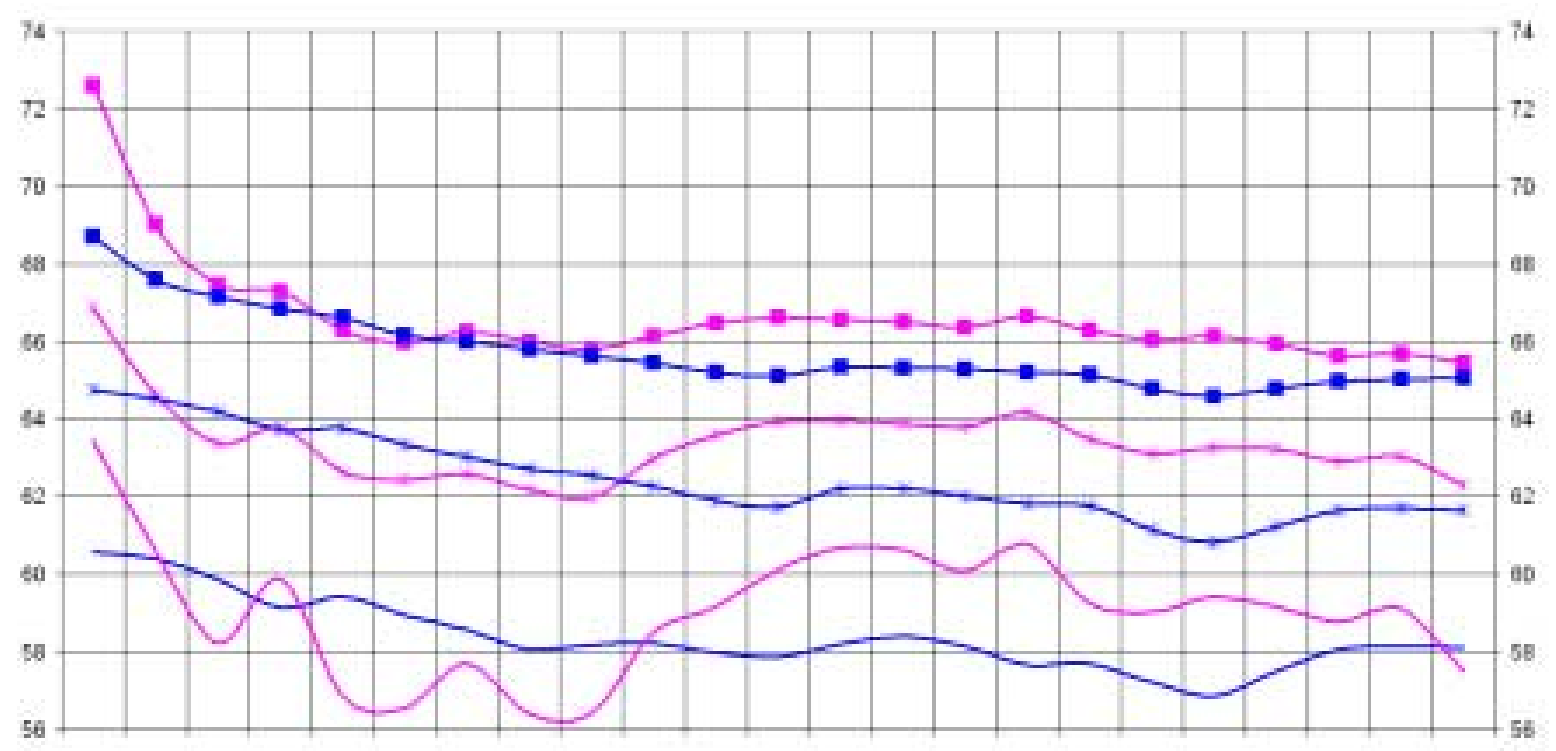

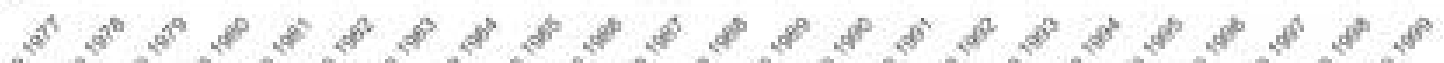

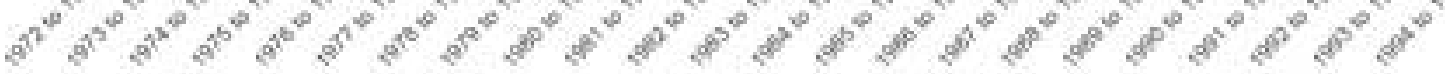

$\rightarrow$ Women: Third quartile $\rightarrow$ Men: Third quartile $\rightarrow$ Women: Median $\rightarrow$ Men: Median $\longrightarrow$ Men: First quartile $\longrightarrow$ Women: First quartile 
Chart 3. Age of withdrawal from the labour force: dynamic estimate (cont.)

\section{SWEDEN}

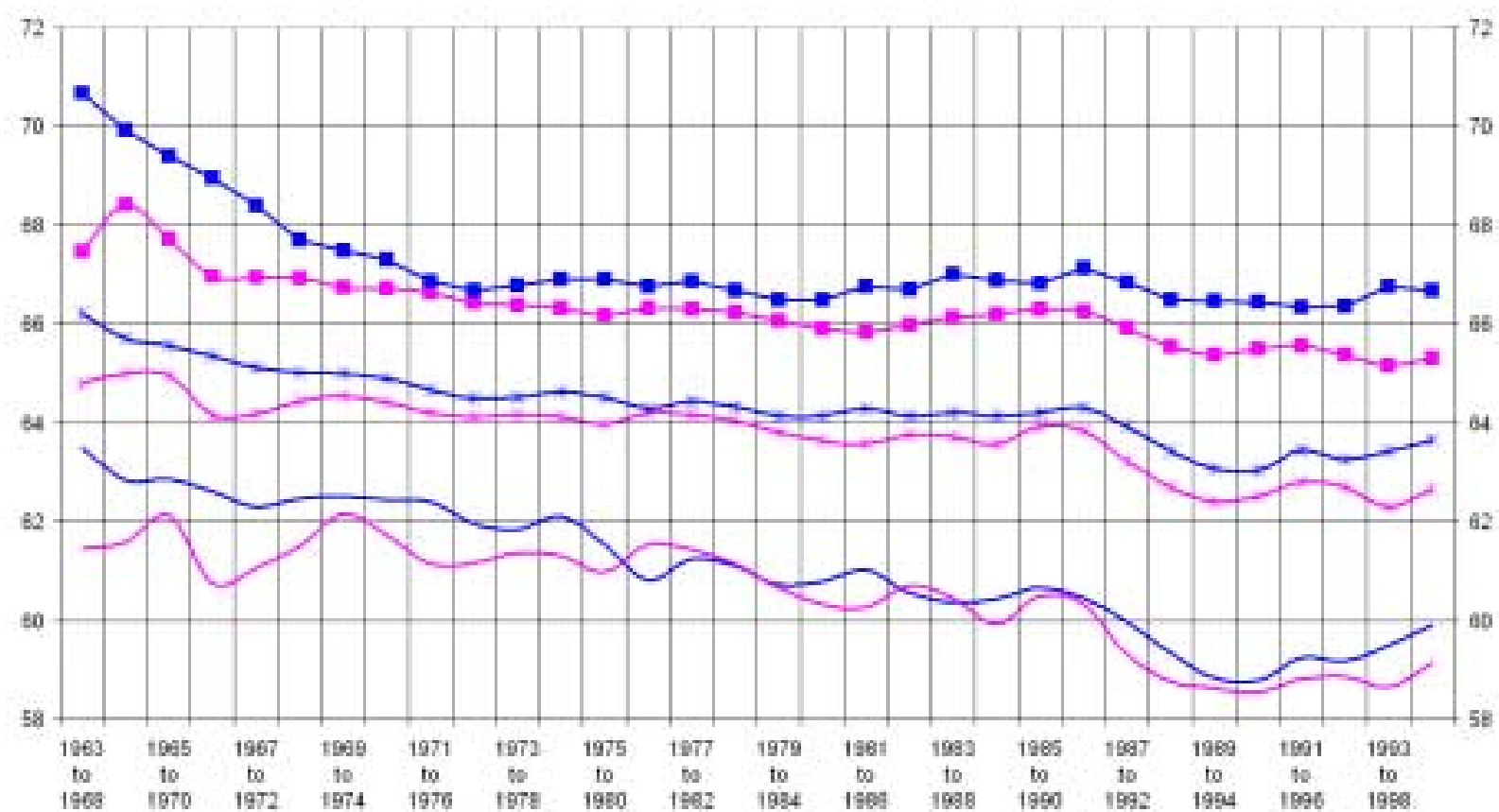


Table 4. Distribution of age of withdrawal from the labour force (Dynamic estimates)

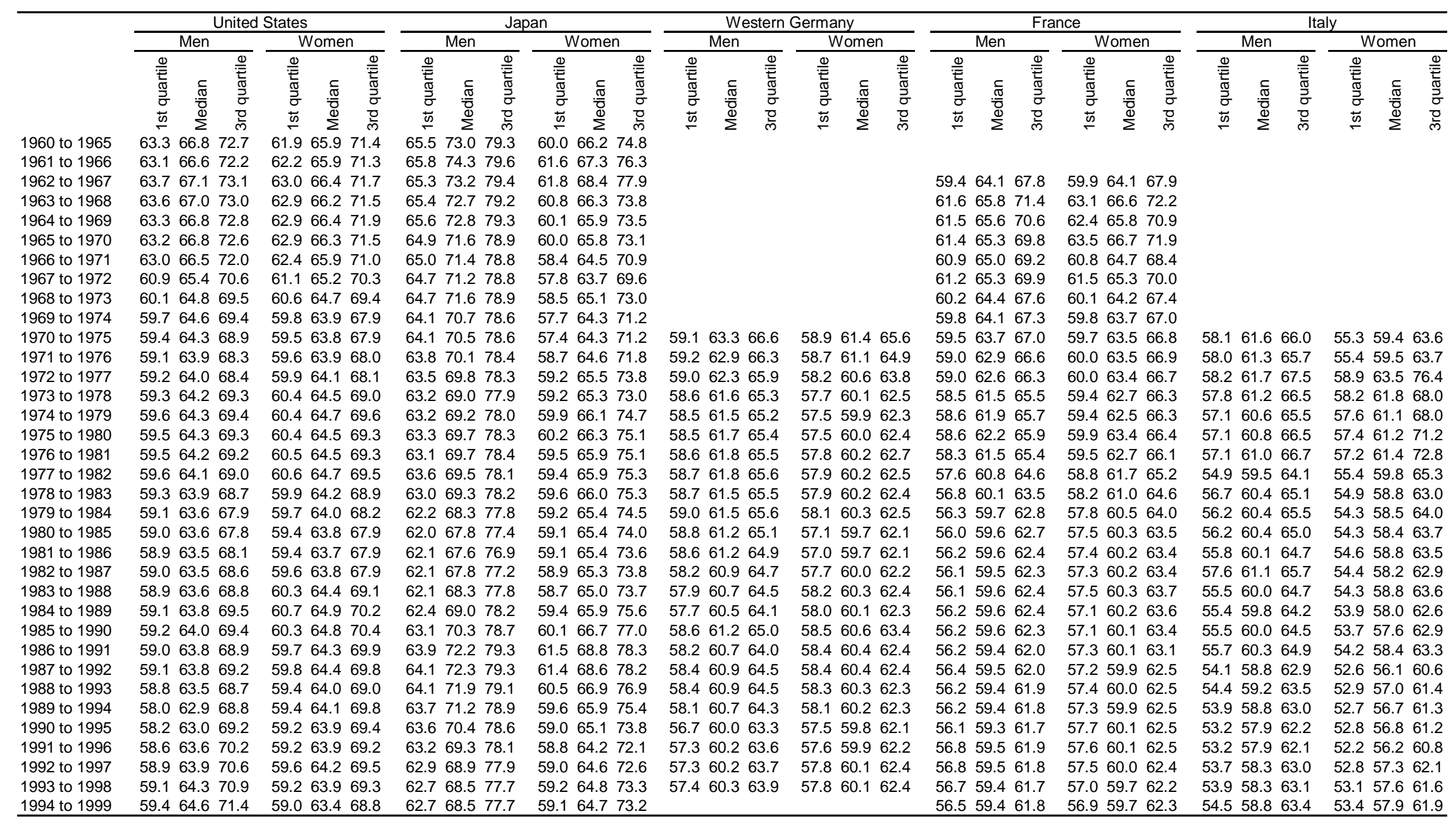


DEELSA/ELSA/WD(2001)2

Table 4. Distribution of age of withdrawal from the labour force (Dynamic estimates)(cont.)

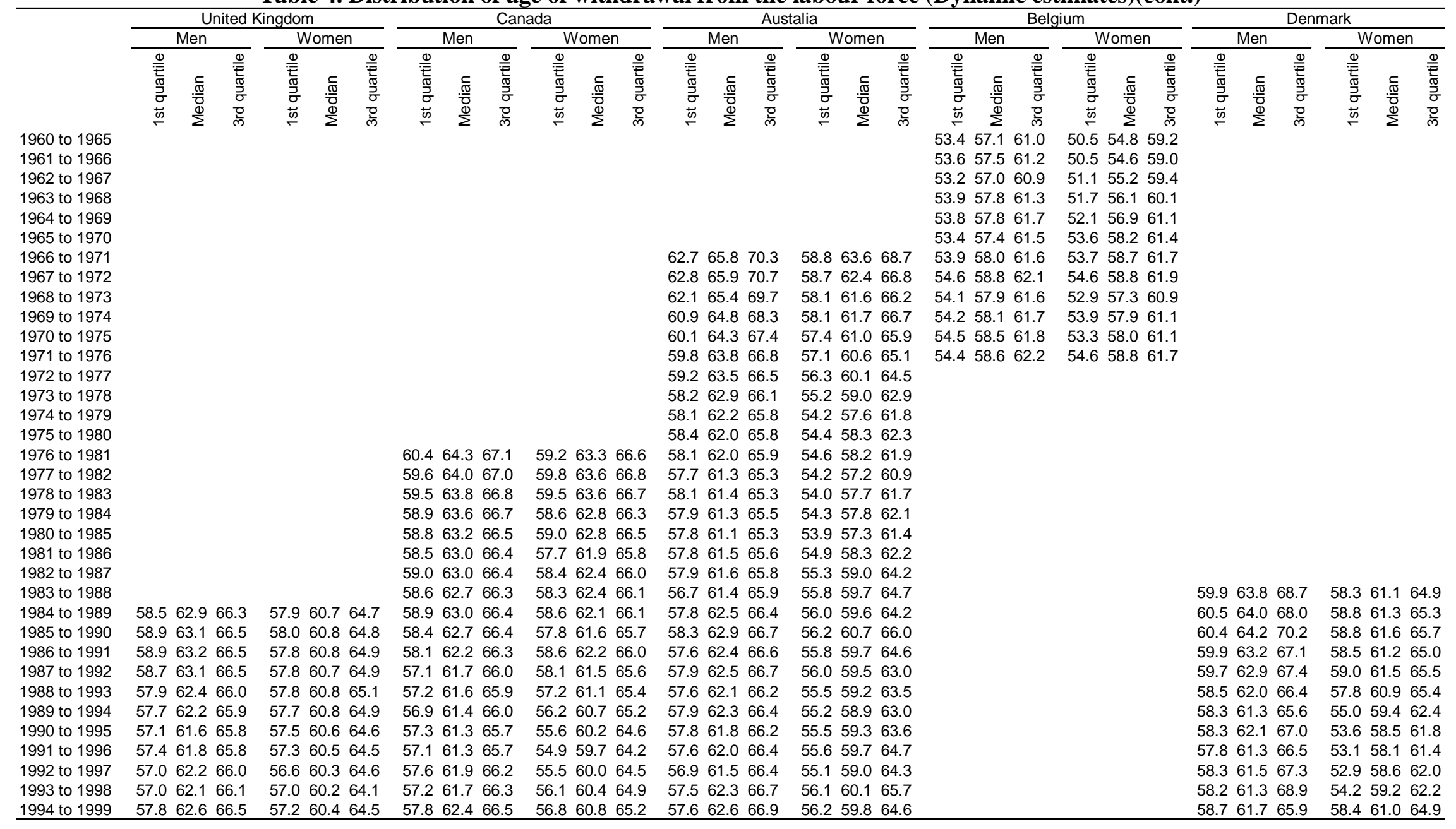


DEELSA/ELSA/WD(2001)2

Table 4. Distribution of age of withdrawal from the labour force (Dynamic estimates) (cont.)

\begin{tabular}{|c|c|c|c|c|c|c|c|c|c|c|c|c|c|c|c|c|c|c|c|c|c|c|c|c|c|c|c|c|c|c|}
\hline & \multicolumn{6}{|c|}{ Finland } & \multicolumn{6}{|c|}{ Greece } & \multicolumn{6}{|c|}{ Korea } & \multicolumn{6}{|c|}{ Netherlands } & \multicolumn{6}{|c|}{ Norway } \\
\hline & \multicolumn{3}{|c|}{ Men } & \multicolumn{3}{|c|}{ Women } & \multicolumn{3}{|c|}{ Men } & \multicolumn{3}{|c|}{ Women } & \multicolumn{3}{|c|}{ Men } & \multicolumn{3}{|c|}{ Women } & \multicolumn{3}{|c|}{ Men } & \multicolumn{3}{|c|}{ Women } & \multicolumn{3}{|c|}{ Men } & & Wome & \\
\hline & 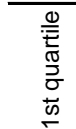 & $\begin{array}{l}\frac{\sqrt{\widetilde{\sigma}}}{\bar{\nabla}} \\
\frac{\mathbb{0}}{2}\end{array}$ & 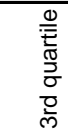 & 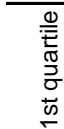 & $\begin{array}{l}\frac{\mathbb{\sigma}}{\bar{\sigma}} \\
\frac{\mathbb{0}}{\Sigma}\end{array}$ & 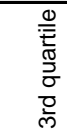 & 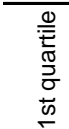 & 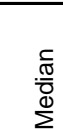 & 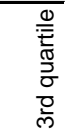 & 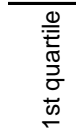 & 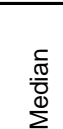 & 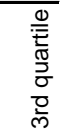 & 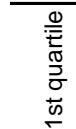 & 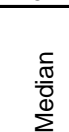 & 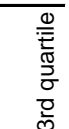 & 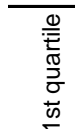 & 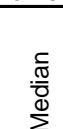 & $\begin{array}{l}\frac{\omega}{T} \\
\frac{\vec{T}}{\omega} \\
\frac{0}{\sigma} \\
\frac{0}{0}\end{array}$ & 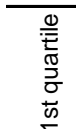 & 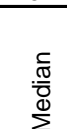 & 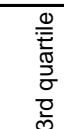 & 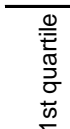 & 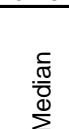 & 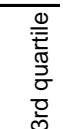 & 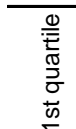 & 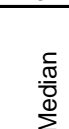 & 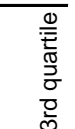 & 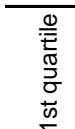 & 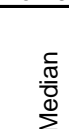 & 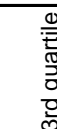 \\
\hline 1961 to 1966 & 63.5 & 65.4 & 67.3 & 61.3 & 63.9 & 66.0 & & & & & & & & & & & & & & & & & & & & & & & & \\
\hline 1962 to 1967 & 63.1 & 65.4 & 67.7 & 57.8 & 62.1 & 65.2 & & & & & & & & & & & & & & & & & & & & & & & & \\
\hline 1963 to 1968 & 60.8 & 64.5 & 67.0 & 58.1 & 63.0 & 65.5 & & & & & & & & & & & & & & & & & & & & & & & & \\
\hline 1964 to 1969 & 58.3 & 63.6 & 66.6 & 57.6 & 61.9 & 65.1 & & & & & & & & & & & & & & & & & & & & & & & & \\
\hline 1965 to 1970 & 58.7 & 65.8 & 76.7 & 58.2 & 61.4 & 65.6 & & & & & & & & & & & & & & & & & & & & & & & & \\
\hline 1967 to 1972 & 57.6 & 63.1 & 70.3 & 58.1 & 61.3 & 65.8 & & & & & & & & & & & & & & & & & & & & & & & & \\
\hline 1968 to 1973 & 57.6 & 63.0 & 71.1 & 58.9 & 62.2 & 66.4 & & & & & & & & & & & & & & & & & & & & & & & & \\
\hline 1969 to 1974 & 58.0 & 63.9 & 72.4 & 58.9 & 61.9 & 66.1 & & & & & & & & & & & & & & & & & & & & & & & & \\
\hline 1970 to 1975 & 56.8 & 62.7 & 67.1 & 58.6 & 61.4 & 65.3 & & & & & & & & & & & & & & & & & & & & & & & & \\
\hline 1971 to 1976 & 55.3 & 60.5 & 65.8 & 58.0 & 61.0 & 65.0 & & & & & & & & & & & & & 57.7 & 63.2 & 66.0 & 59.0 & 62.7 & 66.1 & & & & & & \\
\hline 1972 to 1977 & 55.4 & 60.4 & 65.3 & 58.0 & 61.0 & 64.8 & & & & & & & & & & & & & 57.8 & 63.1 & 65.9 & 58.4 & 61.9 & 65.5 & 63.5 & 66.8 & 72.3 & 64.3 & 66.9 & 71.6 \\
\hline 1973 to 1978 & 55.8 & 60.3 & 64.9 & 57.2 & 60.4 & 64.0 & & & & & & & & & & & & & 57.3 & 62.8 & 65.7 & 58.1 & 61.7 & 65.2 & 63.4 & 66.6 & 72.0 & 64.7 & 67.3 & 72.3 \\
\hline 1974 to 1979 & 56.3 & 60.6 & 64.9 & 56.4 & 60.0 & 63.8 & & & & & & & & & & & & & 56.4 & 61.9 & 65.4 & 58.0 & 61.9 & 65.5 & 63.5 & 66.7 & 72.0 & 63.9 & 66.9 & 72.1 \\
\hline 1975 to 1980 & 56.6 & 61.0 & 65.4 & 57.4 & 60.6 & 64.5 & & & & & & & & & & & & & 57.0 & 61.7 & 65.2 & 58.0 & 61.5 & 65.2 & 63.1 & 66.2 & 71.0 & 63.1 & 65.5 & 68.8 \\
\hline 1976 to 1981 & 57.0 & 61.7 & 66.1 & 57.4 & 61.2 & 65.3 & & & & & & & & & & & & & 56.0 & 60.4 & 64.2 & 56.9 & 60.2 & 63.6 & 62.7 & 66.1 & 71.4 & 63.3 & 65.9 & 70.1 \\
\hline 1977 to 1982 & 57.4 & 62.1 & 66.4 & 58.0 & 61.7 & 65.5 & & & & & & & & & & & & & 55.7 & 60.1 & 63.9 & 57.2 & 60.4 & 64.0 & 63.1 & 66.1 & 70.8 & 63.2 & 65.6 & 68.8 \\
\hline 1980 to 1985 & 56.1 & 60.4 & 64.9 & 57.5 & 61.3 & 65.2 & & & & & & & & & & & & & 55.0 & 59.3 & 62.4 & 55.8 & 59.4 & 62.2 & 63.0 & 65.7 & 69.7 & 59.5 & 64.5 & 68.7 \\
\hline 1981 to 1986 & 56.2 & 60.3 & 64.7 & 56.4 & 60.1 & 64.0 & & & & & & & & & & & & & 55.0 & 59.2 & 62.0 & 55.3 & 58.9 & 61.6 & 61.0 & 65.0 & 68.6 & 59.4 & 64.3 & 67.7 \\
\hline 1982 to 1987 & 55.6 & 59.5 & 63.6 & 55.9 & 59.3 & 62.4 & & & & & & & & & & & & & 56.8 & 60.0 & 63.3 & 58.2 & 61.1 & 64.8 & 58.6 & 64.5 & 68.1 & 61.3 & 64.9 & 68.2 \\
\hline 1983 to 1988 & 55.3 & 59.2 & 63.3 & 55.7 & 59.2 & 62.3 & 57.2 & 61.9 & 66.7 & 58.3 & 64.0 & 69.8 & & & & & & & 57.0 & 60.1 & 63.3 & 58.5 & 60.9 & 64.1 & 57.8 & 63.9 & 67.4 & 58.6 & 63.6 & 67.1 \\
\hline 1984 to 1989 & 55.4 & 59.3 & 63.4 & 56.4 & 59.7 & 62.8 & 57.3 & 61.8 & 66.4 & 56.1 & 62.0 & 66.6 & & & & & & & 57.0 & 60.0 & 62.9 & 58.5 & 61.3 & 64.9 & 57.9 & 63.5 & 67.1 & 59.0 & 63.9 & 67.0 \\
\hline 1985 to 1990 & 55.9 & 59.8 & 64.0 & 56.4 & 59.6 & 62.4 & 57.2 & 61.6 & 66.4 & 53.7 & 59.3 & 65.8 & & & & & & & 57.4 & 60.0 & 62.8 & 58.7 & 61.2 & 64.9 & 58.3 & 63.5 & 67.6 & 58.2 & 63.6 & 66.9 \\
\hline 1986 to 1991 & 55.1 & 59.2 & 63.3 & 56.3 & 59.7 & 62.7 & 56.6 & 61.4 & 66.1 & 51.0 & 56.7 & 62.3 & & & & & & & 57.4 & 60.0 & 62.7 & 57.8 & 60.6 & 64.7 & 58.6 & 63.6 & 66.8 & 57.1 & 63.2 & 66.5 \\
\hline 1987 to 1992 & 55.0 & 59.1 & 63.1 & 56.3 & 59.6 & 62.5 & 57.5 & 62.0 & 66.9 & 52.8 & 58.2 & 64.3 & & & & & & & 55.4 & 59.3 & 62.3 & 55.0 & 58.8 & 61.6 & 57.9 & 63.5 & 66.6 & 55.0 & 61.9 & 65.8 \\
\hline 1988 to 1993 & 55.3 & 59.2 & 62.6 & 56.4 & 59.5 & 62.2 & 57.7 & 61.8 & 66.4 & 52.3 & 57.8 & 63.5 & & & & & & & 55.2 & 59.1 & 61.9 & 54.3 & 58.6 & 61.8 & 59.1 & 63.7 & 66.8 & 55.8 & 62.3 & 66.1 \\
\hline 1989 to 1994 & 55.3 & 59.2 & 62.3 & 56.3 & 59.3 & 61.8 & 58.0 & 62.4 & 67.2 & 52.9 & 58.6 & 64.9 & 64.4 & 74.0 & 79.6 & 60.7 & 67.2 & 76.4 & 55.4 & 59.1 & 62.1 & 56.4 & 59.6 & 62.1 & 59.3 & 63.9 & 67.0 & 58.4 & 63.4 & 66.5 \\
\hline 1990 to 1995 & 55.4 & 59.2 & 62.3 & 56.8 & 59.6 & 62.1 & 58.1 & 62.7 & 67.3 & 53.6 & 60.5 & 66.1 & 63.7 & 72.5 & 79.4 & 60.4 & 67.4 & 77.5 & 55.9 & 59.3 & 62.0 & 56.2 & 59.5 & 62.2 & 59.9 & 64.1 & 66.8 & 59.1 & 63.9 & 66.6 \\
\hline 1991 to 1996 & 56.4 & 59.9 & 63.4 & 57.2 & 59.9 & 62.4 & 58.6 & 63.2 & 67.8 & 59.1 & 64.6 & 70.7 & 62.9 & 72.3 & 79.4 & 60.3 & 68.1 & 78.2 & 55.9 & 59.4 & 62.1 & 55.7 & 59.5 & 62.4 & 61.4 & 64.7 & 67.4 & 60.9 & 64.3 & 66.8 \\
\hline 1992 to 1997 & 55.5 & 59.3 & 62.7 & 56.4 & 59.3 & 61.9 & 58.5 & 63.0 & 67.3 & 55.6 & 62.9 & 67.0 & 62.6 & 72.9 & 79.5 & 61.4 & 70.3 & 79.0 & 57.0 & 59.9 & 62.5 & 56.8 & 59.8 & 62.3 & 62.3 & 64.9 & 67.4 & 61.8 & 64.5 & 66.9 \\
\hline 1993 to 1998 & 55.9 & 59.5 & 62.9 & 56.4 & 59.4 & 62.0 & 57.0 & 61.8 & 66.3 & 55.9 & 62.9 & 67.1 & 60.4 & 68.9 & 78.7 & 59.0 & 66.3 & 75.4 & 57.8 & 60.4 & 64.1 & 56.9 & 59.8 & 62.4 & 62.5 & 65.0 & 67.6 & 62.6 & 64.8 & 67.0 \\
\hline 1994 to 1999 & 56.0 & 59.6 & 63.0 & 56.8 & 59.8 & 62.5 & & & & & & & 59.1 & 67.1 & 78.4 & 58.5 & 67.7 & 78.3 & & & & & & & 61.2 & 64.4 & 67.0 & 61.6 & 64.6 & 67.1 \\
\hline
\end{tabular}


Table 4. Distribution of age of withdrawal from the labour force (Dynamic estimates) (cont.)

\begin{tabular}{|c|c|c|c|c|c|c|c|c|c|c|c|c|c|c|c|c|c|c|c|c|c|c|c|c|}
\hline & \multicolumn{6}{|c|}{ Poland } & \multicolumn{6}{|c|}{ Portugal } & \multicolumn{6}{|c|}{ Spain } & \multicolumn{6}{|c|}{ Sweden } \\
\hline & \multicolumn{3}{|c|}{ Men } & \multicolumn{3}{|c|}{ Women } & \multicolumn{3}{|c|}{ Men } & \multicolumn{3}{|c|}{ Women } & \multicolumn{3}{|c|}{ Men } & \multicolumn{3}{|c|}{ Women } & \multicolumn{3}{|c|}{ Men } & \multicolumn{3}{|c|}{ Women } \\
\hline & 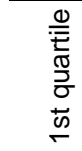 & 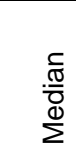 & 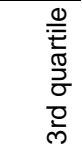 & $\begin{array}{l}\frac{0}{\underline{T}} \\
\frac{\sigma}{D} \\
\frac{\sigma}{\sigma} \\
\frac{\pi}{\sigma}\end{array}$ & $\begin{array}{l}\frac{\bar{\sigma}}{\mathrm{T}} \\
\frac{\mathrm{d}}{\Sigma} \\
\sum\end{array}$ & 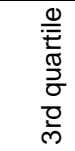 & 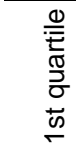 & 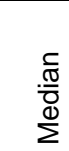 & 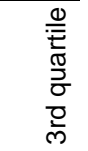 & 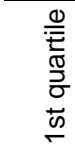 & 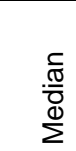 & 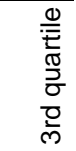 & 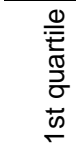 & 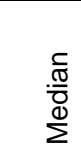 & 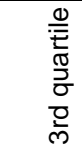 & 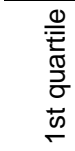 & 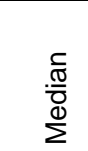 & 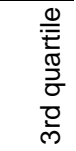 & 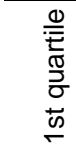 & 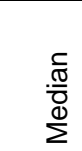 & 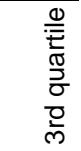 & 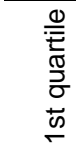 & 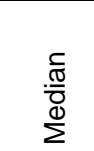 & 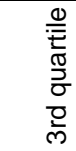 \\
\hline 1960 to 1965 & & & & & & & & & & & & & & & & & & & & & & & & \\
\hline $\begin{array}{l}196 \\
196\end{array}$ & & & & & & & & & & & & & & & & & & & 63.5 & 66.2 & 70.7 & 61.5 & 64.8 & 67.5 \\
\hline & & & & & & & & & & & & & & & & & & & 62.8 & 65.7 & 69.9 & 61.6 & 65.0 & 68.4 \\
\hline 1965 to 1970 & & & & & & & & & & & & & & & & & & & 62.9 & 65.6 & 69.4 & 62.1 & 65.0 & 67.7 \\
\hline 1966 to 1971 & & & & & & & & & & & & & & & & & & & 62.6 & 65.4 & 69.0 & 60.8 & 64.2 & 67.0 \\
\hline 1967 to 1972 & & & & & & & & & & & & & & & & & & & 62.3 & 65.1 & 68.4 & 61.1 & 64.2 & 67.0 \\
\hline 1968 to 1973 & & & & & & & & & & & & & & & & & & & 62.5 & 65.0 & 67.7 & 61.5 & 64.4 & 66.9 \\
\hline 1969 to 1974 & & & & & & & & & & & & & & & & & & & 62.5 & 65.0 & 67.5 & 62.1 & 64.5 & 66.7 \\
\hline 1975 & & & & & & & & & & & & & & & & & & & 62.4 & 64.9 & 67.3 & 61.7 & 64.4 & 66.7 \\
\hline 197 & & & & & & & & & & & & & & & & & & & 62.4 & 64.7 & 66.9 & 61.1 & 64.2 & 66.6 \\
\hline 977 & & & & & & & & & & & & & 60.6 & 64.8 & 68.7 & 63.4 & 66.9 & 72.6 & 62.0 & 64.5 & 66.7 & 61.2 & 64.1 & 66.4 \\
\hline $1973 t$ & & & & & & & & & & & & & 60.4 & 64.5 & 67.6 & 60.6 & 64.6 & 69.0 & 61.8 & 64.5 & 66.8 & 61.4 & 64.2 & 66.4 \\
\hline 1974 to 1979 & & & & & & & 59.3 & 65.1 & 71.2 & 60.4 & 65.4 & 71.3 & 59.9 & 64.2 & 67.1 & 58.2 & 63.4 & 67.5 & 62.1 & 64.6 & 66.9 & 61.3 & 64.1 & 66.3 \\
\hline 1975 to 1980 & & & & & & & 59.6 & 65.3 & 71.1 & 60.9 & 65.5 & 71.3 & 59.1 & 63.7 & 66.8 & 59.9 & 63.8 & 67.3 & 61.5 & 64.5 & 66.9 & 61.0 & 64.0 & 66.2 \\
\hline 1976 to 1981 & & & & & & & 58.6 & 64.0 & 69.2 & 61.0 & 65.2 & 70.4 & 59.4 & 63.8 & 66.6 & 56.8 & 62.6 & 66.3 & 60.8 & 64.3 & 66.8 & 61.5 & 64.2 & 66.3 \\
\hline 1977 & & & & & & & 58.2 & 63.9 & 68.7 & 58.8 & 63.4 & 67.7 & 58.9 & 63.3 & 66.2 & 56.5 & 62.4 & 66.0 & 61.2 & 64.4 & 66.9 & 61.4 & 64.2 & 66.3 \\
\hline 197 & & & & & & & 59.1 & 65.1 & 71.9 & 60.9 & 67.1 & 76.8 & 58.6 & 63.0 & 66.0 & 57.7 & 62.6 & 66.3 & 61.1 & 64.3 & 66.7 & 61.2 & 64.0 & 66.2 \\
\hline 1979 to 1984 & & & & & & & 57.6 & 63.6 & 68.8 & 62.0 & 65.7 & 71.0 & 58.1 & 62.7 & 65.8 & 56.4 & 62.2 & 66.0 & 60.7 & 64.1 & 66.5 & 60.7 & 63.8 & 66.1 \\
\hline 1980 tc & & & & & & & 57.3 & 63.1 & 67.4 & 60.9 & 65.1 & 70.1 & 58.2 & 62.5 & 65.6 & 56.4 & 62.0 & 65.8 & 60.8 & 64.1 & 66.5 & 60.3 & 63.6 & 65.9 \\
\hline 1981 to 1986 & & & & & & & 56.9 & 62.6 & 67.0 & 59.1 & 63.6 & 69.2 & 58.2 & 62.3 & 65.4 & 58.5 & 63.0 & 66.1 & 61.0 & 64.3 & 66.8 & 60.3 & 63.6 & 65.8 \\
\hline 1982 to 1987 & & & & & & & 57.1 & 62.8 & 67.4 & 59.2 & 64.5 & 71.7 & 58.0 & 61.9 & 65.2 & 59.2 & 63.6 & 66.5 & 60.5 & 64.1 & 66.7 & 60.7 & 63.8 & 66.0 \\
\hline 1983 to 1988 & & & & & & & 57.0 & 62.8 & 67.3 & 56.1 & 62.2 & 66.9 & 57.9 & 61.7 & 65.1 & 60.1 & 63.9 & 66.6 & 60.4 & 64.2 & 67.0 & 60.4 & 63.7 & 66.1 \\
\hline 1984 to 1989 & & & & & & & 58.2 & 63.7 & 69.0 & 57.3 & 62.0 & 67.5 & 58.2 & 62.2 & 65.3 & 60.7 & 64.0 & 66.6 & 60.4 & 64.1 & 66.9 & 59.9 & 63.6 & 66.2 \\
\hline & & & & & & & 58.8 & 64.7 & 70.6 & 58.2 & 63.0 & 69.0 & 58.4 & 62.2 & 65.3 & 60.6 & 63.9 & 66.5 & 60.7 & 64.2 & 66.8 & 60.5 & 63.9 & 66.3 \\
\hline 1986 & & & & & & & 59.6 & 66.3 & 75.6 & 62.1 & 68.0 & 77.6 & 58.1 & 62.0 & 65.3 & 60.1 & 63.8 & 66.4 & 60.5 & 64.3 & 67.1 & 60.3 & 63.8 & 66.3 \\
\hline 1987 to 1992 & & & & & & & 58.0 & 65.0 & 73.4 & 58.6 & 66.0 & 76.8 & 57.7 & 61.8 & 65.2 & 60.8 & 64.2 & 66.6 & 60.0 & 63.9 & 66.8 & 59.3 & 63.2 & 65.9 \\
\hline 1988 to 1993 & & & & & & & 57.9 & 64.6 & 75.2 & 58.6 & 64.8 & 77.9 & 57.7 & 61.8 & 65.1 & 59.3 & 63.5 & 66.3 & 59.3 & 63.4 & 66.5 & 58.8 & 62.7 & 65.5 \\
\hline 1989 to 1994 & & & & & & & 57.9 & 64.6 & 77.2 & 59.7 & 67.5 & 79.0 & 57.2 & 61.1 & 64.8 & 59.0 & 63.1 & 66.0 & 58.8 & 63.1 & 66.5 & 58.6 & 62.4 & 65.4 \\
\hline 1990 to 1995 & & & & & & & 57.0 & 62.4 & 75.5 & 58.6 & 65.9 & 79.2 & 56.9 & 60.8 & 64.6 & 59.4 & 63.3 & 66.1 & 58.8 & 63.0 & 66.5 & 58.5 & 62.5 & 65.5 \\
\hline 1991 to 1996 & & & & & & & 57.5 & 62.8 & 76.5 & 56.1 & 62.3 & 78.0 & 57.5 & 61.2 & 64.8 & 59.2 & 63.2 & 65.9 & 59.2 & 63.5 & 66.3 & 58.8 & 62.8 & 65.6 \\
\hline 1992 to 1997 & 53.4 & 59.0 & 65.8 & 51.6 & 55.7 & 61.5 & 57.5 & 65.0 & 78.3 & 60.2 & 72.4 & 79.6 & 58.1 & 61.6 & 65.0 & 58.8 & 62.9 & 65.6 & 59.2 & 63.3 & 66.4 & 58.9 & 62.7 & 65.4 \\
\hline 1993 tc & 53.3 & 58.8 & 65.5 & 51.6 & 55.6 & 61.0 & 58.9 & 65.7 & 75.9 & 56.5 & 66.6 & 78.6 & 58.2 & 61.7 & 65.0 & 59.1 & 63.0 & 65.7 & 59.5 & 63.4 & 66.8 & 58.6 & 62.3 & 65.2 \\
\hline 1994 to 1999 & 54.0 & 59.7 & 66.3 & 52.2 & 56.1 & 61.4 & 58.2 & 64.7 & 74.2 & 55.6 & 66.6 & 78.7 & 58.1 & 61.6 & 65.0 & 57.5 & 62.3 & 65.4 & 59.9 & 63.7 & 66.7 & 59.1 & 62.7 & 65.3 \\
\hline
\end{tabular}




\section{ANNEX A \\ ESTIMATING AVERAGE AGE OF WITHDRAWAL WITH CENSORED DATA}

48. Since data for activity rates by age are generally not available above age 65 , some form of truncation or imputation has to be used to derive central estimates of age of withdrawal from the labour force. One simple possibility is to simply ignore workforce participation above the highest age known, or to assume that all those in the labour force above age 65 are in fact aged 65-70. Such an assumption will, however, bias changes over time and comparisons between countries. Chart A1 compares estimates of average age of withdrawal for France and the USA which assume, respectively, that no-one works above age 70 and no-one works above age 80. It will be seen that for the USA for all years, and for France in the 1960 's and 1970's, the "censored" series is significantly below the uncensored one. Only when average withdrawal ages are very low (as is the case for France in recent decades) do the two series converge. It is clear that any truncation will bias the series downwards, but that a truncations at an age about 20 years greater than the average will have little substantive impact.

49. This annex proposes a method to take account of withdrawal that occurs at ages 65 and above. However, to keep the calculations tractable it does assume that activity is truncated at age 80: that is,

$L_{a}^{y}=A_{a}^{y}=0 \quad a \geq 80$ for

for all countries. This means that all those in the labour force aged 75 and over are assumed to be 75-79.

50. For most countries, data are only available for five year age groups up to age 60-64. However, for three countries we do know $L_{65}^{y}$ and $L_{70}^{y}$ and (by the above assumption) $L_{75}^{y}$ for some years.

51. Hence for these countries, we can calculate $W_{a}^{y}$ and $d_{a}^{y}$ for a $=65,70$ and 75 for a range of years (in all cases, we assume $W_{80}^{y}=1$ in all years).

52. However, for most countries we only know

$$
L_{65+}^{y}=\sum_{a=65}^{75} L_{a}^{y}
$$

(we assume in these cases also that $L_{a}^{y}=0$ for $a \geq 80$ )

To calculate average retirement age for these countries, we will have to impute values of $S_{a}^{y}$ for $a \geq 65$.

This requires the addition of some additional terminology:

$d_{a}^{y}=P_{a}^{y} / P_{a-5}^{y-5}$ is the population survival rate over the past five years for those in age group a in year $\mathrm{y}$

$\left[\left(1-d_{a}^{y}\right)\right.$ is the sum of death rate and net out-migration rate for this age group over the five years] 
By definition,

$$
\begin{aligned}
S_{a}^{y} & =A_{a}^{y} / A_{a-5}^{y-5} \\
& =\left(L_{a}^{y} / L_{a-5}^{y-5}\right) /\left(P_{a}^{y} / P_{a-5}^{y-5}\right)
\end{aligned}
$$

Hence

$$
L_{a}^{y}=L_{a-5}^{y-5} \cdot d_{a}^{y} \cdot S_{a}^{y}
$$

$$
\begin{aligned}
L_{70}^{y} & =L_{65}^{y-5} \cdot d_{70}^{y} \cdot S_{70}^{y} \\
& =L_{60}^{y-10} \cdot d_{65}^{y-5} \cdot d_{70}^{y} \cdot S_{65}^{y-5} \cdot S_{70}^{y} \\
L_{79}^{y} & =L_{60}^{y-15} \cdot d_{65}^{y-10} \cdot d_{70}^{y-5} \cdot S_{65}^{y-10} \cdot S_{70}^{y-5} \cdot S_{75}^{y}
\end{aligned}
$$

Now, $L_{65+}^{y}=L_{65}^{y}+L_{70}^{y}+L_{75}^{y}$

As $\quad L_{a}^{y}=0$ for a $>79$ by assumption.

$$
\begin{aligned}
& L_{65+}^{y}=L_{60}^{y-5} d_{65}^{y} S_{65}^{y} \\
& +L_{60}^{y-10} \cdot d_{65}^{y-5} \cdot d_{70}^{y} \cdot S_{65}^{y-5} \cdot S_{70}^{y-5} \\
& +L_{60}^{y-15} \cdot d_{65}^{y-10} \cdot d_{70}^{y-5} \cdot d_{75}^{y} \cdot S_{65}^{y-10} \cdot S_{70}^{y-5} \cdot S_{75}^{y}
\end{aligned}
$$

53. Those in the labour force above the age of 65 represent the survivors of previous cohorts who worked when aged less than 65 . The greater the rate of withdrawal at age 65 and above, the smaller this total will be. Hence the total number working aged 65 and over contains information about the rate of withdrawal above age 65 . However, since we only have only one figure, it is not possible to derive any information about differences in the rate of withdrawal above age 65 . The simplest way to address this is to impose the assumption that retention rates are the same in a particular year for all age groups above 65.

i.e.

$$
\begin{gathered}
S_{*}^{y}=S_{60}^{y}=S_{70}^{y}=S_{70}^{y} \text { i.e. } \\
L_{65+}^{y}=L_{60}^{y-5} \cdot d_{65}^{y} \cdot S_{*}^{y}+L_{60}^{y-10} \cdot d_{65}^{y-5} \cdot d_{70}^{y} \cdot S_{*}^{y-5} \cdot S_{*}^{y} \\
+L_{60}^{y-15} \cdot d_{65}^{y-10} \cdot d_{70}^{y-5} \cdot d_{75}^{y} \cdot S_{*}^{y-10} \cdot S_{*}^{y-5} \cdot S_{*}^{y} \\
=S_{*}^{y}\left[L_{60}^{y-5} \cdot d_{65}^{y}+L_{60}^{y-10} \cdot d_{65}^{y-5} \cdot d_{70}^{y} \cdot S_{*}^{y-5}\right. \\
\left.+L_{60}^{y-15} \cdot d_{65}^{y-10} \cdot d_{70}^{y-5} \cdot d_{75}^{y} \cdot S_{*}^{y-10} \cdot S_{*}^{y-5}\right] \\
=S_{*}^{y} \cdot F(L, d, S)
\end{gathered}
$$


54. This equation allows $S_{*}^{y}$ to be calculated for a given value of $L_{65+}^{y}$ if an estimate of $\mathrm{F}(\mathrm{L}, \mathrm{d}, \mathrm{S})$ can be derived. The problem is that $F(L, d, S)$ is a function of lagged values of $L, d$ and $S$, which will not be available for the initial years for $\mathrm{L}$ and $\mathrm{d}$, and which have to be estimated for $\mathrm{S}$.

55. The only possibility for the initial five year period is to assume that past population and labour force structure and withdrawal rates were the same as for this period. This means for the last year of this initial five year period, we have

$$
\begin{aligned}
& S_{*}^{y}=S_{*}^{y-5}=S_{*}^{y-10} \\
& L_{60}^{y-5}=L_{60}^{y-10}=L_{60}^{y-15} \\
& =d_{65}^{y}=d_{65}^{y-15}=d_{65}^{y-10} \\
& d_{60}^{y}=d_{70}^{y-5}
\end{aligned}
$$

So that the equation (A7) is a cubic in $S_{*}^{y}$ :

$$
\begin{aligned}
L_{65+}^{y}= & L_{60}^{y-5} \cdot d_{65}^{y} \cdot\left(S_{*}^{y}\right)+L_{60}^{y-5} \cdot d_{65}^{y} \cdot d_{70}^{y} \cdot\left(S_{*}^{y}\right)^{2} \\
& +L_{60}^{y-15} \cdot d_{65}^{y} \cdot d_{70}^{y} \cdot d_{75}^{y} \cdot\left(S_{*}^{y}\right)^{3}
\end{aligned}
$$

56. This can be solved to yield an initial estimate of $S_{*}^{y}$. The same formulation can be used for subsequent years, though there is an internal contradiction in the estimation, as the assumption that $S_{*}^{y}$ does not vary is contradicted by the change over time in the estimate as the (current) parameters of equation (8) change. This is the "cross-section" estimate of $S_{*}^{y}$.

57. An alternative procedure is to revert to equation (A7), but to use the initial values of $d_{a}^{y}$ and $L_{60}^{y}$ as proxies for the unavailable lagged values. That is, if we denote the initial year as year I, the function $\mathrm{F}$ is evaluated using the initial values (ie. the value for $\mathrm{y}=\mathrm{I}$ ) for $\mathrm{L}, \mathrm{D}$ and $\mathrm{S}$ where $\mathrm{y}-10$ and $\mathrm{y}-15<\mathrm{I}$, and using the actual past values for $L$ and $D$ and the calculated value of $S$ where $y-10$ and $y-15 \geq I$. This is the "recursive" estimate of $S_{*}^{y}$

58. These calculations yield two alternative series for $S_{y}^{*}$, which can be inserted in equation (3) to derive imputed estimates of the average age of retirement. Table A1 shows these estimates, and compares them with the known (uncensored) estimates for France, the US and Japan. Charts A2 and A3 show the two estimated values of $S_{y}^{*}$ and compares them with the average of the empirical estimates of $S_{65}^{y}, S_{70}^{y}$ and $S_{75}^{y}$ for two of the countries for which detailed data are available. 
59. It will be seen from Table A1 that both alternative series for censored data yield an average age which is almost identical to the uncensored series. The "recursive" estimate (which uses more information) is slightly better, and so this is the one which is used in the estimates for all countries.

60. Chart A2 indicates that the empirical estimate is close to $S_{65}^{y}$ and $S_{70}$, but is generally less than $S_{75}$. However, the latter is biased upwards by the assumption that $S_{80}=0$. It is apparent that no upper bound on age of participation is strictly correct. However, this has little or no effect on the average. The accumulated probability of still being in the labour force at age 75 is so low that the upward censorship has no noticeable effect on the mean, and does not impact on the upper quartile either.

61. The exception is the case of Japan which, since the underlying data are sparser and more unreliable, has not been included in Chart A3. In the case of that country, the comparison is approximate because the uncensored data, available only for employment and only at five-year periods, are from a different source to the censored data. In spite of this, the overall trends in the two sources for men are similar. The considerable divergence in the estimates for women is not due to the method, but to the fact that the uncensored data are have an inconsistent relation over time with the censored data ${ }^{8}$.

62. Finally, for the static estimate the equation (A8) simplifies still further: the estimates $d_{a}$ all have the form $\mathrm{P}_{\mathrm{a}} / \mathrm{P}_{\mathrm{a}-5}$, so that the equation collapses to

$$
\mathrm{L}_{65}+\left(\mathrm{L}_{60} / \mathrm{P}_{60}\right)=\mathrm{P}_{65} \cdot \mathrm{s}+\mathrm{P}_{70} \cdot \mathrm{s}^{2}+\mathrm{P}_{75} \cdot \mathrm{s}^{3}
$$

63. The static estimates use the estimate of $\mathrm{s}$ derived from this equation for the proportion of those working in each age group aged 60 to 74 who stay in the labour force when they are five years older. (The value is assumed to be zero for those aged 75 to 79). These values of $s$ are inserted in equation (2) to derive the static estimate of the average retirement age.

8 The employment data for the 1960's, when compared with the labour force data, suggest a high unemployment rate for women, which is totally at variance with what we know of the state of the labour market inthat period. It appears that in this period some forms of non-standard employment were not included. 
DEELSA/ELSA/WD(2001)2

Table A1. Comparison of Direct and Censored Estimates of Expected Age of Withdrawal, adjusted for censored "Direct" data

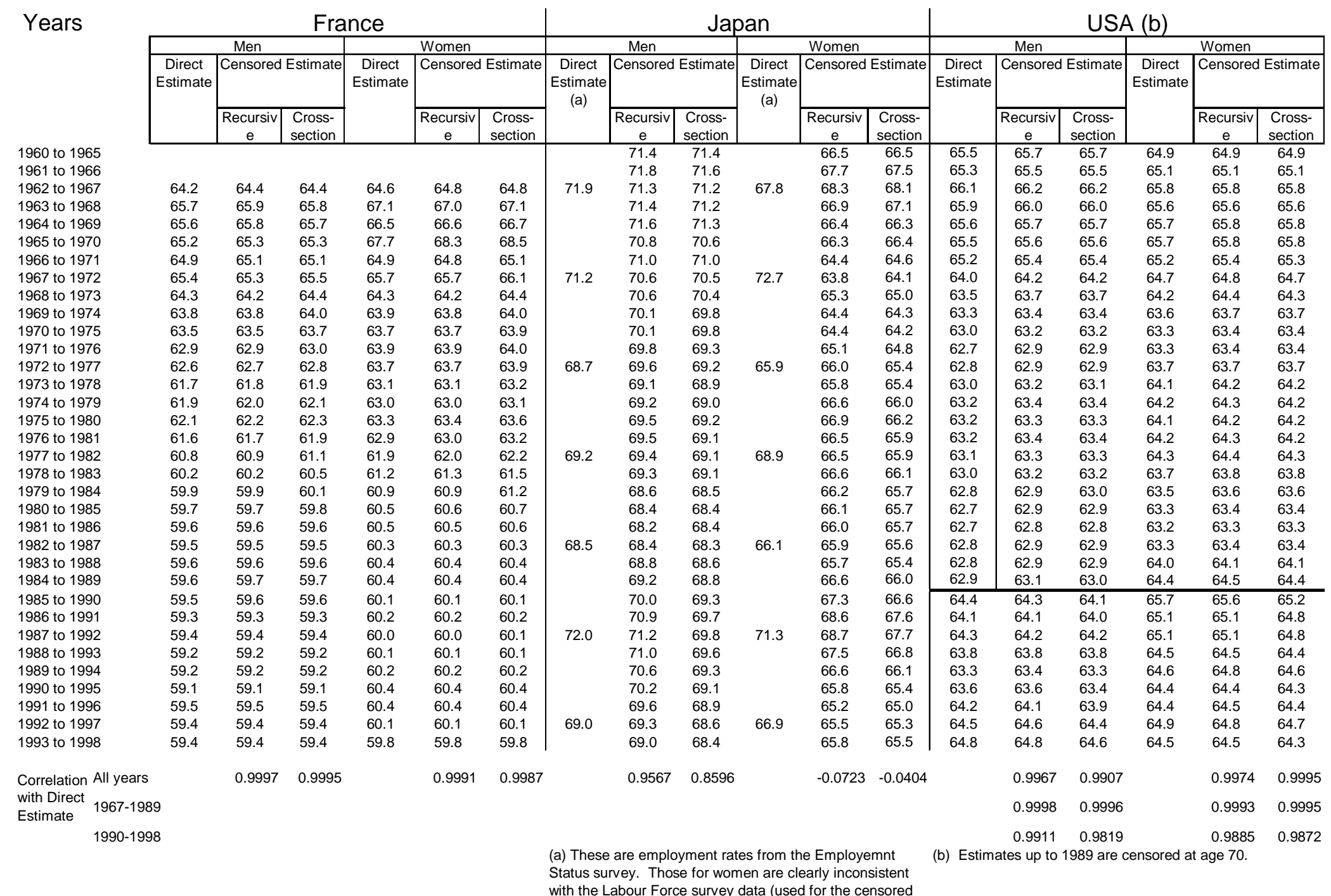



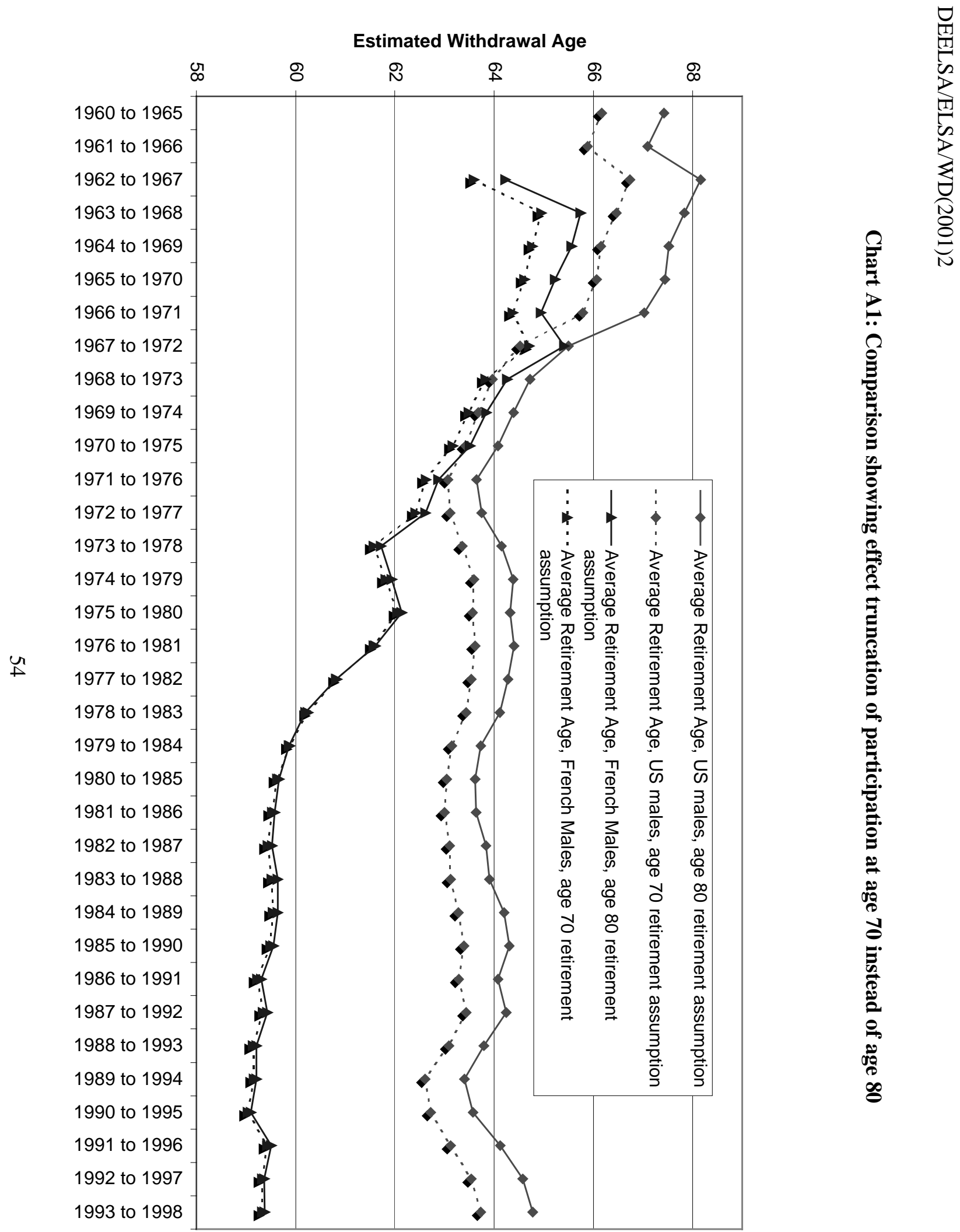

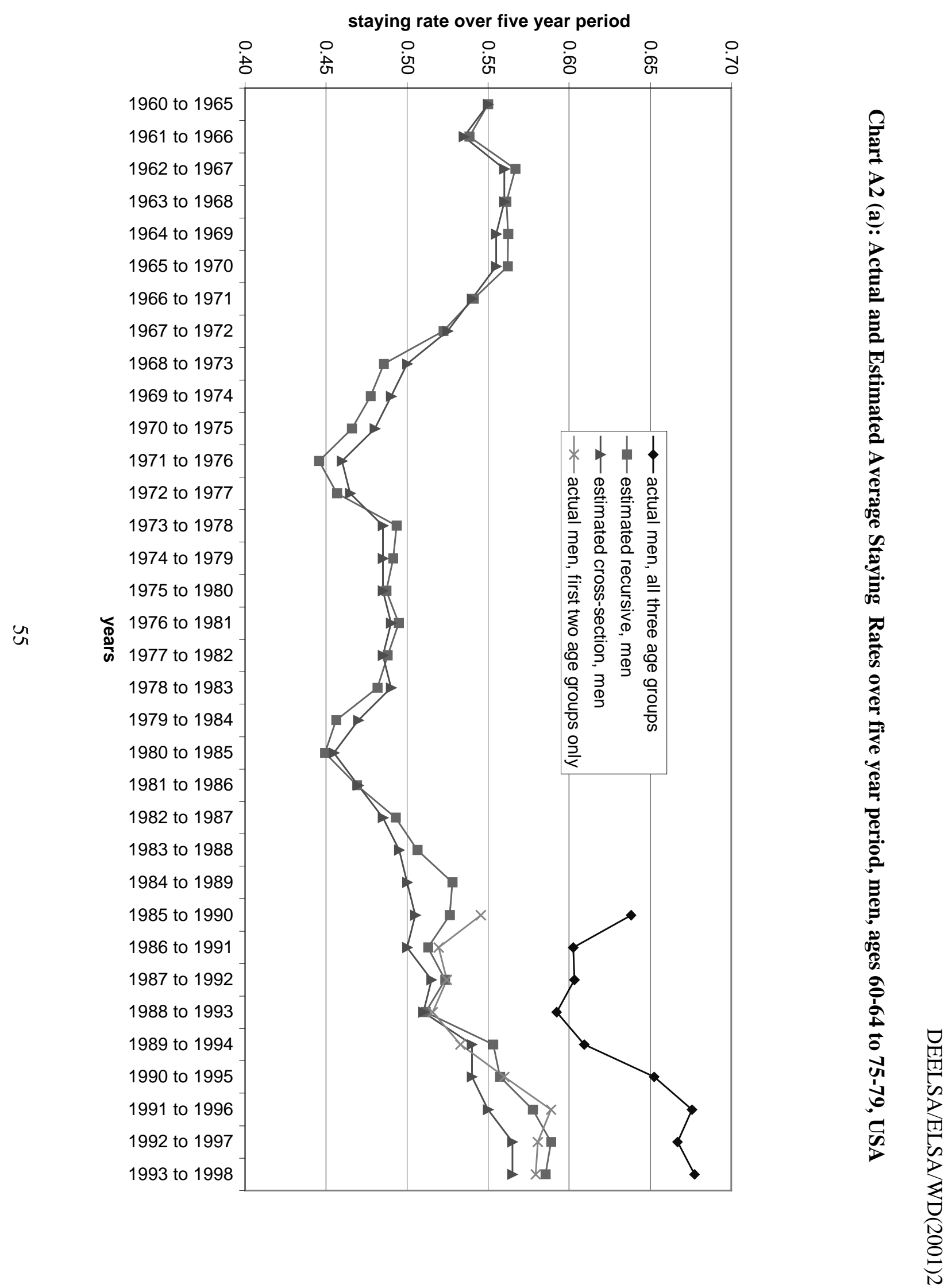


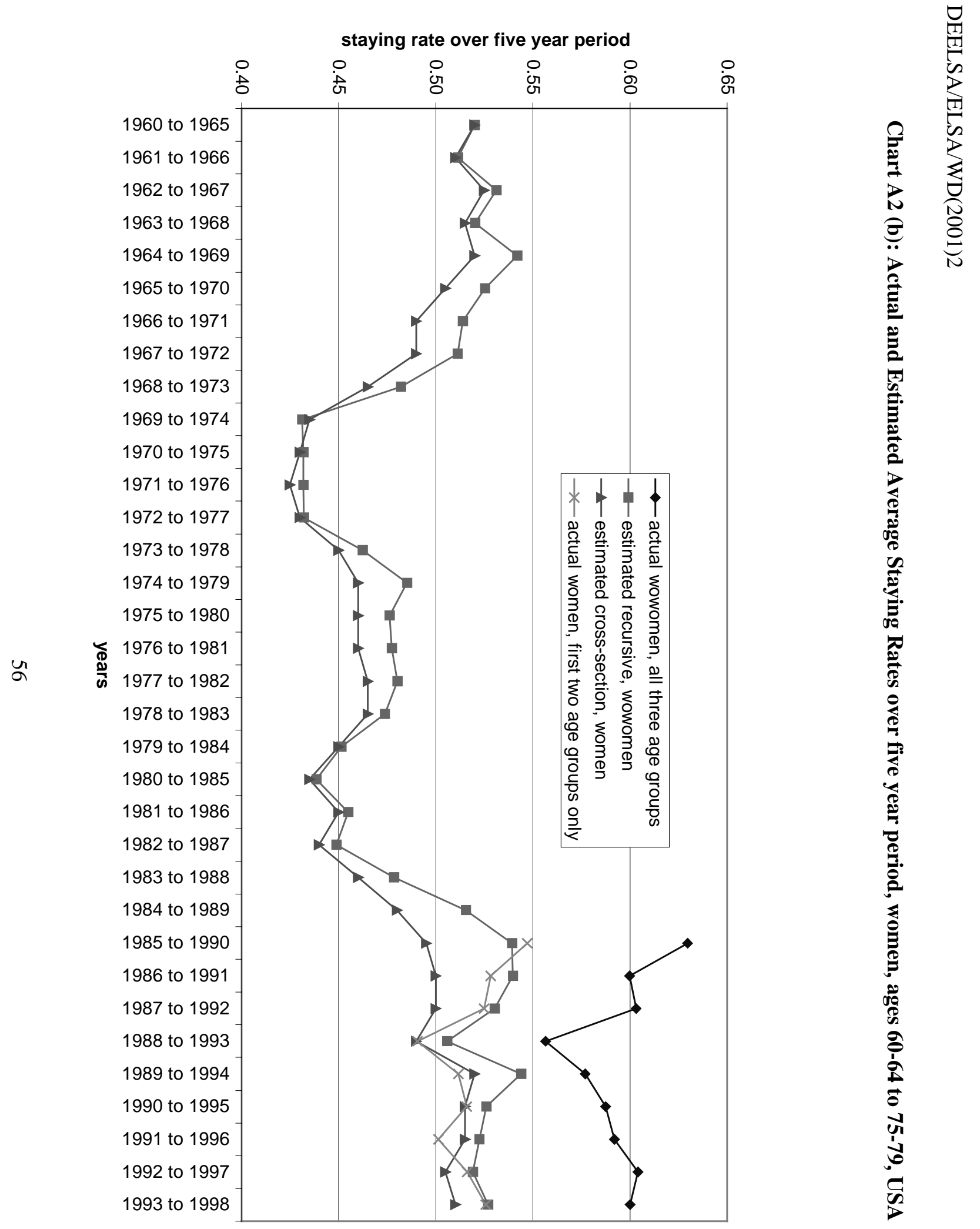




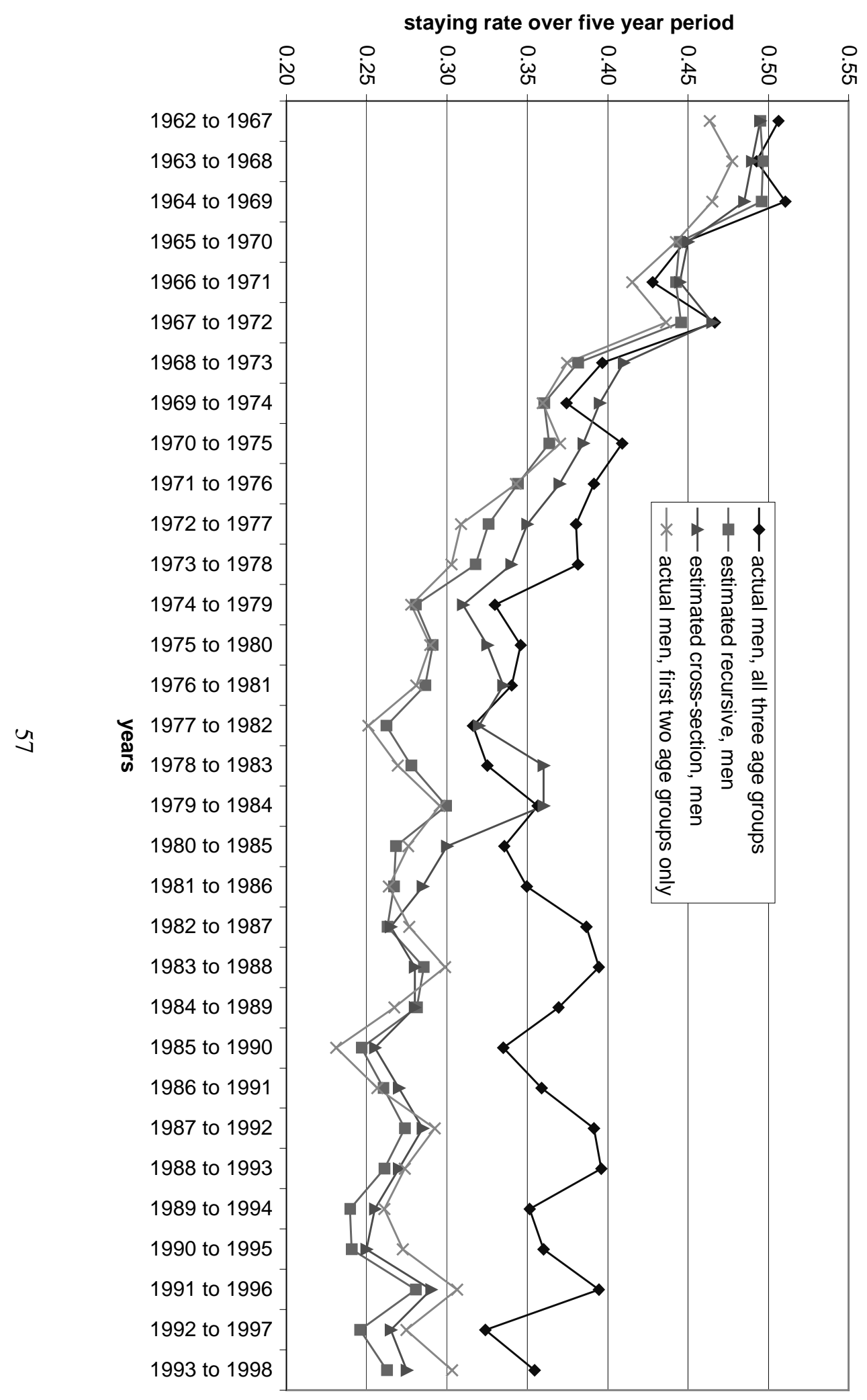




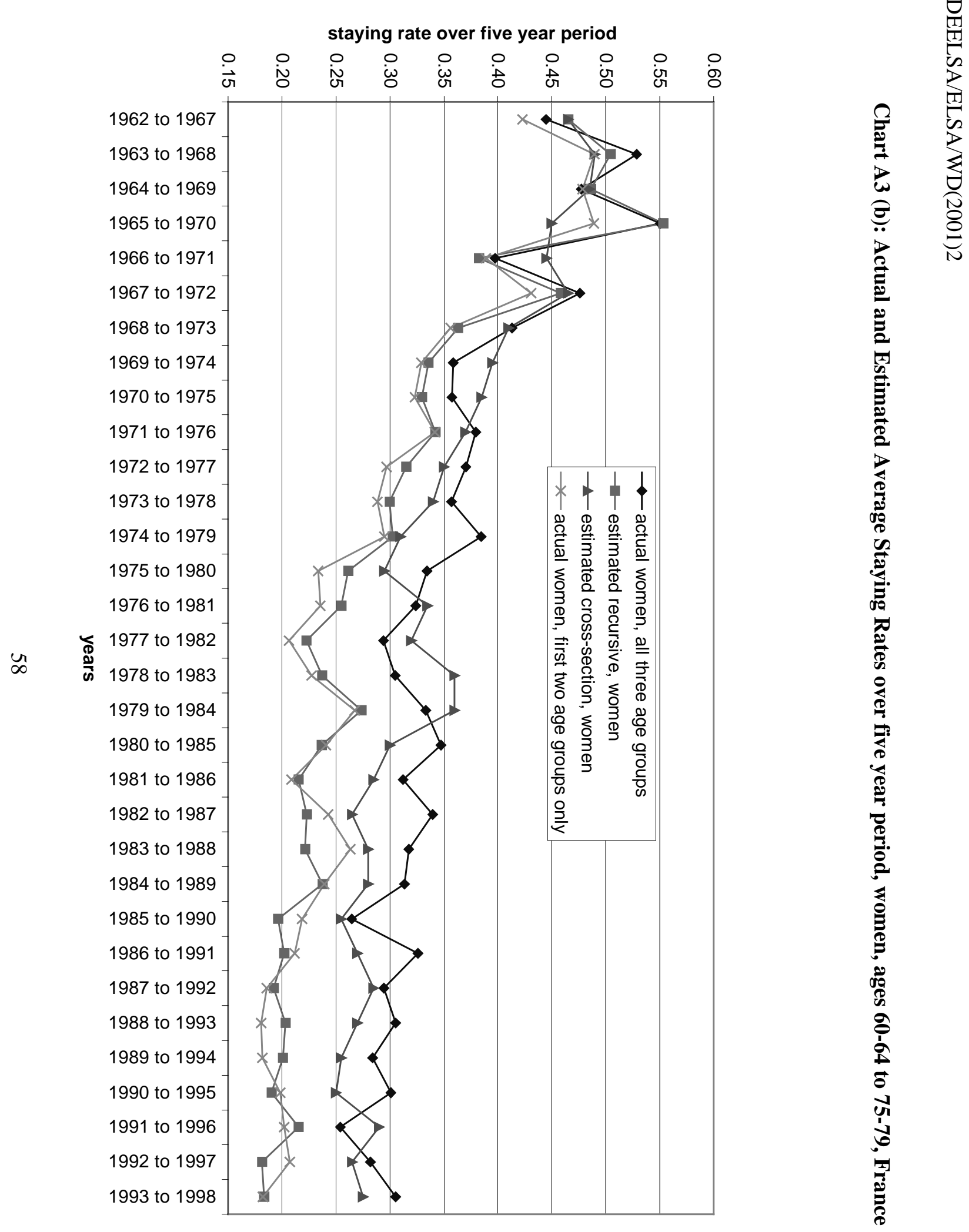




\section{LABOUR MARKET AND SOCIAL POLICY OCCASIONAL PAPERS}

Most recent releases are:

No. 56 AN ASSESSMENT OF THE PERFORMANCE OF THE JAPANESE HEALTH CARE SYSTEM (2001) Hyoung-Sun Jeong and Jeremy Hurst

No. 55 PUBLIC SUPPORT FOR RETIREMENT INCOME REFORM (2001) Peter Hicks

No. 54 PENSION REFORM IN THE SLOVAK REPUBLIC - BACKGROUND AND OPTIONS: CAN LESSONS BE DRAWN FROM OTHER TRANSITION COUNTRIES? (2001) Agnieszka Chlon, Marek Góra, Martina Lubyova, Lawrence H. Thompson

No. 53 TOWARDS MORE CHOICE IN SOCIAL PROTECTION? INDIVIDUAL CHOICE OF INSURER IN BASIC MANDATORY HEALTH INSURANCE IN SWITZERLAND (2001) Francesca Colombo

No. 52 NET SOCIAL EXPENDITURE, $2^{N D}$ EDITION (2001) Willem Adema

No. 51 GROWTH, INEQUALITY AND SOCIAL PROTECTION (2001) Roman Arjona, Maxime Ladaique and Mark Pearson

No. 50 KNOWLEDGE, WORK ORGANISATION AND ECONOMIC GROWTH (2001) Elena Arnal, Wooseok Ok and Raymond Torres

No. 49 AGE OF WITHDRAWAL FROM THE LABOUR FORCE IN OECD COUNTRIES (2001) Peter Scherer

No. 48 FIRMS'CONTRIBUTION TO THE RECONCILIATION BETWEEN WORK AND FAMILY LIFE (2001) John M. Evans

No. 47 PERFORMANCE MEASUREMENT AND PERFORMANCE MANAGEMENT IN OECD HEALTH SYSTEMS (2001) Jeremy Hurst and Melissa Jee-Hughes

No. 46 EXPLORING THE EFFECTS OF HEALTH CARE ON MORTALITY ACROSS OECD COUNTRIES (2000) Zeynep Or

No. 45 TRENDS IN WORKING HOURS IN OECD COUNTRIES (2000) John M. Evans, Douglas C. Lippoldt and Pascal Marianna

No. 44 AN INVENTORY OF HEALTH AND DISABILLITY-RELATED SURVEYS IN OECD COUNTRIES (2000) Claire Gudex and Gaetan Lafortune

Recent available working papers can be found on the OECD internet site: http://www.oecd.org/.

Once at the OECD home page, you should go to the Education, Employment, Labour and Social Affairs Directorate under the OECD Directorates. Then, click on Documentation.

To receive a paper copy of any particular papers or to add your name to our mailing list, please send your name, organisation and full address to:

Labour Market and Social Policy Occasional Papers

Directorate for Education, Employment, Labour and Social Affairs

OECD, 2, rue André-Pascal, 75775 PARIS CEDEX 16, FRANCE

(write in capitals)

Name

Organisation

Address

$\square \quad$ Please send a copy of the following papers: numbers -- , -- , --.

$\square \quad$ Please add my name to the mailing list for future papers. 


\section{RECENT OECD PUBLICATIONS IN THIS FIELD INCLUDE:}

KNOWLEDGE AND SKILLS FOR LIFE: First Results from PISA 2000 (2001)

AGEING AND INCOME: Financial Resources and Retirement in 9 OECD Countries (2001)

HEALTH AT A GLANCE (2001)

SOCIETY AT A GLANCE: OECD Social Indicators (2001)

INNOVATIONS IN LABOUR MARKET POLICIES: The Australian Way (2001)

OECD EMPLOYMENT OUTLOOK June 2001 (published annually)

LABOUR MARKET POLICIES AND THE PUBLIC EMPLOYMENT SERVICE (Prague Conference) (2001)

TRENDS IN INTERNATIONAL MIGRATION: SOPEMI 2000 Edition (2001)

OECD HEALTH DATA (2001)

available in English, French, Spanish and German on CD-ROM (Windows 95, 98, 2000, NT or Me)

REFORMS FOR AN AGEING SOCIETY (2000)

PUSHING AHEAD WITH REFORM IN KOREA: Labour Market And Social Safety-Net Policies (2000)

A SYSTEM OF HEALTH ACCOUNTS (2000)

OECD ECONOMIC STUDIES No. 31, 2000/2 (Special issue on “Making Work Pay”) (2000)

POLICIES TOWARDS FULL EMPLOYMENT (OECD Proceedings) (2000)

LABOUR MIGRATION AND THE RECENT FINANCIAL CRISIS IN ASIA:

(OECD Conference Proceedings) (2000)

OECD SOCIAL EXPENDITURE DATABASE, 1980-1997 (2000)

Second edition - Available in English and French on CD-ROM

A CARING WORLD - The New Social Policy Agenda (1999)

MAINTAINING PROSPERITY IN AN AGEING SOCIETY (1998)

THE BATTLE AGAINST EXCLUSION - Volume 3

Social Assistance in Canada and Switzerland (1999)

THE BATTLE AGAINST EXCLUSION - Volume 2

Social Assistance in Belgium, the Czech Republic, the Netherlands and Norway (1998)

THE BATTLE AGAINST EXCLUSION

Social Assistance in Australia, Finland, Sweden and the United Kingdom (1998)

BENEFIT SYSTEMS AND WORK INCENTIVES (1999) (Published bi-annually)

For a full list, consult the OECD On-Line Bookstore on: http://www.oecd.org or write for a free written catalogue to the following address:

OECD Publications Service

2, rue André-Pascal, 75775 PARIS CEDEX 16

or to the OECD Distributor in your country 